\title{
Ask the user : user perspective in the assessment of assistive technology
}

Citation for published version (APA):

Wessels, R. (2004). Ask the user : user perspective in the assessment of assistive technology. [Doctoral Thesis, Maastricht University]. Datawyse / Universitaire Pers Maastricht.

https://doi.org/10.26481/dis.20040324rw

Document status and date:

Published: 01/01/2004

DOI:

10.26481/dis.20040324rw

Document Version:

Publisher's PDF, also known as Version of record

\section{Please check the document version of this publication:}

- A submitted manuscript is the version of the article upon submission and before peer-review. There can be important differences between the submitted version and the official published version of record.

People interested in the research are advised to contact the author for the final version of the publication, or visit the DOI to the publisher's website.

- The final author version and the galley proof are versions of the publication after peer review.

- The final published version features the final layout of the paper including the volume, issue and page numbers.

Link to publication

\footnotetext{
General rights rights.

- You may freely distribute the URL identifying the publication in the public portal. please follow below link for the End User Agreement:

www.umlib.nl/taverne-license

Take down policy

If you believe that this document breaches copyright please contact us at:

repository@maastrichtuniversity.nl

providing details and we will investigate your claim.
}

Copyright and moral rights for the publications made accessible in the public portal are retained by the authors and/or other copyright owners and it is a condition of accessing publications that users recognise and abide by the legal requirements associated with these

- Users may download and print one copy of any publication from the public portal for the purpose of private study or research.

- You may not further distribute the material or use it for any profit-making activity or commercial gain

If the publication is distributed under the terms of Article $25 \mathrm{fa}$ of the Dutch Copyright Act, indicated by the "Taverne" license above, 
Ask the User

User perspective in the assessment of assistive technology 
ISBN 90-5278-404-3

Copyright @ 2004, Roelof Wessels

Vormgeving: Bianca Fraats, BiFab

Foto op de omslag: Helma van den Heuvel

Correctie Engels: Andrew Davies, Chapter \& Verse

Druk: Datawyse boek- en grafische producties, Maastricht 


\section{Ask the User}

\section{User perspective in the assessment of assistive technology}

\section{PROEFSCHRIFT}

ter verkrijging van de graad van doctor aan

de Universiteit Maastricht,

op gezag van de Rector Magnificus, Prof. mr. G.P.M.F. Mols

voigens het besluit van het College van Decanen, in het openbaar te verdedigen op woensdag 24 maart 2004 om 14:00 uur

door

Roelof Wessels

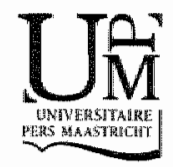


Promotor:

Prof. dr. W.J.A. van den Heuvel

Co-promotor:

Dr. L.P. de Witte

Beoordelingscommissie:

Prof. dr. G.A.M. Widdershoven

Prof. dr. G.I.J.M. Kempen

Prof. J. Persson (Linkopping University, Zweden)

Dr. ir. M. Soede (iRv, Kenniscentrum voor Revalidatie en Handicap,

Hoensbroek)

Prof. dr. D.T. Wade (Rivermead Rehabilitation Centre Oxford,

Engeland) 


\section{Bij de foto op de voorkant van dit proefschrift; Ask the user}

De foto op de omslag illustreert de titel. De strandrolstoel zal door iedereen leuk en goed gevonden worden. Dat was ook mijn idee toen ik hem voor het eerst zag: "wat een handig ding, daar kan ik het strand mee op en zelfs de zee mee in, fantastisch". Maar toen ik er in ging zitten en gebruiker werd, dacht ik: "wat onhandig, ik kan er zelf niet mee rijden, ik kan er alleen mee gereden wordlen". Door gebruiker te worden was mijn mening gewijzigd. Natuurlijk blijft die strandrolstoel een schitterend product, maar dit voorbeeld geeft wel aan dat een gebruiker op andere dingen let dan een niet-gebruiker. En omdat hel de gebruiker is die het hulpmiddel moet gebruiken "is het niet meer dan logisch om de gebruiker bij een evaluatie naar zijn mening te vragen. 



\section{Inhoudsopgave}

1 User perspective in the assessment of assistive devices: 9 an introduction

2 Measuring effectiveness of and satisfaction with assistive devices 23 from a user perspective: an exploration of the literature

3 IPPA, a user-centred approach to assess effectiveness of 39 assistive technology provision

4 Effectiveness of provision of outdoor mobility service and devices 63 in the Netherlands

5 Key dimensions of client satisfaction with assistive technology: A cross-validation of a Canadian measure in the Netherlands

6 Reliability and validity of the Dutch version of QUEST 2.0 with users of various types of assistive devices

7 Conclusions and Discussion

Summary

Samenvatting

Dankwoord

Over de auteur 



\section{User perspective in the assessment of assistive devices: an introduction}





\section{User perspective in the assessment of assistive devices: an introduction}

This introductory chapter describes recent developments in assessing the outcomes of assistive devices, in relation to user perspective. It is argued that the user perspective is essential in studying the effectiveness of assistive devices. This statement raises two questions: what is user perspective and what criteria do we have at our disposal to measure the effectiveness of assistive devices from the users' perspective? This chapter explores these questions.

Firstly, in paragraphs 1.1 and 1.2 a brief description will be given of the context of the research topic in relation to general health policy, followed in paragraph 1.3 by an analysis of the special characteristics associated with assistive devices and the (necessity of) the user perspective in paragraph 1.4. Secondly, in paragraph 1.5 a framework for the analysis of rehabilitation outcomes including assistive devices will be described. Lastly, the research questions will be elaborated (paragraph 1.6) and the structure of the thesis presented (paragraph 1.7).

For the purposes of this study, assistive devices are defined as all products and related services that are able to compensate for functional limitations, to facilitate independence and to improve the level of participation and quality of life for people with disabilities. This definition includes a wide variety of devices, ranging from 'simple' walking sticks to complex 'high-tech' robot manipulators. An important, though not absolute, distinction in the domain of assistive devices is that relating to devices that primarily restore or compensate body functions (often body-worn) such as glasses, prostheses, orthoses or some functional electro-stimulation devices, as opposed to devices that primarily support people in performing activities (often not body-worn) like wheelchairs, scoot mobiles, computers, etc. In this thesis the emphasis is an the second group of devices, that is assistive devices that support activities.

\section{1 Major developments in health care policy}

During the last decade three major developments in health care policy, which have a bearing on assistive technology, can be identified. The first development relates to a political desire to control the volume and costs of health care, which has led to the implementation of a variety of 'efficiency' measures, such as budgeting, assessment systems, co-payment and output financing. The effects of these measures are debatable, but one result is that the collection of data on the outcomes and costs of medical interventions is widespread, even obligatory. 
The second development is the emphasis on "evidence-based" interventions. New methods of treatment and technologies first have to be evaluated in medical technology assessment studies before they become accepted forms of medical practice. No pill gets sold without years of research. This development contributes to the quality of health care and calls for validated instruments to measure health care outcomes.

A third development relates to the role of patients/consumers in health care. In the Netherlands this role has increased, supported by legislation. Both on an individual level (informed consent and the Medical Treatment Agreements Act) as well as on an organisational level (Participation (Clients of Care Institutions) Act), consumers have instruments at their disposal with which to protect their rights and interests. User perspective has become an aspect to be taken into account in relation to quality of care. As a consequence, instruments are required to assess this quality from a user perspective. And indeed several instruments have been developed for this purpose, for example the QUOTE questionnaire (quality of care through the patients' eyes) (van Campen et. al. 1998) or the SERVQUAL questionnaire (Parasuraman, 1988), whose aim likewise was to assess the quality of service and care.

\subsection{Why outcome assessment of assistive devices?}

Strangely enough, the developments described above have not affected the field of assistive technology very much until recently. The Dutch ministry of health is currently developing a policy on assistive devices. The importance of costs and evidence of the effects of assistive technology interventions is evident. A great deal of money is being spent to provide assistive devices, whilst little is known about their effectiveness, let alone any evidence-based information. For instance, in 1999, 54 million euros were spent on providing electric scooters in the Netherlands (Dutch Ministry of Social Affairs, 2000) although it was unclear how this related (in terms of costs and outcomes) to alternatives like the use of a shared taxi service. It is estimated that internationally between $10 \%$ and $70 \%$ of assistive devices prescribed are not actually used (Soede, 2003).

Cost-outcome analysis in the domain of assistive technology is at an embryonic stage at the moment (Andrich, 1998). Although a growing need exists for costeffectiveness, cost-utility and evidence-based research on assistive devices, appropriate instruments are scarce. Both in North America (DeRuyter, 1995; Scherer \& Vitaliti, 1997) and in Europe (Andrich, Ferrario, \& Moi, 1998; Gelderblom \& de Witte, 2002), there is a growing demand for the use of instruments which allow us to carry out standardised assessments of the outcome of the provision of assistive devices. 
But it is not only the efficiency aspect that is important; it is also the potential for participation through the availability of assistive devices for people with functional limitations, which is receiving more interest. People with disabilities encounter problems in everyday life. The purpose of providing them with assistive technology is to help them solve these problems so that they are better able to lead a life of their own choosing. For example, if it were not for assistive technology (e.g. speech recognition software, a wheelchair or a taxi service) it would not have been possible to write this thesis. In the Netherlands over 1.5 million persons are affected by functional limitations (de Klerk, 2002). Their participation in society is limited: for example, only $38 \%$ of people with functional limitations participate in the labour force as opposed to $61 \%$ of the 'general' population (de Klerk, 2002).

In relation to outcome measures, the consumer perspective has become an important aspect. This also applies to people with functional limitations. The need for outcome research and validated instruments in the field of disability has been growing strongly for a number of reasons:

- The proportional increase in the ageing population, resulting in an increasing number of people with functional limitations;

- The general tendency to advocate autonomy and participation in all aspects of society for people with disabilities;

- Technological developments creating new opportunities; whilst new assistive technologies are being developed, new general-purpose technologies are also creating opportunities for people with disabilities; - The general tendency towards consumerism, resulting in emancipated service delivery clients.

Alongside these motives, there is also a general trend towards increasing levels of professionalism. In every aspect of society "we see calls for efficiency and for evidence-based practice. To the assistive technology user, however, the most significant reason for assessing effectiveness is the wish for his or her problem to be solved to an optimum level. The client wishes to attain the best quality of life possible, for which the use of assistive devices may be crucial. Also, clients are becoming increasingly aware of their rights. They know what they are entitled to. New developments, such as the Dutch provision of a personal budget' which allows a client to select the assistive device of their own choice, require evidence-based knowledge about the effectiveness of available devices. 


\subsection{Special characteristics of assistive devices and requirements for instruments to measure their outcomes}

Although assistive device interventions are part of the wealth of interventions that exist in rehabilitation, the instruments available to assess the outcomes of rehabilitation are not ideally suitable for assessing the effectiveness of these assistive devices. This is caused by a number of specific characteristics of assistive devices, which make those instruments available less appropriate for use in the field of assistive devices. Mast instruments are unsuitable in one or more of the following aspacts:

Domain: Instruments, which are available for outcome assessment, are often related to disease. A person who does not suffer from a disease is considered healthy. However, people with a long-term disability who need to use assistive devices will often not consider their problems to be health-related and, therefore, their goals will not be related to their perception of the concept of health. Assistive technology does not usually save lives or reduce morbidity. Frame of reference: The instruments available are mostly based on the frame of reference for an average population. Individual goals, served by using assistive technology, are related to the expectations held by people with disabilities (and not to those held by the "normal" population). So the frame of reference of the respondents may differ from that of a normal or average population.

Validity: Most available instruments deal with general domains of disability and are not sensitive enough to measure the quality of devices in specific areas, save a few. Goals, served by using assistive technology, can vary individually and thus be very specific. In general they consist of performing a certain activity or type of participation (WHO, 2002). The desired outcome then consists of the attainment of these individual, specific goals.

Responsiveness: Most available instruments deal with a broad range of disabilities and are not very responsive to small, subtle changes. In the perception of individual persons with disabilities, small subtle changes can be very important in terms of quality of life or autonomy.

A specific characteristic of assistive devices, especially those that primarily aim to support people in performing activities, is that they become effective only in interaction with the user and with the environment in which they are used. A wheelchair, for example, can be very effective for a trained user in an accessible environment, but the same wheelchair can be of no use when the user has not enough strength in his arms or when it is used in an inaccessible environment. This characteristic makes evaluation of effects more complicated than in many other interventions, where the intervention can more easily be 'separated' from its context. Assistive devices are in this respect not 
fundamentally different from other (medical) interventions, and this characteristic is not equally relevant to all assistive dlevices. On top of the four aspects mentioned above, however, this underlines the importance of specific instruments to measure the effects of assistive devices.

Instruments for evaluating the effects of assistive devices should be responsive to small, subtle changes in specific fields identified by the respondent, they should not be related to disease or to disfunctioning, but instead to activity and participation and they should use scales that fit in with the frame of reference of people with long-term disabilities.

To assess the user opinion on the outcomes of provided assistive technology, it is not sufficient to assess effectiveness on its own. Another important and widely used measure is the assessment of user satisfaction. Not only is the intention of the provision to solve the problem, but the user should also be happy with it. User satisfaction is a strong indicator of the service quality. Assessment of both effectiveness and satisfaction provides us with a useful tool to assess user-focused outcomes of a provision. This thesis deals with the assessment of both effectiveness and satisfaction.

\subsection{User perspective}

In this thesis, user perspective is a central issue. There is no "formal' definition of user perspective. What we mean by it is that we look at those outcomes of assistive devices that are considered relevant and important by the user, and at satisfaction with those aspects that are considered relevant and important by the user. Another central aspect of user perspective is that measurement is based on user judgements: subjective evaluations and/or self-reported effects.

In the previous paragraphs it was argued that the user's opinion is the most important one in evaluating assistive technology provision. Other stakeholder opinions like those of providers, manufacturers, counsellors or payers are important too "but the bottom line is: does the user feel his or her problem has been solved to his or her satisfaction? It can be also argued that the user knows best when it comes to his or her own specific individual situation. He or she is best able to judge whether the situation has improved. Of course, this judgement of the user should not be the only source, but it should be the central one. This is in line with the philosophy of a user-focused perspective, which requires recognition of the autonomy of the individual client and of the client's need to make choices (Towsend, 1997). Working in accordance with a userfocused approach not only means asking questions of the user, but also allowing the user to decide on what topics are of interest and what questions should be asked. The client is really given a central position. 


\subsection{Outcomes assessment of assistive devices}

In this paragraph a framework is presented for outcome assessment in assistive device interventions. First, objective versus subjective outcomes will be discussed. Next, a general framework for evaluating assistive devices will be presented.

\subsubsection{Objective versus subjective outcomes and the relevance of satisfaction}

Outcomes of rehabilitation, and therefore outcomes of assistive device interventions, can be objectively quantified (objectivity means observable, as opposed to subjectivity which in this case means someone's personal perception). The functioning of an impaired organ can be objectively compared to the functioning of a non-impaired organ. The degree to which an activity can be performed by a person can be objectively assessed, by using one of numerous observation instruments or questionnaires available for this purpose. The degree to which a person participates in society can be objectively assessed by comparing this social role to that of the general population. The objective point of view is overwhelmingly dominant in the prevailing models and measures of disablement (Fuhrer, 2000). But, as Whiteneck (1994) stated, "Not all reality is objective. The subjective reality of persons with disabilities forms an equally valid and equally important perceptual domain requiring measurement." These subjective perceptions of a client can be considered as an outcome, which is related to, but nevertheless distinct from, the objective assessment of his impairments ${ }_{\text {" }}$ disabilities and handicaps (Whiteneck, 1994). The subjective perceptions of the client with respect to his or her own situation should be considered as an outcome that is relevant, in addition to (and not instead of) conventional 'objective' outcome measures.

Outcome research in health care is the study of the end results of health service provisions, which take into account patients' experiences, preferences and values (Clancy, 1998), additional to 'objective' measures of outcome.

Within subjective outcomes several aspects can be distinguished. Aspects often mentioned in this respect are:

- feelings of safety and trust;

- satisfaction with professional performance (information, attention);

- Satisfaction with professional outcomes (feeling cured, restored, better);

- satisfaction with role performance (participation, quality of life).

It is obvious that within subjective outcomes satisfaction plays an important role. 


\subsubsection{A framework for assistive device outcomes}

A relevant framework in relation to outcome assessment of rehabilitation interventions is that of the ICF (WHO, 2002). Within this framework, assistive devices can be considered to represent a contextual factor and, more precisely. an environmental factor. "Environmental factors (can) interact with all dimensions of functioning and disability, namely body functions and structure, activity and participation (WHO, 2002)." Most assistive devices are used to enhance an individual's ability to do things independently; to enable an individual to perform activities in daily life. The problems that are tackled by an assistive device intervention are (usually) problems associated with activities The outcomes of these interventions can also relate to participation. For example: solving a problem in mobility (activity) can enable someone to keep a job (participation). Within the ICF framework the levels of activities and participation are the most relevant dimensions of assistive device outcome.

Apart from activities and participation, several other dimensions are relevant in assessing the outcomes of assistive devices. In a recent special issue of the journal Technology and Disability on outcome assessment of assistive technology, the following dimensions of outcome are mentioned as relevant to assistive devices: 1) quality of life; 2) social participation (employment, social roles); 3) functional performance (in relation to $A D L$ activities) and functional independence; 4) psychosocial impact; 5) user satisfaction; and 6) costs (Gelderblom and De Witte, 2002). All these dimensions are relevant for the assessment of assistive devices. Social participation and functional performance are similar to participation and activities in the ICF. The other four (quality of life, psychosocial impact, user satisfaction and costs) are additional to the ICF. For obtaining a complete view on the outcomes of an assistive device, information on all six dimensions is needed.

As discussed in the previous paragraph, some of the dimensions mentioned can be measured both objectively and subjectively. Quality of life is by definition a subjective concept, as too is user satisfaction. Costs, on the other hand, can be seen as objective. The other dimensions can have both an objective and a subjective side.

For measuring quality of life a large number of instruments are available in the literature. These are not specifically designed for use in relation to assistive devices $_{n}$ but the number of high quality generic instruments is high. The same goes for the "objective' assessment of functional performance or activities and participation. For measuring the subjective side of activities and participation only very few instruments are available. Therefore the emphasis in this thesis is put on subjective outcomes at the level of activities and participation.

Next to activities and participation, the concept of user satisfaction is considered relevant when thinking about evaluating assistive devices from a user 
perspective, as was already stated in paragraphs 1.3 and 1.5.1. In the opinion of the authors there is a great need for instruments that measure the subjective side of participation and activities, and the concept of user satisfaction. The assessment of costs of assistive technology is not discussed in this thesis.

In paragraph 1.3 it was argued that outcomes of assistive technology may be very individual. A specific type of assistive device may result in various types of outcomes and, conversely, one specific type of outcome can be achieved by various types of assistive technology. For example: for some people, the use of a communication device with a synthetic speech output can result in overcoming a disability in the participation domains 'social relationships' and 'education', yet for other people the same device can enable them to perform roles in the participation domains of 'work and employment' and 'economic life' (ICF). And, conversely, for some people improvement in the participation domain of 'community, social and civic life' can be achieved by using a communication device, but this could be achieved for others by using a mobility device or incontinence aids. In order to assess the effects of an assistive device, therefore, one first has to establish what the desired outcome should be in the case in question. "To determine the most appropriate measure for outcome of an assistive technology intervention, the objectives and goals of the intervention must be identified. (Smith, 1996). Outcomes vary among individuals, and one must obtain consumers' perspectives on the most desired outcomes, as well as the perspectives of secondary consumers (e.g. family members, caretakers, payers, vendors and employers)"(in: Dittmar \& Gresham, 1997). Following this line of thinking, there is a need for instruments that help identify the individual needs or goals of clients and that assess outcomes in relation to these needs or goals. Individualised user-focused instruments can be seen as an operationalisation of this line of reasoning. They are therefore very promising as outcome measures for assessing the outcomes of assistive devices. This thesis focuses on the development of such an individualised userfocused instrument ${ }_{2}$ as a specific approach within subjective evaluation of effects on the level of activities and participation.

A highly effective solution, which is not accepted by the client, will, in the end, not solve his or her problem. An instrument is therefore also required for assessing user satisfaction with the assistive device. When looking for outcomes from the user perspective, user satisfaction is an obvious choice. From a user perspective, one can argue that if the user is satisfied, the device is successful. From the broader perspective, this is of course a limited view. But since the user is the most central actor in the process, in fact he or she is the one for whom the process was started in first place, his or her view is considered to be a crucial one. A satisfaction instrument should not only assess user satisfaction with the assistive device itself, but also with the process of 
service delivery. In this manner, the intervention of assistive device provision as a whole can be evalluated.

Assessment of user satisfaction is not easy. It is not sufficient to simply ask: are you satisfied? In order to assess satisfaction with a certain device, one general question does not suffice. One has to investigate all kinds of aspects that might influence this satisfaction. These aspects can vary greatly. They can be specific features of a certain device, personal characteristics of a certain user or specific aspects of a certain environment. Yet in order to be able to compare interventions, it would be useful to have one generic instrument. Such an instrument should be uniformlly applicable to different kinds of assistive devices and different kinds of users.

\subsection{Objectives and specification of the research question}

In the introduction the question was raised what measurement instruments are available to determine the outcomes of assistive devices from a user perspective. In the subsequent paragraphs it was argued that such measurement instruments should meet a number of specific requirements and that there are only few such instruments available. The aim of this thesis is to bring this area further by identifying, testing and (further) developing potentially valuable instruments. The thesis focuses on two specific instruments, one to measure the effects of assistive devices from the users perspective and another to measure user satisfaction with assistive devices and their provision. The first is the IPPA (Individually Prioritised Problem Assessment; Wessels et al, 2000), the second is the Dutch version of QUEST (Quebec User Evaluation of Satisfaction with assistive technology; Demers et al, 1996). In chapter 2 the selection of these two instruments from the set of potentially available instruments is clarified. The concrete research questions discussed in this thesis are:

1. Is the IPPA a useful, reliable and valid instrument for determining the effects of assistive devices from a user perspective?

2. $\| s$ the Dutch version of QUEST (D-QUEST) a useful, reliable and valid instrument to determine the satisfaction of assistive device users with their device and the provision process?

IPPA (Individually Prioritised Problem Assessment) was developed as part of a European project. It assesses the effectiveness of a provision in terms of problems, identified by the individual user, and the way the problem is solved in the perception of that user. The D-QUEST assesses user satisfaction with an assistive device provision. Both instruments are discussed and tested by using them on people who receive an assistive device provision. The objective of this thesis is to test IPPA and D-QUEST for feasibility, reliability and validity in the context of Dutch assistive technology service delivery. If they prove to be 
sound, they may help towards improving the assistive technology service delivery.

\subsection{Content of this thesis}

Chapter 2 presents an overview of the literature in order to identify potentially valuable instruments. This overview is not a complete systematic literature review. The chapter is meant to present the context of the selected instruments. Chapter 3 presents the IPPA instrument. This instrument follows a really userfocused and individualised approach. The rationale behind the instrument is discussed and the instrument itself presented including the results of the first tests in terms of feasibility and validity. The IPPA instrument undergoes further testing in Chapter 4 in relation to the Dutch service delivery system for outdoor mobility devices and services, as well as in relation to the provision of a hi-tech robot arm.

Chapter 5 preserits QUEST and the Dutch translation. QUEST was developed in Montreal, Canada, by Louise Demers et al (Demers et al, 1996). Although user satisfaction is an aspect of assistive technology often assessed, this is really the only instrument that is validated, backed up by some degree of theory and is internationally recognised. A Dutch translation of this instrument was made, called D-QUEST (Dutch version of QUEST). Together with Louise Demers, QUEST and D-QUEST were tested and improved. Chapter 5 therefore describes the process of testing QUEST and shortening it to D-QUEST 2.0. In chapter 6 this Dutch version of QUEST 2.0 is applied to a large population of people who have received an assistive device provision from their health insurance company.

Finally, in chapter 7, all previous chapters are discussed. The research questions are answered and discussed, consideration is given as to how these and other instruments may be used to make an integral outcome assessment of assistive devices and their provision. This aspect will be discussed in the last chapter together with the findings of this study. The chapter concludes with recommendations for policy, research and practice. 


\section{References}

R. Andrich, M. Ferrario, M. Moi. A model of cost-outcome analysis for assistive technology. Disability and Rehabilitation: 1998, 20 (1) 1-24.

C. Van Campen, H. Sixma, J. Kerssens, L. Peters, J. Rasker. Assessing patients' priorities and perceptions of the quality of health care: the development of the QUOTE-Rheumatic Patient instrument. Br J Rheumatol: 1998 April, 37 (4) $362-8$.

C.M. Clancy, J.M. Eisenberg. Outcomes research: measuring the end results of health care. Science: $1998,282: 245-246$.

L. Demers, R. Weiss-Lambrou, B. Ska. Development of the Quebec User Evaluation of Satisfaction with assistive Technology (QUEST). Assistive Technology: 1996, 8: 3-13.

S.S. Dittmar, G.E. Gresham. Functional assessment and outcome measures for the rehabilitation health professional. Gaithersburg 1997, Md: Aspen Publishers.

Dutch Ministry of Social Affairs. Kerncijfers WVG, aantallen en kosten van verstrekte WVG voorziening (landelijke cijfers). Elsevier bedrijfsinformatie BV. 2000 .

M.J. Fuhrer. Subjectifying quality of life as a medical rehabilitation outcome. Disability and Rehabilitation: 2000, 22 (11) 481-489.

G.J. Gelderblom \& L.P. de Witte. The assessment of assistive technology outcomes, affects and costs. Technology and disability: 2002, 14: 91-94.

De Klerk (red.) SCP. Rapportage gehandicapten, maatschappelijke positie van mensen met lichamelijke beperkingen of verstandelijke handicaps. Den Haag 2002.

A. Parasuraman, V. Zeithaml, L. Berry. SERVQUAL: multiple item scale measuring consumer perceptions of service quality. J Retailing: 1988,64 (1) 1240.

M. Post. Quality of life and the ICIDH: towards an integrated conceptual model for rehabilitation outcomes research: clinical rehabilitation. Clinical Rehabilitation: 1999, 13: 5-15.

F. DeRuyter. Evaluating outcomes in assistive technology: and we understand the commitment? Assist Technol: 1995, 7: 3-16. 
Scherer \& Vitaliti. Assistive technology outcomes - bibliography \& web resource. Aspen Publishers, 1997.

R.O. Smith. Measuring the outcomes of assistive technology: challenge and innovation. Assistive Technology: 1996, 8: 71-81.

M. Soede. Non-use of provided assistive technology. RTH project, internal report iRv, 2003.

E. Towsend, S. Stanton, M. Law, H. Polatajko, S. Baptiste, T. ThompsonFranson, C. Kramer, F. Swedllove, S. Brintnell, L. Campanile. Enabling occupation; an Occupational Therapy Perspective. Ottawa: CAOT Publications, 1997.

G.G. Whiteneck. Measuring what matters: key rehabilitation outcomes. 44th annual John Stanley Coulter lecture. Arch Phys Med Rehabil 75, October 1994.

WHO, ICIDH-2; international Classification of Impairments, Activities and Participation. 1999. http://www. who.ch/icidh

WHO, ICF International Classification of Functioning Disability and Health. 2002 http://www. who.int/icidh/ 


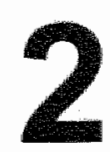

\section{Measuring effectiveness of and satisfaction with Instruments for the assessment of outcomes of assistive devices from the users' perspective: an exploration of the literature}

Roelof D. Wessels, Luc P. de Witte and Wim J.A. van den Heuvel Institute for Rehabilitation Research, the Netherlands 



\section{Introduction}

Since assistive technology is applied for a variety of purposes, many outcome measures are used in studies examining its effectiveness. Several main outcome categories can be identified: quality of life, social participation, functional performance, psychosocial impact, costs and user satisfaction (DeRuyter, 1995; Gelderblom and de Witte, 2002). In the last decade the user perspective' has become an increasingly important criterion in evaluating the quality of care and health services. Internationally many instruments have been developed, but in the field of rehabilitation and assistive devices, the lack of tested instruments is remarkable. In this paper the most useful of these will be presented.

If we look at outcomes from a user perspective, two aspects are important. On the one hand, user-focused measures that take into account the personal expectations and goals of an individual are important, since the personal preference of the user and his or her prior expectations with respect to the device and the expectations of the user carry a great deal of weight. On the other hand, user satisfaction with respect to the device provided has to be considered. The first objective of this paper is to identify instruments that have been developed for measuring outcomes from a user perspective.

In 1996 Demers studied the theoretical concept of satisfaction in relation to assistive technology (Demers, 1996). Demers concluded on the basis of a narrative review that "the literature reviewed did not disclose any theoretical framework that could be applied to user satisfaction with assistive technology." In the health domain, theoretical models do exist, but there is no particular model agreed upon. As a result there is no consensus on a standard definition, either theoretical or operational, of satisfaction. The second objective of this paper is to see whether any more consensus has materialized in theoretical models, definition and measurement of user satisfaction in the literature on assistive technology since Demers' publication in 1996.

\subsection{User-focused instruments for assessing services in rehabilitation}

Several methods and instruments have been developed for measuring outcome on the basis of dimensions defined by the individual respondent. The most widely used method is Goal Attainment Scaling (GAS) (Kiresuk, 1994). GAS was first described in 1968 by Kiresuk and Sherman as a method of evaluating the outcome of mental health treatment. It consists of a procedure to structure and evaluate the goals of individual clients in the service delivery process. The method can be applied in every situation where problems need to be analysed. 
goals specified and the degree of goal attainment evaluated afterwards. GAS is used in fields such as mental health care, education, public service delivery, management and research. Because of its general structure, it could allso be applicable in the field of assistive technology interventions.

GAS in fact measures the difference between the expected level of outcome and the actual level of outcome realised. In order to guarantee a reliable prediction of the level of outcome and a proper formulation of indicators, certain conditions have to be met. It has to be applied:

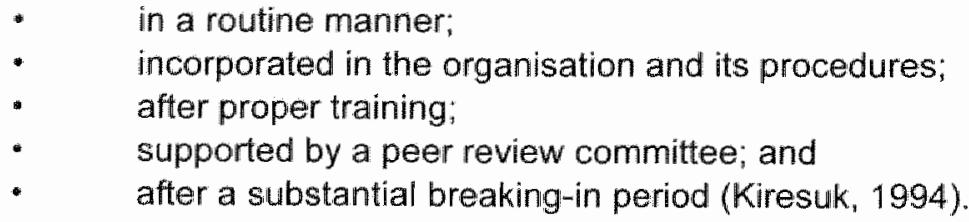

These conditions make GAS inappropriate to be applied as a research tool.

An instrument that less drastically interferes with the process of service delivery and can more easily be used, is the Patient Generated Index (PGI) (Ruta, 1994). It was initially developed to assess Quality of Life in patients with low back pain. Its method is simple: the patient is asked to identify the five most important activities that have been affected by the disorder in question. The patient then has to assign a score to each of the activities to indicate how badly it has been affected. Finally, the patient has to divide up a sum of points among the activities, in order to indicate how he would prefer to see his score improved (Ruta, 1994). An advantage of the PGI is that it is self-administered. However, it is not primarily designed to measure change (or outcome), but to quantify a condition. In addition, the scoring procedure is rather complicated.

An individualised patient-focused questionnaire to assess disability in arthritic patients is the MACTAR patient preference disability questionnaire (PPDQ) (Tugwell, 1987). The patient is asked to identify activities, which have been restricted as a result of the arthritis and rank these. At follow-up, the client is asked whether there have been any changes in his or her ability to perform each of the activities identified and if so, whether this has improved or deteriorated. The MACTAR ppdq was later incorporated into the Problem Elicitation Technique (PET) (Bakker, 1995). This also asks the patient to identify problem activities. The patient is asked to rate the level of difficulty, the degree of severity or the frequency of occurrence of the problem and the importance of the problem. At follow-up the patient is asked to complete the same ratings again (Bakker, 1995). A disadvantage of the PET for our purposes is that, like the PGI, it is designed to be applied in a specific field and not for assistive technology interventions. 
One user-focused questionnaire designed for use in the field of assistive technology service delivery is the COPM (Canadian Occupational Performance Measure) (Law, 1998). It was developed in the field of Occupational Therapy as an instrument for listing and quantifying the (activity related) problems a user encounters. It is a tool for implementing the philosophy of a user-centred perspective within the service delivery process. It is not just a measurement tool, it is a method of performing the service delivery process in a certain way. Because it cannot be separated as a measuring instrument from the process it measures, it is less suitable for use in scientific research.

In principle, all these measures (GAS, PGI, MACTAR-PPDQ, PET and COPM) are similar in concept. The client has to identify the problems he or she wishes to solve. This may be operationalised by asking what his/her goals are (GAS) or by asking which activities are affected by the problem (PGI, MACTAR-PPDQ, PET, COPM). Next, the client has to rate the severity of each problem. At follow-up the severity of the same problems (or the dlegrees of attainment of the same goals) are rated again. The exact procedure of rating may differ. The beauty of these instruments is that they are conceptually very pure. Their aim is to assess the degree to which problems are solved and that is precisely what they request. They fit perfectly within the philosophy of a user-focused practice; not only do they ask user opinion, the client can choose the aspects for which he or she provides an opinion. However, for reasons mentioned above, none of these instruments is really suitable for use in their original form for research on assistive technology interventions.

- For applying GAS several conditions have to be met to ensure reliable predictions of the levell of outcome that make GAS inappropriate to be applied.

- $\quad$ PGI is not primarily designed to measure change (or outcome), but to quantify a condition. In addition, the scoring procedure is rather complicated.

- The MACTAR ppdq and the PET focus specifically on arthritis. COPM is not just a measurement tool, it is a method of performing the service delivery process in a certain way. As a measuring instrument it cannot be detached from the process it measures, so it is less suitable for use in scientific research.

We believe that for the purpose of research an instrument is required that can assess the degree to which problems identified by individuals can be solved by an assistive technology intervention. It is our view that in order to assess the outcome of assistive technology provisions from a user perspective, an instrument is required that measures the subjective perception of the user with respect to the relevant domains. This instrument must be constructed in such a way, that the individual user himself or herself can choose what dimensions compose the outcome that needs to be assessed. 


\subsection{Satisfaction with assistive devices from a user perspective}

Firstly, an overview will be given of some general literature on consumer satisfaction and patient satisfaction, then a search will be made for more specific literature, which has been written on satisfaction with assistive techrology since 1996

\section{General literature on consumer satisfaction}

Theory about satisfaction with assistive technology may be expected to be embodied in theories about consumer satisfaction in general. It appears that in contemporary models of consumer satisfaction, expectations play an important role. Consumer satisfaction models include the following. Baron-Epel (2001) examined whether a consumer satisfaction model could be applied to the health care environment by studying the relationship between a) expectations, b) perceived degree of fulfillment of these expectations, c) satisfaction and d) changing family doctor. The model used is a fairly simple, linear one. It starts with a patient's expectations, followed by the degree of fulfilment of these expectations. The degree of agreement between these two leads to a certain degree of satisfaction. This satisfaction in turn influences the decision (or not) to change family doctor. The difference between expectations and their fulfilment showed a low correlation with satisfaction. These results would suggest that with patients visiting a primary care doctor, this consumer satisfaction model can only explain variation in satisfaction to a modest extent.

An extensive study of consumer and patient satisfaction was published by Pascoe (1983). He discussed three consumer satisfaction models related to expectancy: the contrast model; the assimilation model; and the assimilationcontrast model. The contrast model states that: "judgments are determined by previous experience with the general category of stimuli (adaptation level) and the perceived discrepancy between this level and the new stimulus. The consumer magnifies discrepancies between expectations and performance. Performance that is somewhat higher than expectations will be evaluated as satisfactory, whereas performance slightly less than expected will be judged as unsatisfactory" (Pascoe, 1983). The assimilation model states that inconsistencies between expectations and performance produce psychological tension for the consumer. "Consumers alleviate this tension by adjusting their perception of performance to match their expectations. Unlike the contrast model, the assimilation approach predicts that performance that is moderately lower than expectations will not cause dissatisfaction because perceptions of performance will be assimilated to match higher expectations" (Pascoe, 1983). In the assimilation-contrast model, expectations serve as a standard for judging a performance, but there is a latitude of acceptance surrounding this standard. 
"Discrepancies that are within this latitude will be assimilated as follows: expectations that are lower than outcomes will lead to decreased performance evaluation, lessening satisfaction; expectations that are higher than outcomes will increase performance judgments, causing greater satisfaction. Contrast effects occur when discrepancies exceed the latitude of acceptance" (Pascoe, 1983).

With a fairly broad latitude of acceptance, the assimilation-contrast approach tends to lead to a relatively high level of satisfaction amongst the population. Even when the perception is that the service delivery system is underperforming and complaints are frequent, the actual assessment of user satisfaction will show relatively high satisfaction rates. This was well illustrated by two studies by Wessels. In one study the satisfaction with mobility devices provided was evaluated. People appeared to be fairly satisfied with provisions provided under the widely criticized act (Service for the Disabled Act), which was responsible for providing mobility aids (Wessels, 1998). In another study the satisfaction of users of different kinds of assistive devices was evaluated. Although the users reported many complaints, when satisfaction was measured, scores were high (Wessels, 2003).

Focusing on health care, in the same study referred to above, Pascoe (1983) extensively reviewed alternative models for patient satisfaction in primary health care. Pascoe begins with the remark that "patient satisfaction research has not been explicitly guided by a well-supported definition or psychological model of satisfaction." Pascoe discusses three models of patient satisfaction here, originally developed in job satisfaction research: the value-expectancy model, the fulfilment model and the discrepancy model. The value-expectancy model states that (dis)satisfaction is determined by particular perception-value interactions. The fulfilment model defines satisfaction as a function of the amount received from a situation, regardless of how much a patient feels he or she should and/or wants to receive. It assumes that objective outcomes alone determine satisfaction. Expectations do not play a role. The discrepancy model on the other hand, does address the comparison of outcomes to some psychological standard, assuming that any deviation from what is expected produces dissatisfaction. This would imply that receiving more than anticipated. would produce less satisfaction (Pascoe, 1983).

A different view is hell by Owens (1996). After a study on patient satisfaction among the elderly he concludes that "in some contexts at least, expressions of satisfaction are not explained to any major extend by patients expectations." And "even where levels of general satisfaction are high, patients expectations may be low or even non-existent. These high levels of satisfaction can be explained in part by the relationship of dependency and friendship between patient and nurse." 
Summarizing, we can see that there are various models for client and patient satisfaction. It seems fair to assume that there is not one single model that suffices in every case. Expectations appear to be relevant. Both the contrast model and the assimilation model will sometimes be applicable, as will the assimilation-contrast model, depending on the subject and on the situation. The fulfilment model does not seem appropriate because it completely ignores the influence of expectations. The discrepancy model does not seem very plausible because receiving more than anticipated would automatically result in dissatisfaction. Owens' findings seem credible, especially with older people. There is no reason to believe that these models would not be applicable to assistive technology.

\section{User satisfaction with assistive technology}

One instrument to assess user satisfaction with assistive technology is QUEST. Since 1996, Demers published several papers about the development and validation of the instrument. QUEST (Quebec User Evaluation of Satisfaction with assistive Technology) is based on a limited amount of theoretical perceptions on user satisfaction. QUEST was originally published in 1996 (Demers, 1996) and it has been tested and improved since. QUEST was originally based on five criteria:

1. Satisfaction is a multidimensional phenomenon that embodies a broad range of variables most likely to influence the degree of user satisfaction with assistive technology;

2. The variables should represent all the relevant sources of satisfaction and dissatisfaction: the environment, the user and the assistive technolagy device. In the latest version of QUEST these three dimensions have, based on factor analysis, been replaced by two dimensions: the assistive technology device and the service delivery process (Demers, 2002);

3. The relative importance of the satisfaction items should be determined by the user of the assistive technology (i.e. the individual respondent) because satisfaction is a highly subjective concept. This criterion was later abandoned, after it appeared that respondents generally considered all variables equally important. In the latest version of the instrument (Demers, 2002) this question was omitted.

4. The interviewee should be allowed to express his or her opinion freely and openly within the constraints of the interview context;

5. The instrument should be simple and easy to use by assistive technology professionals when evaluating user satisfaction with all kinds of assistive devices (Demers, 2002).

Criteria 1, 2 and 3 can be considered part of a theoretical framework about satisfaction with assistive technology. Criteria 4 and 5 relate solely to the instrument for measuring satisfaction. 


\section{A review of recent literature on assistive technology user satisfaction}

A literature search was performed, using the databases MEDLINE, CIRRIE and CINAHL. Because the purpose of this paper was to study the development of new theoretical frameworks of the concept "satisfaction with assistive technology from a user perspective" after 1996, the search focused on generic, non-disability-specific, non-disease-specific literature published after 1996. In the MEDLINE database a search was performed using PublMed, available through the internet on hitp://www.ncbi.nlm.nih.gov/entrez/query.fogi. A combination of the keywords 'satisfaction' and 'assistive' was used. In the CIRRIE database (Centre for International Rehabilitation Research Information and Exchange in Buffalo), available through the internet on http://cirrie.buffalo.edu/search/, a search was performed using the title keyword 'satisfaction'. The search parameters were: all research areas, all geographical areas, all languages and all available years. The database contains citations from 1990 up to the present (2002). Only publications from after 1996 were included.

In the CINAHL database a search was performed using the CD ROMs containing the contents of the database for 1997 until 2002. A combination of keywords used was: 'satisfaction' and ('device' or 'technology') and ('research' or 'science') and 'assistive".

From the citations found, a selection was made based on the titles. The three authors each screened the list of citations independently from each other by assigning one of three possible values to each citation: ' 0 ' for not relevant, ' 1 ' for possibly relevant and ' 2 ' for relevant. All citations considered relevant by at least two of the three authors were listed. The citations were screened using the following criteria: the publications should - as far as can be judged on the basis of the title - relate to, or at least make use of a theoretical framework about satisfaction. This theoretical framework should be of a generic nature, that is, the papers should not be about one specific disability or disease.

The search of the MEDLINE database resulted in 74 citations, CIRRIE in 76 citations and CINAHL in 141. When identical citations were eliminated, a total of 287 remained. It was striking to see that between the three databases only four identical citations were presented. After the selection procedure-based on the titles of the citations - there were only 8 citations that were considered relevant by at least two of the three authors, not taking the publications by Demers into account: Fuhrer, 2001; Heaton and Bamford, 2001; Shone Stickel, 2002; Ryan, 2001; Jedeloo, 2000; Jedeloo, 2002; Geertzen, 2002; Sherer, 2000. The other citations related mainly to the actual measurement of user satisfaction levels amongst users of one specific type of device or one specific group of users. The eight publications selected are briefly discussed below. In table 1 a summarizing overview of these publications is presented. 
Table 1: Papers about user satisfaction published after 1996

\begin{tabular}{|c|c|c|}
\hline Study & Instrument or methods & Subject \\
\hline $\begin{array}{l}\text { Fuhrer. } \\
2001\end{array}$ & Description of QUEST & $\begin{array}{l}\text { An analysis of assistive } \\
\text { technology outcomes research }\end{array}$ \\
\hline $\begin{array}{l}\text { Heaton and } \\
\text { Bamford, } 2001\end{array}$ & Description of QUEST & $\begin{array}{l}\text { Description of key issues and } \\
\text { approaches used for assessing } \\
\text { the outcomes of equipment and } \\
\text { adaptations }\end{array}$ \\
\hline $\begin{array}{l}\text { Snone-Stickle, } \\
2002\end{array}$ & FIM, QUEST & $\begin{array}{l}\text { The impact of electronic aids on } \\
\text { daily living, evaluation of } \\
\text { consumer satisfaction }\end{array}$ \\
\hline $\begin{array}{l}\text { Ryan, } \\
2001\end{array}$ & QUEST & $\begin{array}{l}\text { Study of user satisfaction with } \\
\text { electronic leads to daily living }\end{array}$ \\
\hline $\begin{array}{l}\text { Jedeloo, } \\
2000\end{array}$ & $\begin{array}{l}\text { QUEST with } 7 \text { additional items } \\
\text { related to service delivery }\end{array}$ & Outdoor mobility service or device \\
\hline $\begin{array}{l}\text { Jedeloo, } \\
2002\end{array}$ & An adapted version of QUEST & Outdoor mobility service or device \\
\hline $\begin{array}{l}\text { Geertzen, } \\
2002\end{array}$ & $\begin{array}{l}\text { A modified SERVQUAL } \\
\text { questionnaire }\end{array}$ & Prosthetics and Orthotics facilities \\
\hline $\begin{array}{l}\text { Scherer, } \\
2000\end{array}$ & Several specific instruments & $\begin{array}{l}\text { Assessment of validity of a tool to } \\
\text { predict satisfaction with assistive } \\
\text { technology }\end{array}$ \\
\hline
\end{tabular}

Fuhrer (2001) discusses QUEST, along with two other assistive technology outcome measures (not related to user satisfaction), in an analysis of assistive technology outcome research. He starts by emphasizing the importance of and the difficulty of assistive technology outcome measures. He then points out the attraction of user satisfaction scales like QUEST for evaluating assistive technology outcomes: "These instruments have the compelling feature of assigning sovereignty to users' judgments as opposed to the judgments of payers, clinicians or researchers." However, he questions the sufficiency of user satisfaction scales for evaluating outcomes by mentioning two reservations. The first reservation relates to the role of expectations. "Conceptual models of (satisfaction) judgment emphasize the conjoint role of individuals' perceptions on the one hand and their expectations on the other. Satisfaction judgments are posited as varying inversely with the disparity between perceptions of an entity's performance and expectations for that performance." The second reservation for using user satisfaction scales relates exclusively to the fact that "doing so would neglect the perspectives of stakeholders who may prefer other ways of gauging outcomes. The different parties are presumed to be far from uniform in the value they assign to various outcome states and in the information they desire from outcome studies. Fuhrer states that user satisfaction is an important and meaningful outcome, but that assessing user satisfaction alone is not enough. User satisfaction is strongly influenced by (the fulfilment of) 
expectations. The other limitation is that only asking the user's opinion excludes the opinion of other important stakeholders.

QUEST (the older 24 items version, administered in a face-to-face interview) is also discussed by Heaton and Bamford (2001) in their description of key issues and approaches used for assessing the outcomes of equipment and adaptations. They call the instrument unusual, because it asks not only for the degree of satisfaction with each of the items, but also for the importance of each item. In the latest version of the instrument however (Demers, 2002) this aspect has been omitted, based on analyses of results. One significant limitation of QUEST mentioned by Heaton and Bamford is that the instrument relates to only one single item of equipment. It cannot be used to evaluate a combination of devices. Also, they point out the problem of assessing outcomes with users with progressive conditions, where the best outcomes may be maintaining an acceptable level or preventing an accident. In these circumstances comparison of before and after will be insensitive. The outcomes have to be assessed in terms of the difference between actuall outcomes and the outcomes that would have been expected in the absence of the intervention. Nothing is added to the theory on satisfaction with assistive technology.

The work by Shone-Stickel (2002) relates to the impact of electronic aids on daily life. In the study described, QUEST is used. Shone-Stickell asked respondents to rate all devices together. Despite these specific instructions, three respondents (out of twenty) would not do this and instead provided different satisfaction ratings for each device. Other limitations mentioned by Heaton and Bamford are dealt with in the latest version of QUEST. They conclude that combining QUEST with outcome measurement tools which explore other important dimensions, such as the effect on quality of life and psychosocial impact, will help service providers justify the costs associated with the prescription of sophisticated, costly assistive devices. Again, nothing is added to the existing theory on satisfaction with assistive technology.

Ryan (2001) also studied satisfaction amongst users of electronic aids for dailly activities. Subjects were people with degenerative neuromuscular conditions, both users and non-users. Amongst other measures he used QUEST. Subjects turned out to be relatively satisfied and this level remained comparatively stable over time. However, many subjects were concerned about the costs associated with these technologies and their associated services. In this study "nothing new was added to the existing theory on satisfaction with assistive technology.

Jedeloo studied client satisfaction with service delivery of assistive technology and service for outdoor mobility (2000 and 2002). She used adapted versions of QUEST. These adaptations consisted of seven additional items specifically related to a transportation service, like waiting time and access to a call centre. 
These were the items that were missing in the original version when evaluating a service instead of a device. She concluded that differences in client satisfaction between service delivery systems are caused by delivery time, user opinion, access and quality of information. Here too, nothing new was added to the existing theory on satisfaction with assistive technology.

The work by Geertzen et al (2002) relates to prosthetics and orthotics facilities. They used a modified SERVQUAL questionnaire (Parasuraman, 1988). The modifications were based on two focus group discussions with the consumers concerned and the intention was to adapt the questionnaire to prosthetics and orthotics facilities. A general statement they make is: "consumer satisfaction is also depending on the agreement between consumer priorities and experiences". The instrument SERVQUAL is not related to assistive technology itself, but to service delivery. So nothing new was added to the theory on satisfaction with assistive technology.

Scherer (2000) studied the validity of an instrument to predict satisfaction with assistive technology for adults with recent spinal cord injuries. She conducted the tool on people with recent spinal cord injuries. One-month post-discharge subjects were asked to rate their satisfaction with assistive technology. Like in all the other studies presented, no new theory was added to the limited amount of existing theory on satisfaction with assistive technology. In fact this means that, since 1996, the amount of theory on satisfaction with assistive technology available has not accumulated significantly.

\subsection{Discussion}

It appears that in the last few years, only little literature has made a contribution to the limited amount of theoretical literature available on satisfaction with assistive technology. A literature search of the MEDLINE, CIRRIE and CINAHL databases revealed that only a very limited amount of theoretical literature actually exists. A large proportion of it relates to QUEST. This instrument was originally based on the limited amount of theory available. Moreover, after testing, part of this theory was abandoned. Scoring the importance of each item and using this as a weighting factor turned out not to add anything. So no theoretical framework really exists on user satisfaction with assistive technology. Is such a framework necessary? On the one hand, it is not. It would be a problem if the intention was to develop a new instrument for measuring user satisfaction. However, such an instrument already exists. QUEST has been evolving over the last few years and is now widely used, well accepted and well validated. Therefore this lack of a theoretical framework would seem to present less of a problem. 
On the other hand, it is necessary to have a theoretical framework if the intention is more than simply measuring the level of user satisfaction. If the requirement is to study the phenomenon of user satisfaction itself, such a framework is needled. If the interest lies in the origin of user satisfaction and in the aspects that affect it, a theoretical framework is indispensable. These questions need to be answered, if user satisfaction is to be improved, so developing a theoreticall framework would certainly seem beneficial.

A few of the studies referred to did actually apply modifications to an existing instrument. This might mean that existing instruments are not perceived to be as generic as was first thought. The instrument SERVQUAL (Parasuraman, 1988 ) is really meant to assess the quality of a service. So the only broadly used and well validated instrument to assess satisfaction with assistive technology is QUEST (and translations, for instance, D-QUEST). One aspect of satisfaction that is considered relevant in almost every model, but plays no role in QUEST, is expectation. Because QUEST is only carried out following a period of use of the assistive device, it is hard to incorporate expectations that existed prior to its provision. One strong point of QUEST is that it is a totally client-focused model. But this is also its weakness: the only stakeholder questioned is the user. Although the user may well be the most important stakeholder, there are others. Another flaw is that QUEST only allows the evaluation of one single device at any one time. A combination of devices can not be evaluated simultaneously.

QUEST is not based on a solid theoretical framework. So a theoretical framework is not required to measure the level of user satisfaction. However, if the aim is to study the phenomenon of satisfaction itself and to identify the aspects which are responsible for influencing or changing user satisfaction, a theoretical framework is required, it might not be possible to create a single theoretical framework for satisfaction when applied to all kinds of assistive devices. Different varieties of the framework may be required for different types of assistive devices. 


\section{References}

C.H. Bakker. Problem elicitation in AS and fibromyalgia. Thesis Rijksuniversiteit Limburg; Universitaire Pers Maastricht, 1995; ISBN 90-5278-188-5. Patientoriented outcome assessment in rheumatic diseases: chapter 8 , accepted for publishing in the Journal of Rheumatology.

O. Baron-Epel, M. Dushenat, N. Friedman. Evaluation of the consumer model: relationship between patients' expectations, perceptions and satisfaction with care. International journal for quality in health care: 2001.13 (4) 317-323.

L. Demers, R. Weiss-Lambrou, B. Ska, Item analysis of the Québec User Evaluation of Satisfaction with assistive Technology (QUEST). Assist Technol 2000, 12 (2) 96-105.

L. Demers, R. Wessels, R. Weiss-Lambrou, B. Ska, L. de Witte. Key dimensions of client satisfaction with assistive technology: a cross-validation of a Canadian measure in the Netherlands. Journal of Rehabilitation Medicine: 2001, 33: 187-191.

L. Demers, M. Monette, Y. Lapierre, D. Arnold, C. Wolfson. Relability, validity and applicability of the Quebec User Evaluation of Satisfaction with assistive Technology (QUEST 2.0) for adults with multiple sclerosis. Disability and Rehabilitation: 2002, 24(1/2/3) 21-30.

M. Fuhrer. Assistive technology outcomes research, challenges met and yet unmet. Am J Phys Med Rehabil: 2001, 80 (7).

G.J. Gelderblom \& L.P. de Witte. The assessment of assistive technology outcomes, affects and costs. Technology and disability: 2002, 14: 91-94.

J. Geertzen, H Gankema, J. Groothoff, P. Dijkstra. Consumer satisfaction in prosthetics and orthotics facilities. Prosthetics and Orthotics international: 2002 , 26: 64-71.

J. Heaton, C. Bamford. Assessing the outcomes of equipment and adaptations: issues and approaches. British journal of occupational therapy: 2001, 64 (7).

http://cirrie.buffalo.edu/search/

http://www ncbi.nlm.nih.gov/entrez/query.ficgi 
S. Jedeloo, L. de Witte, B. Linssens, A. Schrijvers. Client satisfaction with service delivery of assistive technology for outdoor mobility. Disability and Rehabilitation: 2002, 24 (10) 550-557.

T.J. Kiresuk, A. Smith, J.E. Cardillo. Goal Attainment Scaling: Applications, Theory and Measurement. Hillsdale, New Jersey, 1994, Lawrence Eribaum Associates.

M. Law, S. Baptiste, A. Carswell, M. McColl, H. Polatajko. Pollock, Canadian Occupational Performance Measure. Ottawa, 1998, CAOT Publications.

D. Owens, C. Batchelor. Patient satisfaction and the elderly. Soc Sci Med: 1996,42 (11) 1483-1491.

A. Parasuraman, V. Zeithaml, L. Berry. SERVQUAL: multiple item scale measuring consumer perceptions of service quality. J Retailing: $1988_{n} 64$ (1) $12-$ 40.

G. Pascoe. Patient satisfaction in primary health care: the literature review and analysis. Evaluation and program planning: 1983, 6: 185-210.

D.A. Ruta, A.M. Garratt, M. Leng, J.T. Russell, L.M. McDonald. A new approach to the measurement of quality all for life, the Patient Generated Index. Medical care: 1994,32 (11) $1109-1126$.

F. DeRuyter. Evaluating outcomes in assistive technology: and we understand the commitment? Assist Technol: 1995, 7: 3-16.

S. Ryan, M. Stickel, P. Rigby, J. Jutai. Understanding the impact of electronic aids to daily living: evaluation of consumer satisfaction. Proceedings of the international conference on technology and aging. September 12-14 2001, Toronto, Canada.

M. Sherer, L. Cushman. Predicting satisfaction with assistive technology for a sample of adults with new spinal cord injuries. Psychol Rep: 2002, 87 (3 Pt 1) $981-7$.

M. Shone Stickel, S. Ryan, P. Rigby, J. Jutai. Toward comprehensive evaluation of the impact of electronic aids to daily living: evaluation of consumer satisfaction. Disability and Rehabilitation: 2002, 24 (1/2/3) 115-125. 
P. Tugwell, C. Bombardier, W.W. Buchanan, C.H. Goldsmith, E. Grace, B. Hanna. The MACTAR patient preference disability questionnaire - an individualized functional priority approach for assessing improvement in physical disability in clinical trials in rheumatoid arthritis. Journal of the rheumatology: 1987,14 (3) 446-51.

R. Wessels, L. de Witte, R. Weis-Lambrou, L. Demers, G. Wijlhuizen. A Dutch version of QUEST (D-QUEST) applied as a routine follow-up within he service delivery process. In: Placencia E, Ballabio E (Eds.), Improving the Quality of Life for the European Citizen. Washington, DC: IOS Press: 1998, 420-424.

R. Wessels, L. de Witte. Reliability and validity of the Dutch version of QUEST 2.0 with users of various types of assistive devices. Disability and Rehabilitation: 2003, 25 (6) 267-272. 


\section{IPPA, a user-centred approach to assess effectiveness of Assistive Technology provision}

Roelof D. Wessels', Luc P. de Witte' ${ }^{1}$ Renzo Andrich ${ }^{2}$, Massimo Ferrario ${ }^{2}$, Jan Persson ${ }^{3}$, Birgitta Oberg ${ }^{3}$, Wija Oortwijn ${ }^{4}$, Taeke Van Beekum ${ }^{4}$ and Øivind Lorentsen ${ }^{5}$

1 Institute for Relhabilitation Research, the Netherlands

2 SIVA, Italy

${ }^{3}$ Center for Medical Technology, Sweden

${ }^{4}$ TNO-PG, the Netherlands

${ }^{5}$ REHABNOR, Norway 



\subsection{Introduction}

As with other (medical) interventions, a growing need exists to prove the effectiveness of the resources spent on assistive technology (AT) service delivery. The growth in the demand has outstripped the increase in available budgets, mainly on account of the following reasons:

- The proportional increase of the ageing population;

- The general tendency to advocate autonomy and participation in all aspects of society for people with disabilities;

- Technological developments creating new opportunities; whilst new assistive technologies are being developed, new general purpose technologies too are creating opportunities for people with disabilities;

- The general tendency towards consumerism resulting in emancipated service delivery clients.

Alongside this economic motive, there is also a general trend towards increasing levels of professionalism. In every aspect of society, we see calls for efficiency and for evidence-based practice. To the AT user however, the most significant reason for assessing effectiveness is that his or her problem has been solved to an optimum level. The client wishes to attain the best quality of life possible.

In very general terms, people start using AT to eliminate (or at least reduce) one or more problems. The domain of interest here is problems that clients encounter in everyday life (outcome on the level of person/disability/activity) (Post, 1999) (WHO, 1999). The effectiveness of an AT provision can, in its most basic form, be defined as the degree to which the problem is actually solved in relation to its intended aim. The most direct way to effectuate this is to assess the degree to which goals are attained or problems are solved. Existing instruments in the field of health technology assessment (HTA) appear to be inadequate for use in the field of AT provision, the main reasons being:

- When people start using AT, they aspire to attain individual goals (Andrich, 1997) (Persson, 1997) (Persson, 1999). So the intended outcome, in terms of effectiveness, consists of the attainment of these specific, individually pursued goals;

The individual goals, pursued by the application of AT, bear a direct relation to the expectations held by people with disabilities and not to those held by people in the "normal" population. So the frame of reference of the respondents differs from that of the normal or average population;

- Existing instruments used in HTA for outcome assessment focus mainly on illness and health. However, people with long-term disabilities will often not consider their problems to be health-related and therefore. their goals will not be related to their perception of the concept of health; 
- Outcome of AT can manifest itself in a variety of fields: activities of daily living, social interactions, mental well-being, intellectual development, general well-being, etc.

In the field of rehabilitation research, several instruments exist for assessing an individual's 'disability-status' (Barthel (Mahoney, 1965), SIP68 (Bruin, 1994), FIM (Hamilton, 1987) etc.). If, after being provided with AT, a person is better able to perform certain activities, his or her 'disability-status' has decreased and the problems will have been (partly) solved. It might seem that these instruments could serve as effectiveness AT provision, but in fact they measure only the general condition of respondents and pay no attention to the specific individual goals pursued by those who apply for an AT provision. Meeting the specific, individual goals is the key purpose of AT provision and should therefore be the key aspect (although not necessarily the only aspect) when assessing the effectiveness. Also, because these instruments cover a very broad range of disabilities, they are not very responsive to small, subtle changes. Individuals with disabilities may perceive these small, subtle changes as being highly important in terms of quality of life or autonomy.

In the research project EATS (Efficiency of Assistive Technology and Services), a project within the EU TELEMATICS Applications Programme, Sector Disabled and Elderly (Persson, 1997), an instrument was developed the specific aims of which were to assess the effectiveness of AT provision. This new instrument the IPPA (Individually Identified and Prioritised Problem Assessment) - was developed on the basis of international literature and experts" opinions (Andrich, 1997). It extended the line of reasoning with respect to existing instruments using individualised scales, (e.g. Goal Attainment Scaling (GAS) (Kiresuk. 1994), the MACTAR patient preference disability questionnaire (Tugwell, 1987) and the Problem Elicitation Technique (PET) (Bakker, 1995)).

This paper gives a description of IPPA, as well as empirical data to support our contention that IPPA is a valid measure of the change caused by AT service delivery as perceived by the service delivery client. The international study described in this paper was used as a basis for refining the instrument, the final version of which is presented here.

While IPPA and its underlying rationale were being developed in Europe, a similar instrument - the Canadian Occupational Performance Measure (COPM) - was being formulated in Canada (Law, 1998). Although the two groups of researchers were unaware of each other's work, the two instruments differ only in detail; the line of reasoning is the same. Only the exact procedure of problem identification and priority setting, the scoring scales and the calculation of the total scores are different. The fact that these two instruments, developed in parallel, but completely independently of each other, are so much alike can be 
considered a serious indication of construct validity for the instruments and of the reasoning behind them.

\subsection{Methods}

\subsubsection{The instrument: IPPA}

IPPA is intended to measure the effectiveness of the provision of AT. It assesses the extent to which the problems in daily activities identified by the respondent have been diminished as a result of this provision. In short, IPPA is applied as follows (Wessels, 1998). The client is asked to identify the problems that he or she experiences in daily life and that he or she hopes are eliminated or diminished as a result of an AT provision. This is done as early in the service delivery process as possible (preferably at the very start) so that a client's account of his or her problems is not influenced by service providers. This identification process is interactive and the interviewer takes care to designate problems on the basis of concrete activities. These problems may differ per client. The client is allowed to identify up to seven problems. For each of the major problems identified (i.e. up to a maximum of seven), the client has to assign scores both with respect to the importance of the problem and the level of difficulty associated with performing the said activity. Scores are rated on a seven-point scale. The 'difficulty scores' are added up, using the 'importance scores' as weighting factors, the result of which is then divided by the number of problems, resulting in the total IPPA score (ranging between 1 and 49). This score represents the total average perceived inconvenience experienced by the client with respect to the problems associated with daily activities. During the follow-up interview, a few months after the client has started using the newly provided AT, the client again has to assign a 'difficulty score' for each of the same activities. The total IPPA score is re-calculated, using the 'importance scores' from the first interview as weighting factors. (In the follow-up interview, the respondent is not asked to re-assign a score with respect to importance. In this way, the frame of reference for the baseline situation is maintained and the effects are assessed in that context.) The difference between the total IPPA score before and after provision of AT is considered to represent the effectiveness, thus indicating the degree to which the perceived inconvenience with respect to the problems has diminished. An English version of the instrument was then translated into the languages of the four participating countries (Italian, Dutch, Norwegian and Swedish), using the guidelines for cross-cultural adaptation presented by Guillemin et al. (Guillemin, 1993) (Wessels, 1998). The results were discussed amongst research group members from the various countries. The (improved) forms used for the IPPA 
interview are presented in the annex (the scoring method was modified following this study) as well as the instructions for use.

\subsubsection{Study design}

The instrument was applied in the context of AT service delivery in italy, The Netherlands, Norway and Sweden (Wessels, 1999). Subjects were clients of service delivery centres in the four participating countries. During a four-months period, all clients aged 16 years or older with a problem in the field of mobility, hearing, speech-related communication or self-care related to use of the bathroom, who requested a new AT device through one of the participating centres were asked to take part in the investigation. People with serious cognitive impairments were excluded from the study. Subjects were interviewed twice by the same independent interviewer. The baseline interview was carried out during the early stages of AT service delivery and the follow-up interview took place after the AT provided had been used for three months. A total period of 9 months was made available for data collection. Interviewers were therapists/counsellors working as professionals in the service delivery process. The interviews were strictly independent from the service delivery process. The interviewers were instructed and trained beforehand.

\subsubsection{Reliability}

Because of the nature of IPPA, it proved very difficult to assess reliability of the instrument in the traditional, psychometric sense. Every respondent in fact creates his or her own questionnaire with a variable number of questions. Analysis of internal consistency is not possible. Content analysis of the problems identified in two consecutive interviews (in order to anaiyse test-retest stability) in fact means comparing the (self-created) questionnaires, so a comparison of the scores (i.e. the answers to the questionnaires) of two consecutive interviews is not meaningful unless the problems identified are identical (Kiresuk, 1994) (Streiner, 1998). The aim of IPPA is to assess change and, more importantly, to apply it in a context where this change is brought about. If, for the purposes of test-retest stability assessment, the instrument were to be used on respondents who were in a stable, changeless condition (i.e. not entering the process of AT service delivery), they would not have a specific (set of) problem(s) giving any cause for an interview in the first place. It is likely that this would result in 'unstable' problem identification. Because of the aforementioned, a test-retest study is difficult to perform and 'hard' evidence about the reliability of IPPA is not yet available. 


\subsubsection{Feasibility}

To assess the feasibility of IPPA, the interviewers were asked to rate the following aspects of each interview, using an evaluation form:

- the duration of the assessment;

- the level of difficulty experienced by the respondent with respect to the assessment, as perceived by the interviewer;

- the number of problems identified by each subject;

- $\quad$ other observations relevant to improve the instrument.

Apart from evaluating each individual interview, a meeting with all interviewers was also arranged. During this one-day meeting experiences were exchanged and relevant aspects of feasibility discussed. After the last interview, each interviewer received a questionnaire with questions about their experiences and opinions on aspects of feasibility.

\subsubsection{Validity}

The construct validity of IPPA was assessed by comparing the scores with the results of two other instruments:

- $\quad$ EuroQol, a general health measure (Kind, 1998); and

- SIP68, a measure for assessing problems in daily functioning (Bruin, 1994).

EuroQol consists of five questions (dimensions) and a Visuall Analogue Scale (VAS). The combination of answers to the five questions was valued, using the weights derived from a UK general population survey (Dolan, 1995) and resulting in a weighted health index. The rating on the VAS indicates the respondent's own assessment of his or her state of health (Kind, 1998). SIP68 consists of 68 questions. One total score can be calculated, which represents an estimation of an individual's functional status (Bruin, 1994).

The emphasis of the validity tests lies on the reported change. Changes in IPPA scores are expected to co-vary with changes in SIP68 scores but, at the same time, EuroQol scores (both VAS and weighted health index (from hereon called 'EuroQol Score')) are supposed to remain fairly stable (an AT provision is not supposed to have any substantial effect on an individual's general health). Positive correlations with SIP68 scores (expected to be fairly weak) will be interpreted as evidence to support the (construct) validity of IPPA. In addition to there being a positive relationship between the reported change with the two instruments, the expectation is that IPPA total scores (on both assessments) will bear some relationship to the SIP68 scores: it is expected that respondents who mention a greater number of 'highly important' problems as well as high levels of difficulty, will have higher SIP68 scores, indicating more serious 
problems in dally functioning. Assessing the relationship between the scores of IPPA and the other two instruments at one point in time is done by using nonparametric correlation coefficients (Spearman's rho).

Since the objective of IPPA is to measure the degree of change, it is important to obtain information about the responsiveness (sensitivity to change) of the instrument. The basic criterion for this responsiveness is whether the measure can detect differences in outcome that are important, however small these may be. The effect sizes of IPPA, SIP68 and EuroQol will be compared with each other.

\subsection{Results}

\subsubsection{Subjects}

Because clients were supposed to be interviewed at the earliest possible stage during the service delivery process, it was not always possible to gather an adequate amount of information beforehand for final inclusion in the study. For this reason, it was necessary to exclude a number of clients at a later stage in the study. In total, around 300 clients were approached, 248 of whom participated in a baseline interview. A breakdown per country and per problem area is given in table 1.

Table 1: Problem areas and numbers of clients included

\begin{tabular}{|c|c|c|c|c|c|c|}
\hline & & Mobility & $\begin{array}{l}\text { Speech } \\
\text { rel. com. }\end{array}$ & Hearing & $\begin{array}{c}\text { Self-care } \\
\text { in } \\
\text { bathroom }\end{array}$ & Total \\
\hline \multirow[t]{2}{*}{ Nornay } & baseline & 41 & & 38 & & 79 \\
\hline & Follow-up & 38 & & 33 & & 71 \\
\hline \multirow[t]{2}{*}{ Swedan } & baseline & 29 & 11 & & & 40 \\
\hline & Follow-up & 19 & 7 & & & 26 \\
\hline \multirow[t]{2}{*}{ Itally } & baselline & 27 & 30 & 19 & & 76 \\
\hline & Followmup & 27 & 30 & 19 & & 76 \\
\hline \multirow[t]{2}{*}{ Netherlands } & baseline & 28 & & 6 & 19 & 53 \\
\hline & Follow-up & 10 & & 3 & 2 & 15 \\
\hline \multirow[t]{2}{*}{ Total } & baseline & 125 & 41 & 63 & 19 & 248 \\
\hline & Follow-up & 94 & 37 & 55 & 2 & 188 \\
\hline
\end{tabular}

Some basic characteristics are given in table 2 . Of these 248 clients, 188 participated in a follow-up interview. The other 60 clients dropped out of the study because they did not actually receive a new AT provision or because the service delivery process (especially home adaptations) had not been concluded 
by the time this study was completed. A few clients were unable to participate in a follow-up interview on account of their poor state of health.

Table 2: Characteristics of the population

\begin{tabular}{|c|c|c|c|c|c|c|}
\hline & & Norway & Sweden & litaly & Netheriands & Total \\
\hline Baseline & $\begin{array}{l}\% \text { female } \\
\text { mean age (SD) }\end{array}$ & $\begin{array}{c}61 \\
71(12)\end{array}$ & $\begin{array}{c}62 \\
68(20)\end{array}$ & $\begin{array}{c}59 \\
45(21)\end{array}$ & $\begin{array}{c}60 \\
63(17)\end{array}$ & $\begin{array}{c}60 \\
61(21)\end{array}$ \\
\hline Follow-up & $\begin{array}{l}\% \text { female } \\
\text { mean age (SD) }\end{array}$ & $\begin{array}{c}62 \\
70(13)\end{array}$ & $\begin{array}{c}73 \\
68(20)\end{array}$ & $\begin{array}{c}59 \\
45(21)\end{array}$ & $\begin{array}{c}53 \\
67(17) \\
\end{array}$ & $\begin{array}{c}62 \\
59(21)\end{array}$ \\
\hline
\end{tabular}

Regarding the characteristics of the study population, $60 \%$ was female and $40 \%$ male (table 2). This was true of the total population, as well as with respect to each country and to each type of problem, except for clients with mobility problems ( $71 \%$ female) and for clients with hearing problems, which was the only category with more males than females ( $44 \%$ female). The mean age of the clients was about 60 to 70 years old, except for clients with speech-related communication problems. This group was much younger (mean age 32) with clients in the Italian population being considerably younger than in those in other countries.

\subsubsection{Feasibility}

The duration of every interview was recorded. Since (for validation purposes) the interviews consisted of more than just the IPPA, exact figures on the duration of the IPPA interviews themselves are not available. The duration of an IPPA baseline interview was estimated to take between 10 and 30 minutes; the duration of an IPPA follow-up interview less than 15 minutes.

In general the interviews could be performed without difficulty. The questions fit well into the frame of reference of both clients and service delivery professionals. Most people understood the questions and the answers were considered relevant and to the point. Subjects had no problems with scoring the scales (although in a few cases the importance question was not well understood). Some people (especially elderly) had trouble rating their problems in terms of numbers. Verbal descriptions would facilitate the rating.

The IPPA interview was designed to include a maximum of seven problems for each client. Table 3 shows the number of problems actually mentioned by clients during the baseline interview. The median number is 3 . The Norwegian clients identified a considerably larger number of problems. This was to be expected, since Norwegian centres use an approach, taking into account all the 
occupational problems a person might have. In the other countries, AT service delivery centres deal with problems within a specific field (e.g. mobility or communication). Clients with speech-related communication problems identified fewer problems. The maximum number of seven problems appears to be sufficient. Only one client (in Sweden) was unable to identify a single problem.

Table 3: Number of problems identified per client

\begin{tabular}{|c|c|c|c|c|c|c|c|c|c|}
\hline$\underset{\overline{\mathbf{g}}}{\overline{\mathrm{p}}}$ & 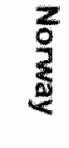 & $\frac{\substack{\frac{9}{9} \\
\frac{8}{9}}}{3}$ & $\frac{\bar{a}}{\varepsilon}$ & $\begin{array}{l}\frac{2}{9} \\
\frac{8}{9} \\
\frac{9}{1}\end{array}$ & $\frac{3}{8}$ & 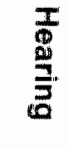 & $\begin{array}{l}\overline{0} \\
\frac{\infty}{8} \\
8 \\
8 \\
3\end{array}$ & $\frac{\mathscr{E}}{\frac{\mathscr{D}}{3}}$ & \\
\hline Median & 5 & 2 & 2 & 4 & 3 & 4 & 2 & 3 & 3 \\
\hline Min. & 1 & 0 & 1 & 1 & 0 & 1 & 4 & 1 & 0 \\
\hline Max. & 7 & 4 & 7 & 6 & 7 & 7 & 4 & 6 & 7 \\
\hline
\end{tabular}

The following observations were made by interviewers:

- IPPA focuses on problems that people have. For some respondents, this can be quite confrontational and evoke a lot of emotions;

After having completed the interview, clients appear to be better able to express their problems during the actual assessment of the service delivery process;

- For some people the problem identification is difficult because they have grown accustomed to their disabilities and no longer perceive them as problems;

Interviewers sometimes had to 'translate' the identified problems into terms of activities or had to continue asking questions to break down the problems to the required level;

Identifying problems could be facilitated by first going through the activities of a regular day;

Sometimes people perceive their problem as being purely assistancerelated (the taxi is often too late) or related to the AT itself (my wheelchair is too old or too heavy) and not to activities.

\subsubsection{Validity}

The relationship between changes measured with IPPA and changes measured with EuroQol (Score and VAS) and SIP68 was analysed. Table 4 shows the baseline scores (and standard deviations) and the changes (and standard deviations) found on the total IPPA score, the EuroQol Score, the EuroQol VAS and the SIP68 score. For all instruments, improvements in the clients' situation are indicated by positive changes to facilitate comparison. Table 4 shows that the direction of the changes measured with IPPA is consistent with what was to 
be expected, even more so than in the other instruments. Changes in IPPA are larger than in the other instruments.

Table 4: Mean baseline (Ba) scores (and standard deviations) and mean changes (Ch) after AT provision (and standard deviations)

\begin{tabular}{|c|c|c|c|c|c|c|c|c|}
\hline & \multicolumn{2}{|c|}{ IPPA } & \multicolumn{2}{|c|}{$\begin{array}{c}\text { EuroQol } \\
\text { Score }\end{array}$} & \multicolumn{2}{|c|}{ EuroQol VAS } & \multicolumn{2}{|c|}{ SIP 68} \\
\hline & $\begin{array}{c}\mathrm{Ba} \\
\text { (SD) }\end{array}$ & $\begin{array}{c}\text { Ch } \\
\text { (SD) }\end{array}$ & $\begin{array}{c}\mathrm{Ba} \\
(\mathrm{SD})\end{array}$ & $\begin{array}{c}\mathrm{Ch} \\
(\mathrm{SD})\end{array}$ & $\begin{array}{c}\mathrm{Ba} \\
(\mathrm{SD})\end{array}$ & $\begin{array}{c}\text { Ch } \\
(S D)\end{array}$ & $\begin{array}{c}\mathrm{Ba} \\
(\mathrm{SD}) \\
\end{array}$ & $\begin{array}{c}\mathrm{Ch} \\
\text { (SD) } \\
\end{array}$ \\
\hline Total $(n=188)$ & $\begin{array}{c}34 \\
(10)\end{array}$ & $\begin{array}{c}14 \\
(12)\end{array}$ & $\begin{array}{c}.50 \\
(.40)\end{array}$ & $\begin{array}{c}.06 \\
(.26)\end{array}$ & $\begin{array}{c}56 \\
(21)\end{array}$ & $\begin{array}{c}5 \\
(21)\end{array}$ & $\begin{array}{c}19 \\
(15)\end{array}$ & $\begin{array}{c}2 \\
(7)\end{array}$ \\
\hline Norway $(n=71)$ & $\begin{array}{l}34 \\
(8)\end{array}$ & $\begin{array}{c}13 \\
(10)\end{array}$ & $\begin{array}{l}.49 \\
(.41)\end{array}$ & $\begin{array}{c}.11 \\
(.27)\end{array}$ & $\begin{array}{c}54 \\
(22)\end{array}$ & $\begin{array}{c}6 \\
(17)\end{array}$ & $\begin{array}{c}13 \\
(12)\end{array}$ & $\begin{array}{c}4 \\
(6)\end{array}$ \\
\hline Sweden $(n=26)$ & $\begin{array}{c}33 \\
(13)\end{array}$ & $\begin{array}{c}11 \\
(18)\end{array}$ & $\begin{array}{c}.47 \\
(.34)\end{array}$ & $\begin{array}{c}.07 \\
(.36)\end{array}$ & $\begin{array}{c}59 \\
(27)\end{array}$ & $\begin{array}{l}-4 \\
(35)\end{array}$ & $\begin{array}{c}24 \\
(11)\end{array}$ & $\begin{array}{c}3 \\
(12)\end{array}$ \\
\hline Italy $(n=76)$ & $\begin{array}{c}33 \\
(10)\end{array}$ & $\begin{array}{l}12 \\
(9)\end{array}$ & $\begin{array}{c}.55 \\
(.40)\end{array}$ & $\begin{array}{c}.01 \\
(.15)\end{array}$ & $\begin{array}{c}56 \\
(18)\end{array}$ & $\begin{array}{c}7 \\
(18)\end{array}$ & $\begin{array}{c}23 \\
(16)\end{array}$ & $\begin{array}{c}0 \\
(3)\end{array}$ \\
\hline Netherlands ( $n=15)$ & $\begin{array}{l}42 \\
(8)\end{array}$ & $\begin{array}{c}29 \\
(11)\end{array}$ & $\begin{array}{c}.44 \\
(.41)\end{array}$ & $\begin{array}{c}.05 \\
(.26)\end{array}$ & $\begin{array}{c}58 \\
(23) \\
\end{array}$ & $\begin{array}{r}5 \\
(21) \\
\end{array}$ & $\begin{array}{c}18 \\
(14)\end{array}$ & $\begin{array}{c}4 \\
(7)\end{array}$ \\
\hline Mobility $(n=94)$ & $\begin{array}{l}38 \\
(9)\end{array}$ & $\begin{array}{c}17 \\
(12)\end{array}$ & $\begin{array}{l}.32 \\
(.39)\end{array}$ & $\begin{array}{c}.12 \\
(.32)\end{array}$ & $\begin{array}{c}46 \\
(18)\end{array}$ & $\begin{array}{c}11 \\
(20)\end{array}$ & $\begin{array}{c}24 \\
(12)\end{array}$ & $\begin{array}{c}4 \\
(8)\end{array}$ \\
\hline Hearing $(n=55)$ & $\begin{array}{l}28 \\
(9)\end{array}$ & $\begin{array}{c}8 \\
(8)\end{array}$ & $\begin{array}{c}.80 \\
(.22)\end{array}$ & $\begin{array}{c}.01 \\
(.18)\end{array}$ & $\begin{array}{c}72 \\
(13)\end{array}$ & $\begin{array}{l}-2 \\
(13)\end{array}$ & $\begin{array}{c}3 \\
(5)\end{array}$ & $\begin{array}{c}0 \\
(3)\end{array}$ \\
\hline Speech $(n=37)$ & $\begin{array}{l}34 \\
(9)\end{array}$ & $\begin{array}{c}11 \\
(14)\end{array}$ & $\begin{array}{c}40 \\
(.29)\end{array}$ & $\begin{array}{l}-.01 \\
(.20)\end{array}$ & $\begin{array}{c}60 \\
(22)\end{array}$ & $\begin{array}{c}0 \\
(29)\end{array}$ & $\begin{array}{l}29 \\
(9)\end{array}$ & $\begin{array}{c}1 \\
(5)\end{array}$ \\
\hline $\begin{array}{l}\text { Use of bathroom } \\
(n=2)\end{array}$ & $\begin{array}{l}47 \\
(2) \\
\end{array}$ & $\begin{array}{r}40 \\
(4) \\
\end{array}$ & $\begin{array}{r}66 \\
(.10) \\
\end{array}$ & $\begin{array}{l}.00 \\
(.00) \\
\end{array}$ & $\begin{array}{c}64 \\
(23) \\
\end{array}$ & 12 & $\begin{array}{l}25 \\
(9) \\
\end{array}$ & 12 \\
\hline Effect size & & & & & & & & \\
\hline
\end{tabular}

Responsiveness of the instruments was analysed by calculating effect sizes (mean change divided by standard deviation of mean baseline score). The result is presented in table 4. IPPA shows a fairly large effect size (1.40). This supports the idea that IPPA measures the construct (i.e. the degree to which problems in daily life are solved) that is specifically affected by AT provision. The effect sizes for the other instruments are smaller. The effect sizes of the EuroQol VAS (.24) and the EuroQol Score (.15) were not expected to be very high, since the general health of people is not really affected by AT provision. The effect size of the SIP68 (.13) was also small.

The last aspect of validity studied is the correlation between IPPA and the other instruments, EuroQol and SIP68, at the same point in time. These correllations were not expected to be very strong but still positive, because they measure a 
different but related concept. In table 5 the results of this analysis are presented, for the first and second assessment separately. It is clear that these correlations are not very high. The direction, however, is as expected. These results give support to the validity of IPPA.

Table 5: Nonparametric Correlations (Spearman's rho) between IPPA and EuroQol/SIP68

\begin{tabular}{|c|c|c|c|c|c|c|c|c|}
\hline & \multicolumn{4}{|c|}{ Baseline interview } & \multicolumn{4}{|c|}{ Follow-up interview } \\
\hline & IPPA & $\begin{array}{c}E Q \\
\text { Score }\end{array}$ & $\begin{array}{c}\text { EQ } \\
\text { VAS }\end{array}$ & SIP68 & IPPA & $\begin{array}{c}\text { EQ } \\
\text { Score }\end{array}$ & $\begin{array}{c}\text { EQ } \\
\text { VAS }\end{array}$ & SIP68 \\
\hline IPPA & - & & & & - & & & \\
\hline EuroQol Score & $36^{* *}$ & - & & & $.22^{* *}$ & - & & \\
\hline EuroQol VAS & $30^{* *}$ & $.59^{* *}$ & - & & $18^{\star}$ & $.52^{\star * *}$ & - & \\
\hline SUP68 & $.40^{* *}$ & $.73^{\star *}$ & $.48^{* *}$ & - & .13 & $.73^{\star \star *}$ & $.35^{* *}$ & - \\
\hline
\end{tabular}

\subsection{Conclusions and discussion}

The results presented in this paper indicate that the feasibility of IPPA is satisfactory. The questions fit well into the service delivery procedures in each country and they can be easily conducted. Based on the experiences with respect to the instrument and the comments of interviewers and respondents in particular, some adjustments were made to the instrument and the instructions for its use. The main adjustment was replacing the seven-point scoring scales with multiple-choice answers with five verbal answering options. The final version is presented in the annex. With respect to the validity, the results show that in most subgroups analysed, changes in IPPA scores are consistent with changes in SIP68 scores, which supports the content validity. The changes in IPPA scores appear to be larger than the others, which is consistent with the theory behind the instrument: IPPA measures the essence of the changes caused by AT provision.

One aspect, which was not recognised until during the study, was the influence of expectations that clients may have before entering the service delivery process on their evaluation afterwards. With the problem identification in particular (i.e. a sort of 'reversed goal setting'), these expectations do play a role. In further developing IPPA we will try to include a recording of these expectations in the baseline interview. Another point that still needs attention is the way of calculating the total IPPA score. Identifying three problems (e.g. going to the supermarket, going to the bank and going to the hairdressers) does not necessarily mean more 'problem load' than when identifying one problem 
(e.g. shopping). By dividing the summed scores by the number of problems, the total score is not effected by the number of problems identified and a scale is created with an equal range for every respondent. (Interpreting individual scores can only be done within the frame of reference of the individual respondent.) Finally, more attention (and more data) is required for analysing whether weighting the scores (by means of the importance scores) has any additional value. Additional research will have to address this question.

The first stage of the development of IPPA is now completed. So far, it has been necessary to limit the tests to some of the most essential aspects of feasibility and validity. Results are promising enough to continue. This multistage procedure was chosen because of the limited number of clients that could be included during the limited period of time available for testing. Also, more extensive testing will only be accountable after basic tests have shown promising results. In the next stage of development, the instrument will be optimised by focusing attention on including previous expectations in the assessment, on the method of calculating the total IPPA score and on the weighting of the scores. In conclusion, the results of this first field test support the underlying ideas and principles of the instrument and are encouraging with respect to its validity and feasibility. Further study into the reliability, validity and responsiveness is, however, necessary before drawing final conclusions. In view of the results such further study is considered worthwhile. 


\section{References}

R. Andrich, M. Ferrario \& R. Wessels. Assessing outcomes of assistive technology and services 3.1/3.2: The EATS instruments. Project DE3101 EATS (Efficiency of Assistive Technology and Services) Fourth Framework Programme of European Community activities in the field of Research and Technological Development, "Telematics Applications Programme", Sector C/8 Disabled \& Elderly. Brussels 1997.

C.H. Bakker. Problem elicitation to assess patient priorities in ankylosing spondylitis and fibromyalgia. J Rheumatol: 1995, 22(7) 1304-1310.

A.F. de Bruin, M. Buys, L.P. de Witte, J.P.M. Diederiks. The Sickness Impact Profile: SIP, a short generic version. First evaluation of the reliability and reproducibility. J Clin Epidemiol:1994, 47 (8) 863-871.

C. Bühler and H. Knops (Eds.) Assistive Technology on the Threshold of the New Millenium. IOS Press 1999.

P. Dolan, C. Gudex, P. Kind, A. Williams. (1995). A social Tariff for EuroQol: Results from a UK general population survey. Discussion paper 138. Centre for Health Economics, University of York 1995.

Guillemin, Bombardier, Beaton. Cross-cultural adaptation of health-related quality of live measures. J Clin Epidemiol: 1993, 46 (12) 1417-1432.

B.B. Hamilton, C.V. Granger, F.S. Sherwin, M. Zielezny, J.S. Tashman. A uniform national data system for medical rehabilitation. In: Fuhrer $M$, edl. Rehabilitation outcomes: analysis and measurement. Baltimore: Brookes 1987. 137-147.

P. Kind, F. de Charro. EQ-5D Resource Pack, Centre for Health Economics, University of York 1998

T.J. Kiresuk, A. Smith, J.E. Cardillo. Goal Attainment Scaling: Applications, Theory, and Measurement. Hillsdale, New Jersey: Lawrence Erlbaum Associates 1994.

M. Law, S. Baptiste, A. Carswell, M. McColl, H. Polatajko, Pollock. Canadian Occupational Performance Measure. CAOT Publications, Ottawa 1998.

F.I. Mahoney, D. Barthel. Functional evaluation: the Barthel Index. Maryland State Med J: 1965, 14: 56-61. 
J. Persson. An overview of the EATS project: effectiveness of assistive technology and services. G. Anogianakis et al. (Eds.) Advancement of Assistive Technology. IOS Press 1997.

J. Persson, et al. Rationale for global outcome measures in the EATS (Efficiency of Assistive Technology and Services) approach.

M.W.M. Post, L.P. de Witte, A.J.P. Schrijvers. Quality of life and the ICIDH: towards an integrated conceptual model for rehabilitation outcomes. Clinical Rehabilitation: 1999, 13: 5-15

D.L. Streiner, G.R. Norman. Health Measurement Scales, A practical guide to their development and use. Oxford University Press 1998.

P. Tugwell, C. Bombardier, W. Buchanan, C. Goldsmith, E. Grace, B. Hanna. The MACTAR patient preference disability questionnaire - An individualized functional priority approach for assessing improvement in physical disability bin clinical trials in rheumatoid arthritis. J Rheumatol: 1987, 14: 446-51.

R. Wessels. L. de Witte \& R. Andrich. Field testing of the EATS instruments: Plan and Procedures. Deliverable 4.1. Project DE3101 EATS (Efficiency of Assistive Technology and Services). Fourth Framework Programme of European Community activities in the field of Research and Technological Development, "Telematics Applications Programme", Sector C/8 Disabled \& Elderly. Brussels 1998.

R. Wessels ${ }_{\text {, }}$. de Witte \& R. Andrich. Field testing of the EATS instruments: Results. Deliverable 4.2. Project DE3101 EATS (Efficiency of Assistive Technology and Services). Fourth Framework Programme of European Community activities in the field of Research and Technological Development, "Telematics Applications Programme", Sector C/8 Disabled \& Elderly. Brussels 1999.

WHO (1999). ICIDH-2; International Classification of Impairments, Activities and Participation. http://www. who.ch/icidh 


\section{Annex}

\section{INSTRUCTIONS FOR IPPA BASELINE INTERVIEW}

The interviewer brings 7 IPPA Baseline Interview Forms, an IPPA Checklist and a pen or pencil and some paper to the interview. The interview consists of 3 steps.

\section{Problem Identification}

The interviewer asks the client to identify those problems that he/she considers to be the most important and that he/she expects or wants to see improved by using Assistive Technology. The interviewer reads to the client the introduction printed above the form: "What are the most relevant problems that you experience and that you expect or want to see improved by using a new assistive device or service? Please focus on problems that you experienced in performing activities during the last month in your daily routine. The problems may relate to a simple activity (walk up the stairs, read the newspaper, have a conversation, et cetera.) or to a more complex activity (prepare a meal, go shopping, go to work/school, et cetera). You may think of things you are not able to do at all or things that you are not able to do as well or as often or as easily as you would like." This part of the interview has to be administered in an informal, interactive manner. Client and interviewer can discuss things in an informal manner.

The interviewer may help the client, by asking him or her to go through the activities of a regular day step by step. The interviewer has to make sure, that problems are identified on the level of activities. If problems are defined too globally (I have problems with communication) the interviewer has to keep asking questions, in order to break it down to the level of concrete activities (In what situation / during what activity do you have problems with communication?).

The interviewer takes notes to list the problems identified by the client. The interviewer can use a notebook or a piece of paper to do this. Once the client has finished identifying problems spontaneously, the interviewer shows him/her the checklist with possible problem areas to make sure the client doesn't overlook any relevant problem. The interviewer says: "Please go through this list with examples of possible problem areas, to check whether there are any problems that you may have overlooked.". 
Clients are allowed to identify up to seven probiems in total. The client should be stimulated to think of possible problem areas, but it is not necessary to push him/her to mention precisely seven problems; the aim is to identify those problems that are relevant to the client. It doesn't matter if the client identifies less than seven problems. If the client identifies more than seven problems, the interviewer shows the client the list with problems that he/she identified and asks him/her to select the seven most relevant problems. The interviewer says: "If you look at this list with problems that you identified, could you please select the seven problems that are most relevant to you and that you would most like to see solved or improved by using a new assistive device.".

For each of the (up to seven most relevant) problems that is identified by the client, the interviewer takes a separate IPPA Baseline Interview Form and writes down (on the top where it says: To be completed by the interviewer) a short description of the identified problem being assessed on this form and the number of the problem ( 1 to 7 ).

\section{$2 \quad$ Scoring}

The interviewer shows the client the IPPA form with the first problem and asks him/her to answer the first question (How do you rate the importance of this problem?). The interviewer says: "How important is this problem to you," (the interviewer points at the description of the problem at the top of the form) "at this moment (so the last couple of days before this interview). You may answer by ticking one of the five boxes" (the interviewer points at five multiple choice answers below the first question) "to indicate how important this problem is to you. "When the client has answered the first question, he/she is to answer the second question (How do you rate the level of difficulty you have with performing this activity in your everyday life?) in the same way. The interviewer says: "Please indicate how much difficulty you have with performing this activity in your everyday life," (the interviewer points at the description of the problem at the top of the form) "at this moment, by ticking one of the five boxes", (the interviewer points at the five multiple choice answers below the second question).

When the client has answered this second question, he/she is to do the same with the other (up to seven) problems. After this the client is ready. The last part, calculation of the IPPA score, can be done by the interviewer after the interview. 


\section{Calculation of IPPA score}

The IPPA score is calculated by adding up the 'difficulty scores' (second question), using the "importance scores' (first question) as weighting factors. The procedure is as follows:

The answers of the clients are translated into number, using the following codes.

$1=$ Not important at all

2 = Not so important

$3=$ Somewhat important

$4=$ Quite important

$5=$ Most important
$1=$ No difficulty at all

2 = Little difficulty

$3=$ Quite some difficulty

$4=$ A lot of difficulty

$5=$ Too much difficulty to perform the activity at all

For each problem, the 'difficulty score' is multiplied by the "importance score'. The results are added up and divided by the number of problems. This results in a total average problem load, rating between 1 and 25 .

For example, if the client has given the following scores:

Problem 1: importance $=5$ and difficulty $=5$

Problem 2: importance $=3$ and difficulty $=4$

Problem 3: importance $=2$ and difficulty $=1$

Then the IPPA score is: $(5 \times 5)+(3 \times 4)+(2 \times 1)=13$ 


\section{INSTRUCTIONS FOR IPPA FOLLOW-UP INTERVIEW}

\section{Preparation}

For each of the (up to seven) problems identified by the client in the first interview, the interviewer takes a separate IPPA Follow-up Interview Form and writes down (on the top where it says: To be completed by the interviewer) the same descriptions and numbers as used on the IPPA forms in the first interview.

\section{Scoring}

The client is not allowed to see his/her scores from the first interview and the interviewer is not allowed to remind the client of his/her previous scores. The interviewer shows the client the IPPA form with the first problem and asks him/her to answer the first question (How much difficulty do you have with performing this activity in your everyday life?). The interviewer says: "Please indicate how much difficulty you have with performing this activity in your everyday life," "(the interviewer points at the description of the problem at the top of the form) "at this moment, by ticking one of the five boxes", (the interviewer points at the five multiple choice answers below the question).

When the client has answered this question, he/she is to do the same with the other (up to seven most relevant) problems. After this the client is ready. The last part, calculation of the IPPA score, can be done by the interviewer after the interview.

\section{Calculation of IPPA Score}

The IPPA score is calculated by adding up the 'difficulty scores', using the 'importance scores" from the first interview as weighting factors. The procedure is as follows: 
The answers of the clients are translated into number, using the following codes. Note that the 'importance answers' from the baseline interview are used here.

$1=$ Not important at all

$2=$ Not so important

$3=$ Somewhat important

$4=$ Quite important

$5=$ Most important
$1=$ No difficulty at all

$2=$ Little difficulty

$3=$ Quite some difficulty

$4=$ A lot of difficulty

$5=$ Too much difficulty to perform the activity at all

For each problem, the 'difficulty score' is multiplied by the 'importance score'. The results are added up and divided by the number of problems. This results in a total average problem load, rating between 1 and 25 .

For example, if the client has given the following scores:

Problem 1: importance $=5$ and difficulty $=5$

Problem 2: importance $=3$ and difficulty $=4$

Problem 3: importance $=2$ and difficulty $=1$

Then the IPPA score is: $\frac{(5 \times 5)+(3 \times 4)+(2 \times 1)}{3}=13$

The difference between the IPPA score from the baseline interview and the IPPA score from the follow-up interview represents the degree to which the total impact of problems on everyday life has diminished. The bigger this difference is, the bigger the effect of the provision of an assistive device apparently has been. 


\section{IPPA BASELINE INTERVIEW FORM}

\section{Complete a separate form for every identified problem}

What are the most relevant problems that you experience and that you expect or want to see improved by using a new assistive device or service? Please focus on problems that you experienced in performing activities during the last month in your daily routine. The problems may relate to a simple activity (walk up the stairs, read the newspaper, have a conversation, et cetera.) or to a more complex activity (prepare a meal, go shopping, go to work/school, et cetera). You may think of things you are not able to do at all or things that you are not able to do as well or as often or as easily as you would like.

\section{To be completed by the interviewer}

Problem no.

Problem

\section{To be completed by the client}

How important is this problem to you? (Please tick one of the boxes below)

Not important at all

Not so important

Somewhat important

Quite important

Most important

How much difficulty do you have with performing this activity in your everyday life? (Please tick one of the boxes below)

No difficulty at all

Little difficulty

Quite some difficulty

A lot of difficulty

Too much difficulty to perform the activity at all 


\section{IPPA CHECKLIST}

\section{Self-care}

- shower / bathe / wash oneself

- care for one's feet, hair, teeth, skin

- dress / undress

- eat / drink

- use the toilet

- sleep and rest

- wake up at appointed time

- health maintenance like taking medicines

\section{Mobility}

- move around indoor / outdoor (walking, using wheelchair or other device)

- climb a stairs

- get in or out of a chair

- got to bed / get out of bed

- get in or out of a car

\section{Transportation}

- by car

- by bicycle

- by public transport

\section{Housework}

- cook / prepare a meal

- clean / do the dishes

- wash / maintain clothes

- shop

- lift things / pick things up

- stoke / maintain heating

\section{Safety / security}

- be alarmed in case of fire

- lock / unlock / open outer door

- call for help if needed

\section{Leisure activities}

- watch TV

- listen to radio / music

- read newspaper/magazine book

- recreation

- gardening

- playing

- use a computer

- hobby activities

- sports

\section{Communication}

- have a conversation

- use the telephone

- read / write

\section{Role activities}

- work

- learn / study

- political / religious activities

\section{Social interaction}

- visit family / friends

- participate in association / organisation 


\section{IPPA FOLLOW-UP INTERVIEW FORM}

\section{To be completed by the interviewer}

Problem no.

Problem

\section{To be completed by the client}

You have used your new assistive device(s) for a period of time now. This may have affected your ability to perform the activities that you had problems with.

How much difficulty do you have with performing this activity in your everyday life? (Please tick one of the boxes below)

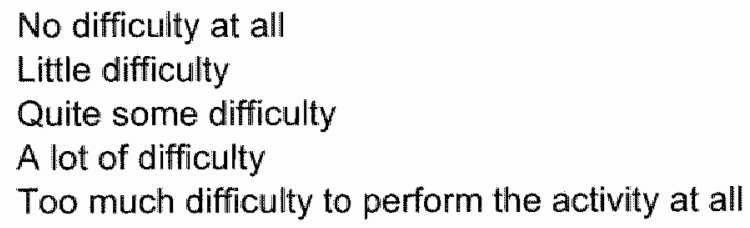





\section{4}

\section{Effectiveness of provision of outdoor mobility service and devices in the Netherlands}

Roelof D. Wessels, Luc P. de Witte, S. Jedeloo, W. P.M. van den Heuvel, Wim J.A. van den Heuvel

Institute for Rehabilitation Research, the Netherlands

Accepted for publication in Clinical Rehabilitation 



\subsection{Introduction}

Despite all the modern communication techniques currently available, mobility is still an important factor in enabling social participation. In the Netherlands, devices and services for people with disabilities in outdoor mobility are provided under a law called the Service for the Disabled Act (SDA) (in Dutch: WVG) (The Dutch Lower House, 1993). This law is based on the principle that people with disabilities and elderly should be able to remain independent and participate in social life for as long as possible. To achieve this, home equipment and transport facilities as well as wheelchairs are supplied. The SDA is administered by the local authorities who are responsible for determining policy.

Because there is a general assumption that mobility is a basic precondition for almost any form of participation in society (if not for the activity itself, then for getting to the place where the activity is to be carried out), the quality of the provision of mobility devices and outdoor mobility services is of crucial importance to people with disabilities. This study will address these issues, by answering the following questions:

1. What problems do people with outdoor mobility disabilities encounter?;

2. What solutions are being offered to them to solve these problems by local authorities in the Netherlands based on the SDA?;

3. How effective are these solutions in the view of users?

4. To further study the responsiveness of IPPA (Individually Prioritised Problem Assessment), the instrument applied to collect data for this study, when used for the specific purpose of outdoor mobility problems.

In order to answer these questions, a presentation is first made of the wide variety of activity limitations and participation restrictions (summarised under the umbrella term 'disabilities in outdoor mobility'). This demonstrates the impact of mobility disabilities and the importance of proper solutions (WHO, 2002). An analysis is then made of the effectiveness of provisions under the SDA in compensating for these disabilities, using the IPPA instrument (Individually Prioritised Problem Assessment) (Wessels, 2000) (Wessels, 2001).

Effectiveness is defined as the degree to which activities have become less difficult to perform. Through analysing IPPA change scores and effect sizes, the responsiveness of the instrument is studied. Although the authors totally agree with and support ICF terminology (International Classification of Functioning, Disability and Health) (WHO, 2002), the terms in the method used in this study are meant to fit in with the respondents' frame of reference. For this reason, more common words like 'problems' and 'solutions' are used. 


\subsection{Methods}

This paper is based on the data collected in two studies, the 'Effectiveness of outdoor mobility devices and services' study (EBV study) (Jedeloo, 2002) and the 'Efficiency of Assistive Technology and Services' study (EATS study) (Wessels, 2000) (Persson, 2000). In the EBV study ( $n=49$ ), clients in several local authorities in the south-west of the Netherlands who applied for an outdoor mobility device or service were subjected to an IPPA interview. The EATS study $(n=10)$ was a project carried out within the framework of the EU TELEMATICS Applications Programme, Sector Disabled and Elderly. It was an international, multi-centre study, in which service delivery clients were subjected to an IPPA interview. This paper only includes data from the EATS study collected in the Netherlands from clients applying for an outdoor mobility device. The populations used in the EATS-study and in the EBV study are similar, as are both study designs (as can be seen in both reports (Wessels, 2000) and (Jedeloo, 2002)). This enables results to be combined, so that the two studies together can be considered as one for the purposes of this paper. The rest of this paper relates to the combined set of data of the two studies together.

The IPPA, the instrument used to collect data in this study, is a generic instrument that assesses the extent to which problems identified by the user of an assistive device in his or her daily activities, have been diminished as a result of its provision (Wessels, 2002). IPPA assesses effectiveness in relation to those activities that the individual respondent considers relevant.

IPPA is based on a client-centred approach (Wessels, 2000) (Wessels, 2001). The underlying principles are the autonomy of the individual client and the necessity of allowing clients to make their own choices in solving problems related to their disabilities. This applies not only to the choice: "how do I solve my problem(s)?" but also to the choice: "which problems do I want solving?" The client identifies the problems that he or she considers relevant and assesses the effectiveness of a provision in relation to these problems. IPPA assesses the effectiveness of an assistive device from the client's perspective. IPPA has been tested in various studies (Wessels, 2000) (Jedeloo, 2002) (Persson, 2000) (de Witte, 2000) (Götherström, 2001) and proven to be a useful instrument with good feasibility and validity.

At the start of the service delivery process, the respondent is asked firstly to identify and then to rate activities that he or she has problems with in everyday life. The respondent is invited to identify up to seven problems and to rate each of these problems on a one-to-seven scale both in relation to the importance of the problem and in relation to the difficulty of performing the related activity. Importance scores and difficulty scores are multiplied, resulting in a baseline score of between 1 and 49 for each problem. These can then be added up and 
divided by the number of problems, ultimately resulting in the total IPPA baseline score. A follow-up assessment, carried out a few months after the respondent has received the new assistive device, asks the individual to repeat this rating in relation to the difficulty of performing the same activities. Follow-up scores for each of the problems are calculated by multiplying this difficulty rating with the baseline importance rating, likewise resulting in a score of between 1 and 49 . Again, these can be added up and divided by the number of problems, resulting in the total IPPA follow-up score. Changes can be calculated by subtracting the follow-up score from the baseline score, either per problem or per total score. IPPA has been used and tested in several studies and has proven to be a useful instrument; feasibility and validity are good (Wessels, 2000) (Wessels, 2001) (Jedeloo, 2002) (Persson, 2000) (Wessels, 2002) (de Witte, 2000) (Götherström, 2001).

A baseline IPPA interview was administered (in both studies) immediately after clients had entered the SDA service delivery process. In the EBV study 128 clients were approached. 69 of them agreed to participate and were interviewed at baseline. 49 were also interviewed at follow-up. The reasons for this dropout are well described in the paper by Jedeloo (2002). In the EATS study a total of about 300 clients were approached. 248 of them participated in the baseline interview, 188 of them also in the follow-up interview (Wessels, 2000). These numbers are for the total EATS study, no statistics are available about the specific group of clients applying for an outdoor mobility device or service in the Netherlands. An IPPA follow-up interview was administered three months after the of had received their provision (but only for those clients who had received a new outdoor mobility provision $(n=49+10=59$ )). All new clients aged 18 years or older, without cognitive problems, who had entered the SDA service delivery system in the set period of time, in the participating local authorities in the provinces Zeeland and Limburg, were asked to participate. They could refuse without any consequences The interviews were performed by an independent occupational therapist (that is, an occupational therapist not involved with the service delivery process). The interviewer received instructions for the interview from one of the authors of IPPA and had some experience applying the instrument. At the time of the second interview, neither the interviewer nor the interviewee had any knowledge of the answers given during the first interview.

An analysis was first made of importance that respondents attached to the problems they had identified. This was done to see whether a differentiation could be identified between problems. If all problems were rated as equally important, it would be possible to group all the problems identified together collectively and treat them as a single collection of equally important problems. This would simplify the rest of the analyses. In IPPA, respondents are provided with the opportunity to identify those activities with which they have problems (disabilities) in their own words. 
These disabilities were classified according to the domains contained within the Activities and Participation component of the ICF (WHO, 2002). This was done by two of the authors and an occupational therapist, all independently from one another. Two of the three had to agree in order to assign a disability to a certain ICF domain. The spread of problems across the various domains were then studied. Next, the effectiveness of the solutions provided in order to solve their problems was analysed, firstly on the basis of the effectiveness per individual problem and then on the basis of the effectiveness per client/solution. To analyse the effectiveness of the provisions per problem, the effect sizes were first calculated per ICF domain. (Effect size equals mean change divided by the standard deviation of the baseline scores.)

To assess the responsiveness of IPPA and the individual problems and the ICF domains, the responsiveness index by Cohen (1997) was applied (as used by Jedeloo (2002) and Middel (2001)). According to Cohen's rule of thumb, an effect size of 0.80 or more can be considered large; an effect size of between 0.50 and 0.80 can be considered moderate; and an effect size of between 0.20 and 0.50 can be considered small.' The distribution of effectiveness was studied. The effectiveness per type of solution was analysed by calculating the effect size for each type of solution.

\subsection{Results}

The study sample includes 59 persons (10 persons from the EATS-study and 49 persons from the EBV-study) who applied for a new assistive device or service related to outdoor mobility. The respondents had a mean age of 73 (Std. Deviation 13.1); 41 were female. The 59 respondents together identified a total of 274 problems, with a mean of 4.6 (Std. Deviation 1.5) problems per respondent. When looking at the importance successively assigned by respondents to the problems they identified (on a scale from 1 (of no importance at all) to 7 (most important)), All the problems identified were considered equally important (table 1).

Table 1: Importance of the problems identified (range 1-7)

\begin{tabular}{|l|ccccccc|}
\hline & $\begin{array}{c}\mathbf{1}^{\text {st }} \\
\text { problem }\end{array}$ & $\begin{array}{c}2^{\text {nd }} \\
\text { problem }\end{array}$ & $\begin{array}{c}3^{\text {rd }} \\
\text { problem }\end{array}$ & $\begin{array}{c}4^{\text {th }} \\
\text { problem }\end{array}$ & $\begin{array}{c}5^{\text {th }} \\
\text { problem }\end{array}$ & $\begin{array}{c}6^{\text {th }} \\
\text { problem }\end{array}$ & $\begin{array}{c}7^{\text {th }} \\
\text { problem }\end{array}$ \\
\hline N & 59 & 58 & 56 & 43 & 31 & 18 & 9 \\
Mean & 6.7 & 6.7 & 6.5 & 6.7 & 6.7 & 6.8 & 6.3 \\
importance & 6.7 & 0.6 & 0.9 & 1.1 & 0.6 & 0.6 & 1.3 \\
\hline Std. Dev. & 0.6 & 0.6 & & & & &
\end{tabular}


The standard deviations are small enough (between 0.5 and 1.3) to conclude that this also applies to individual respondents and that the order in which problems were identified bears no relation to the importance of the problems. Therefore, it was possible to combine all the problems identified and treat them as a single collection of equally important problems.

The problems identified were often very individual and very specific. Examples included, 'visiting my brother in the city of G.'. 'going to the beach with my dog', 'going to the market to buy flowers', 'getting on the bus', 'visiting my children on my own, 'visiting the countryside to take pictures'. The 274 identified problems were classified according to the ICF classification. It was possible to distinguish the following distribution of types of problems (table 2). Most of the identified problems relate to the WHO ICF domains:

- $\quad$ d9 Community, social and civic life (problems associated with going to church, going to a club or society or engaging in outdoor leisure pursuits) (98 problems);

- $\quad$ d7 Interpersonal interactions and relationships (problems associated with visiting family or friends) (78 problems);

- d6 Domestic life (problems associated with shopping) (53 problems); and

d5 Self-care (problems associated with visiting the doctor, visiting the hospital, visiting a therapist or the hairdresser) (27 problems).

Problems in the following domains - $d 6$ Domestic life, $d 7$ Interpersonal interactions and relationships and d9 Community, social and civic life - were mentioned by more than half of the respondents (table 2 ).

In order to solve their problems, the 59 respondents were provided with: a) a mobility device (or a combination of two mobility devices) $(n=20)$; b) the use of a shared taxi service $(n=35)$; or $c)$ a combination of a mobility device and the use of a shared taxi service $(n=4)$. (table 3 ) The most common solution turned out to be either an electric scooter (an electric-motor-driven wheelchair with manual steering) or the use of a shared taxi service. Of the 59 clients, 12 persons (20\%) were provided with only an electric scooter and 35 persons $(59 \%)$ were provided only with the use of shared taxi service. This meant that $79 \%$ of the respondents $(n=47)$ received a single solution to solve all their individual problems. 
Table 2: Types of problems identified

\begin{tabular}{|c|c|c|c|c|c|}
\hline & Type of problem & $\begin{array}{l}\text { Number of } \\
\text { times } \\
\text { identified }\end{array}$ & $\begin{array}{l}\% \text { of total } \\
\text { number of } \\
\text { problems }\end{array}$ & $\begin{array}{l}\text { ldentified } \\
\text { by number } \\
\text { of persons }\end{array}$ & $\begin{array}{l}\text { ldentified } \\
\text { by } \% \text { of } \\
\text { persons }\end{array}$ \\
\hline$d 1$ & $\begin{array}{l}\text { Learning and applying } \\
\text { knowledge }\end{array}$ & 0 & 0 & 0 & 0 \\
\hline$d 2$ & $\begin{array}{l}\text { General tasks and } \\
\text { demands }\end{array}$ & 2 & 0.7 & 2 & 3.4 \\
\hline$d 3$ & Communication & 0 & 0 & 0 & 0 \\
\hline$d 4$ & Mobility & 9 & 3.3 & 9 & 15.3 \\
\hline$d s$ & Self-care & 27 & 9.9 & 28 & 47.5 \\
\hline$d 6$ & Domestic life & 53 & 19.3 & 41 & 69.5 \\
\hline$d 7$ & $\begin{array}{l}\text { Interpersonal } \\
\text { interactions and } \\
\text { relationships }\end{array}$ & 78 & 28.5 & 50 & 84.7 \\
\hline$d 8$ & Major life areas & 7 & 2.6 & 6 & 10.2 \\
\hline$d 9$ & $\begin{array}{l}\text { Community, social and } \\
\text { civic life }\end{array}$ & 98 & 35.8 & 51 & 86.4 \\
\hline & Total & 274 & 100 & - & - \\
\hline
\end{tabular}

Table 3: Types of solution provided and corresponding IPPA effect sizes

\begin{tabular}{|c|c|c|c|c|}
\hline \multirow{2}{*}{ Provision } & \multirow{2}{*}{$\mathbf{N}$} & \multicolumn{2}{|c|}{ Change score } & \multirow{2}{*}{$\begin{array}{l}\text { Effect } \\
\text { silze }\end{array}$} \\
\hline & & Mean & $\mathrm{SD}$ & \\
\hline $\begin{array}{l}\text { Electric scooter (electric-motor-driven } \\
\text { wheelchair with manual steering) }\end{array}$ & 12 & & & \\
\hline $\begin{array}{l}\text { Electric scooter + bimanual rear-wheel- } \\
\text { driven wheelchair }\end{array}$ & 2 & 23.2 & 14.4 & 2.5 \\
\hline Electric scooter + walking frame & 1 & & & \\
\hline Bimanual rear-wheel-driven wheelchair & 1 & & & \\
\hline $\begin{array}{l}\text { Electric-motor-driven wheelchair with } \\
\text { powered steering }\end{array}$ & 1 & & & \\
\hline Bicycle with propulsion unit & 1 & & & \\
\hline Subsidy car costs & 1 & & & \\
\hline Propulsion unit for wheelchair & 1 & & & \\
\hline Shared Taxi Service (STS) & 35 & 18.3 & 12.5 & 1.8 \\
\hline STS + electric scooter & 1 & & & \\
\hline $\begin{array}{l}\text { STS + bimanual rear-wheel-driven } \\
\text { wheelchair }\end{array}$ & 2 & 15.8 & 14.3 & 1.8 \\
\hline $\begin{array}{l}\text { STS * Manual attendant-controlled } \\
\text { wheelchair }\end{array}$ & 1 & & & \\
\hline Total & 59 & 19.8 & 13.3 & 2.0 \\
\hline
\end{tabular}


When looking at the effectiveness of these solutions, the effectiveness per individual problem was first studied and then the effectiveness per client/solution. For 256 problems out of the total collection of 274 , a follow-up score was registered, allowing the calculation of a change score for each of these 256 problems. For 18 problems $(6.6 \%)$, there was no follow-up score. It turned out that - when classified according to the activity and participation domains of the ICF classification - all types of problems had been solved reasonably well (table 4). Domain d8 Major life areas shows a considerably larger effect size than the other domains, but the number of problems within this domain is too small to elicit any conclusions. Problems in this domain relate to doing voluntary work. But all in all, effect sizes of the SDA service delivery system are clearly large.

Table 4: Change score and effect size per type of problem

\begin{tabular}{|c|c|c|c|c|c|}
\hline & \multirow{2}{*}{ Type of probllem } & \multirow{2}{*}{$\begin{array}{l}\text { Numbier of } \\
\text { problems }\end{array}$} & \multicolumn{2}{|c|}{ Change score } & \multirow{2}{*}{$\begin{array}{l}\text { Effect } \\
\text { size }\end{array}$} \\
\hline & & & Mean & SD & \\
\hline d2 & General tasks and demands & 1 & 28.0 & - & - \\
\hline d4 & Mobility & 10 & 13.4 & 12,1 & 1.2 \\
\hline d5 & Self-care & 27 & 18.2 & 13.6 & 1.2 \\
\hline d6 & Domestic life & 47 & 16.0 & 13.5 & 2.4 \\
\hline$d 7$ & $\begin{array}{l}\text { Interpersonal interactions and } \\
\text { relationships }\end{array}$ & 76 & 20.7 & 14.5 & 1.8 \\
\hline$d 8$ & Major life areas & 7 & 19.8 & 11.2 & 7.4 \\
\hline \multirow[t]{2}{*}{ d9 } & Community, social and civic life & 88 & 19.2 & 14.9 & 1.6 \\
\hline & Total & 256 & 19.8 & 13.3 & 1,8 \\
\hline
\end{tabular}

The criterion for responsiveness by Cohen (1997), was applied to the effect of each individual problem. The change scored for each problem was divided by the standard deviation of the baseline scores for all the problems in the ICF domain concerned. It appears that most problems were solved moderately $(7.5 \%, n=19)$ or well $(73.3 \%, n=187)$. Only a very few problems $(1.2 \%)$ show a small effect, but a substantial number of (specifically identified) problems show no effect at all or even a negative effect $(18.1 \%$ ) (table 5). Problems showing a negative effect were mostly in the domains $d 6$ Domestic life (relating to shopping or going out to buy something) and d9 Community, social and civic life (related to leisure activities such as going for a walk, riding a bicycle or going to a social club). 
Table 5: Distribution of the Change score / Std. Dev. per problem

\begin{tabular}{|c|cccccccc|}
\hline & $\begin{array}{c}\text { negative effect } \\
\text { or no effect } \\
(<0.2)\end{array}$ & $\begin{array}{c}\text { small effect } \\
(0.2-0.5)\end{array}$ & $\begin{array}{c}\text { moderate } \\
\text { effect } \\
(0.5-0.8)\end{array}$ & \multicolumn{2}{c|}{ large effect } \\
\hline ICF domains & $N$ & $\%$ & $N$ & $\%$ & $N$ & $\%$ & $N$ & $\%$ \\
\hline D4 & 2 & 20 & 0 & & 1 & 10 & 7 & 70 \\
D5 & 6 & 22.2 & 0 & & 10 & 37.1 & 11 & 40.7 \\
D6 & 7 & 14.9 & 1 & 2.1 & 2 & 4.3 & 37 & 78.7 \\
D7 & 13 & 17.1 & 2 & 2.6 & 2 & 2.6 & 59 & 77.6 \\
D8 & 0 & & 0 & & 0 & & 7 & 100 \\
D9 & 18 & 20.5 & 0 & & 4 & 4.5 & 66 & 75 \\
Total & 46 & 18.1 & 3 & 1.2 & 19 & 7.5 & 187 & 73.3 \\
\hline
\end{tabular}

Table 3 presents the effect sizes of the types of solution provided. Three types of solution are distinguished: an individual provision of one (or two) assistive device(s), the use of a shared taxi service or a combination of both these possibilities. On average the effectiveness of the SDA provision system is very good. An effect size for the total group of 2.0 is notably large (according to Cohen"s rule of thumb (Cohen, 1997), an effect size of 0.8 or more can be considered large).

However, when looking at scores of individual respondents, it appears that some were not being helped particularly well. In fact, three respondents (out of 59) scored negatively with respect to their IPPA total effect; they felt they had more difficulty performing the activities concerned after receiving the provision, than before. Four respondents had a total effect of zero. So 7 clients out of 59 $(12 \%$ ) experienced no (positive) effect at all. Only 10 respondents reported a maximum solution to all their problems, meaning that after provision they reported minimal difficulty in all the activities they had reported to be problematic.

\subsection{Discussion}

Mobility is a precondition for almost every activity in life, if not for the activity itself, then for getting to the place where the activity is to be carried out. People with outdloor mobility disabilities report a large variety of specific, individual problems. Looking at these problems from a more abstract perspective, most mobility problems appear to be related to shopping, social visits and leisure activities. Problems associated with outdoor mobility disabilities can be categorised fairly adequately into just a few of the activity/participation domains of the ICF. The respondents in this study were mostly elderly persons who have relatively similar lifestyles; they no longer have a job or go to school. 
The fact that the problems identified can be categorised into only a few domains "does not mean the problems can be treated similarly when we take into account the solution. The problems are very specific and very individual. In the main, solutions offered for outdoor mobility problems however, can all considered to be generic. For example, an individual will acquire a wheelchair to solve all his or her mobility problems. Most people are provided with a single solution, that is, an electric scooter or a shared taxi service. If the purpose was to solve all problems of one client to an optimal level, one client would have to get provided with a variety of solutions. Since most clients report a variety of problems, they should get provided with a combination of several devices and/or services.

A critique often heard in the Netherlands is that the Dutch SDA system is not demand-oriented but supply-oriented. That it is not centred around helping people or solving problems but around supplying devices. This critique is only supported to a minor extent by the results of this study.

On average, all outdoor mobility problems were solved rather well. However, when looking at individual cases, some problems, which had been expressed explicitly in advance, were not solved at all (or had even been exacerbated). This calls for the service delivery process to adopt a structured, individualoriented approach (similar to the IPPA approach) and, very importantly, for a structured, activity/disability oriented evaluation to be carried out for every individual client afterwards. Of course in general medical practice the success rates accomplished in this study would be extremely high. However, this study is not about a certain agent having a certain effect on the human body, but about professionals doing their work well.

The high responsiveness indices by Cohen suggest sound responsiveness of IPPA when used in relation to outdoor mobility problems. Here, additional research is required to verify the measurement properties of IPPA in other fields.

In the application of IPPA as presented in this paper, the respondents rated all the problems identified as being equally important. When assessing outdoor mobility problems, the omission of the importance-related scores for the various problems identified would simplify the IPPA instrument and the calculation of the scores without really affecting the measurement. This can be considered an improvement of the instrument for future application. Additional research will also be required to find out whether or not this is true with respect to the application of IPPA in other fields. 
IPPA turns out to be a useful instrument for gaining an insight into the effectiveness of assistive devices and service provision. However, when interpreting the results, it is important not only to look at the percentage of successful scores of one group on its own, but also to look at the percentage of unsuccessful scores and to analyse these on an individual level

A limitation of this study is of course that it is performed with only a small sample of assistive device users and therefore that it is based on a limited amount of data. More studies with respondents using different types of assistive devices are required to fully test the instrument $I P P A$. For testing the Dutch SDA system, this small sample already gives some instructive clues. The method used in the SDA system might be improved by using a constructive method like IPPA to record the problems of an individual user and evaluate the solution of each of these problems. This would probably result in a more varied supply of solutions. 


\section{References}

J. Cohen. Statistical power analysis for the behavioural science. New York: Academic Press, 1997.

The Dutch Lower House. Text of the Disability Service Act. Staatsblad, 's Gravenhage: 1993, 545.

U. Götherström, J. Persson. Text telephone relay service and video phone relay service - quantification of benefits for the user, in: Marincek et al. (Eds.)

Assistive Technology - Added Value to the Quality of Life, IOS Press, 2001.

S. Jedeloo, L.P. de Witte, A.J.P. Schrijvers. A user-centred approach to assess the effectiveness of outdoor mobility devices and services. International Journal for Rehabilitation Research 2002: 25 (2), 137-141.

B. Middel, R. Stewart, J. Bouma, E. van Sonderen, W.J.A. van den Heuvel. How to validate clinically important change in health-related functional status. is the magnitude of the effect size consistently related to magnitude of change as indicated by a global question rating? Journal of Evaluation in Clinical Practice: 2001,7 (4) $399-410$.

J. Persson, G. Hellbom, B. Oberg, et al. Efficiency of Assistive Technology and Services, Final Report. DE3101 EATS, Telematics Application Programme, Sector Disabled and Elderly. CMT, Linkoping, Sweden, 2000.

R. Wessels, L. de Witte, R. Andrich, et al.. A user-centred approach to assess effectiveness of assistive technology provision. Technology and Disability: 2000, 13: 105-15.

R. Wessels. IPPA: Individually Prioritised Problem Assessment. In: Marincek, C. et al. (Eds.) Assistive Technology - Added value to the quality of life, IOS Press: 2001, 598-599.

R. Wessels, J. Persson, O. Lorentsen, R. Andrich, M. Ferrario, W. Oortwijn, T. Van Beekum, H. Brodin, L. de Witte. IPPA: Individually Prioritised Problem Assessment. Technology and Disability: 2002, 14: 141-145.

WHO, ICF International Classification of Functioning Disability and Health. 2002 http://www. who.int/icidh/ 
L. de Witte, G. Gelderblom, K. van Soest, et al. MANUS: een helpende hand; Een verkennende studie naar doelgroepen, indicatiecriteria, gebruik en aspecten van kosten-effectiviteit van de MANUS robotarm. IRV , Hoensbroek, the Netherlands, 2000. 


\section{Key dimensions of client satisfaction with assistive technology: A cross-validation of a Canadian measure in the Netherlands}

Ph. D. Louise Demers ${ }^{1}$ Ir. Roelof Wessels ${ }^{2}$, M.Sc. Rhoda Weiss-Lambrou ${ }^{3}$.

Ph.D. Bernadette Ska and Ph.D. Luc P. De Witte ${ }^{2}$

${ }^{1}$ Centre for Clinical Epidemiology and Community Studies, Sir Mortimer B.I

Davis Jewish General Hospital, Montreal, Canada

${ }^{2}$ Institute for Rehabilitation Research, The Netherlands

${ }^{3}$ École de réadaptation, Université de Montréal

${ }^{4}$ Centre de recherche de l'Institut universitaire de gériatrie de Montréal, Canada

Published in: the Journal of Rehabilitation Medicine: 2001, 33: 187-191. 



\subsection{Introduction}

In this new era of evidence-based practice, satisfaction information is conferred considerable importance as a patient outcome and, as a result, measurement of the concept is gaining status (Keith, 1998)(Osborn, 1998) (Robertson, 1997). It is common belief that satisfaction data can help clinicians, researchers, managers, and payers improve what they do, for example, by enabling services monitoring and creating positive attitudes among patients or clients (Scherer, 1997). According to Keith (Keith, 1998), satisfaction can be defined as an attitude about a service, a product, a service provider or a person's health status. This definition emphasises the diversity of purposes satisfaction outcomes may address.

In the field of assistive technology, user satisfaction is identified as one of five main outcomes categories, together with clinical results, functional status, quality of life, and costs (DeRuyter, 1995). Although the use of these outcomes is strongly advocated, satisfaction assessment tools are scarce, due in part, to a vacuum in the theoretical knowledge concerning the phenomenon under study. Indeed, satisfaction determinants are vague and indefinite and this situation is prejudicial for the measurement of the concept, frequently making it totally arbitrary.

Figure 1: Satisfaction with assistive technology model

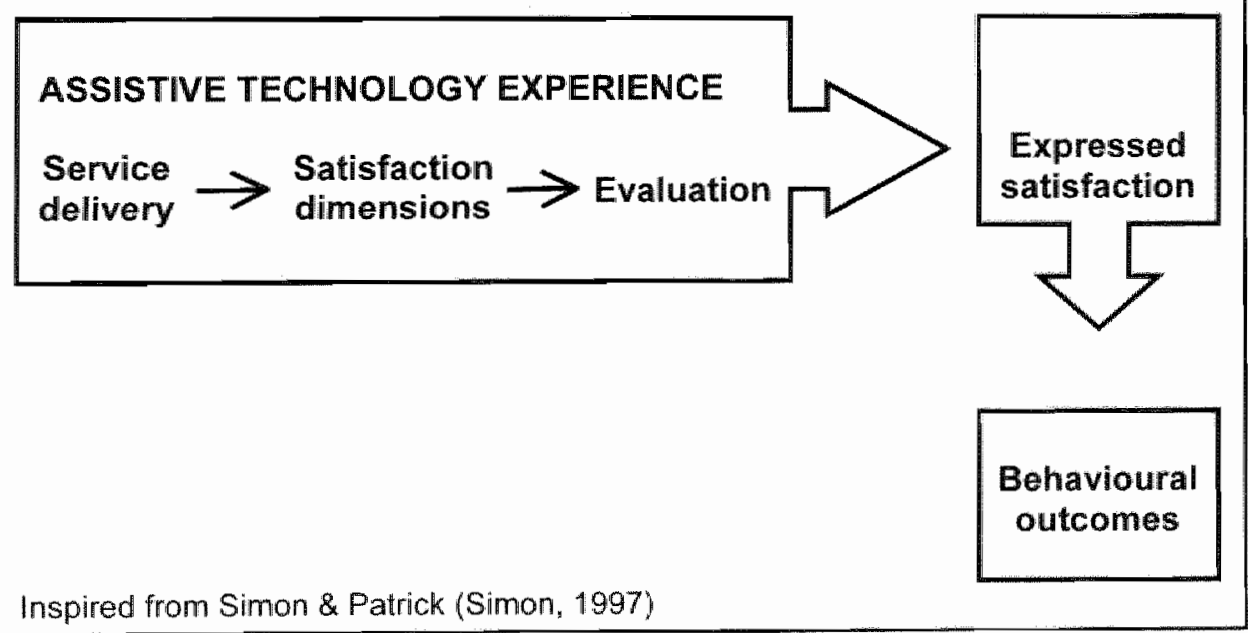

Despite important conceptual limitations, it is useful in the context of this study to represent the relations between the variables involved in the experience of assistive technology within a general frame of reference. The linear satisfaction theoretical model depicted in Fig. 1 was inspired by Simon \& Patrick's work (Simon, 1997) in rehabilitation. Expressed satisfaction, which appears in the 
comer box, may be conceived as a reaction to assistive technology provision and, therefore, as a dependent variable. Satisfaction can also trigger a subsequent action or behaviour, whereby it is approached as an independent variable. According to this model, the core concept under study can be broken down into several dimensions, all of which contribute to the user perception. This multidimensional approach is strongly supported by empirical work in the field of rehabilitation (McComas, 1995) (Wilson, 1995) as well as in other health domains (Fitzpatrick, 1991) (Steiber, 1990). To date however, there is little agreement about the conceptual structure of satisfaction measures with assistive technology.

A first step in the definition of key satisfaction dimensions with assistive technology was recently taken in the context of the development of the Quebec User Evaluation of Satisfaction with assistive Technology (QUEST) tool (Demers, 1996). This outcome measurement instrument was designed to measure satisfaction with assistive technology devices in a structured and standardised way. Although its experimental version consisted of 24 variables, an item analysis subsequently reduced this number by half (Demers, 2001). As part of the same methodological study, the 12 selected items were submitted to factor analysis. Results suggested that the underlying structure of satisfaction consists of two key dimensions respectively related to assistive technology: Device and Services.

Figure 2: Key dimensions of satisfaction with assistive technology

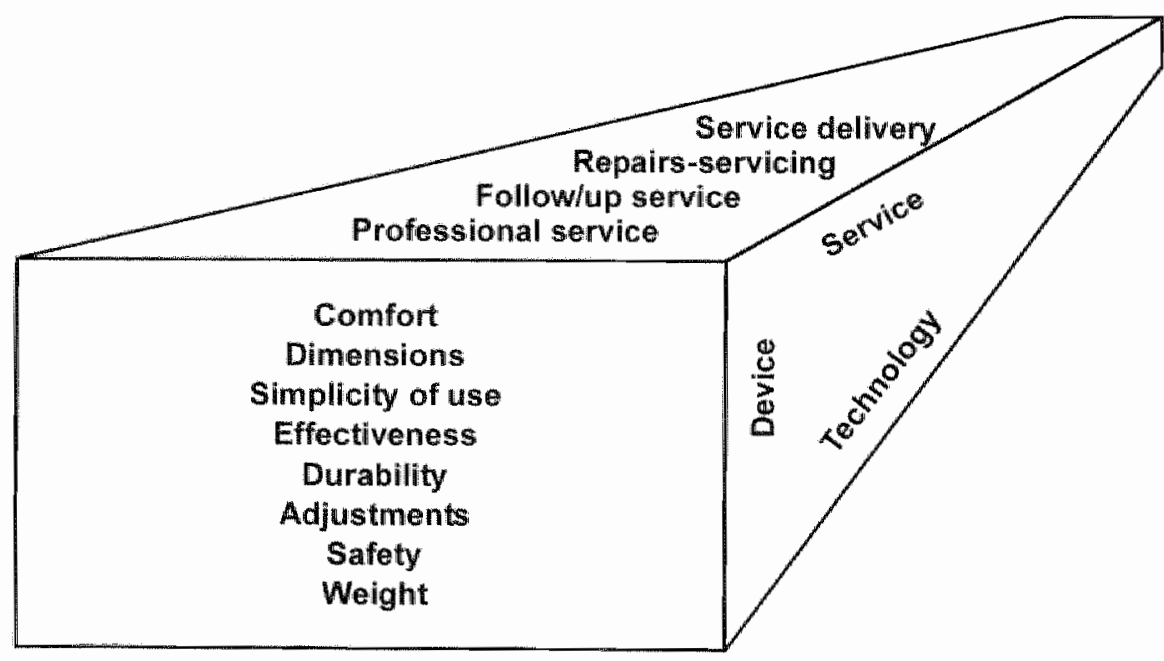


As shown in Fig. 2, the Device dimension embraced eight items related to salient characteristics of the assistive technology whereas the Services dimension encompassed four intercorrelated items. The fit of the proposed measurement model was judged as reasonably good, with an acceptable amount of explained total item variance totalling $48.4 \%$ (Demers, 2001). Several studies (Bain, 1997) (Kohn, 1991) (Vanderheiden, 1987) have been published which support the bidimensional approach of assistive technology, thus strengthening its validity.

From a methodological perspective however, there are two issues that challenge the stability of this conceptual structure. Both stem from the fact that the data used were obtained from a single sample of subjects. The first criticism is that all satisfaction ratings were drawn from seating and mobility aids as well as lower limb prostheses (Demers, 2001). Logically, it can be argued that different patterns of inter-correlated items might have emerged with other types of devices. The second criticism concerns the cross-cultural application of the satisfaction structure proposed, since it was based on a single North American setting, that of Montreal. Provision of assistive technology is likely to vary substantially across countries, not to mention continents.

Both limitations need to be addressed in order to give credibility to the proposed structure and support its adequacy. The goal of the present study was to conduct a cross-validation of the bidimensional structure of satisfaction with assistive technology, using a sample of subjects that differed from the original research with respect to cultural setting and types of devices.

\subsection{Methods}

\section{Subjects}

Data were obtained from a previous Dutch follow-up study involving 375 subjects (Wessels, 1998). The devices used by these people included toilet adaptations, shower seats and chairs, wheelchairs, adapted beds, stairlifts, home adaptations and adapted beds. A large proportion of this sample (82\%) was recruited from the TNO-PG, a Dutch organisation for applied scientific research located in Leiden. These subjects had been provided with an assistive technology device in the past and were taking part in a larger questionnaire survey. The remaining $18 \%$ of the sample were selected from the Institute for Rehabilitation Research (iRv) in Hoensbroek, which houses an assistive technology service delivery centre. A follow-up evaluation was implemented three months after the clients had received a new device. In both of these regions, subjects were visited in their home. No formal training of the evaluators was provided and a large number of them (total of $n=31$ ) were involved in the data collection. Prior to conducting the analysis, the dataset was inspected to ensure it was suitable for the intended purpose. Data were screened with 
regards to age of subjects (children were excluded from sample), aberrant data (zero variability), missing data and non-applicable responses (individuals who responded to less than $50 \%$ of the questions were excluded).

\section{Items}

All subjects were administered the Dutch version of the experimental QUEST, the D-QUEST (Wessels, 2000). The translation was based on a set of standardised procedures as discussed in two articles (Wessels, 1998) (Demers, 1999a). The consistency of viewpoints between the authors of the tool, the researchers from the iRv and several Dutch occupational therapists was a strong contributing factor for obtaining conceptual equivalence between the English and Dutch versions. It also permitted the adaptation of the instrument to the specific context of assistive technology provision and use in the Netherlands.

The D-QUEST was administered in full. However in this study, satisfaction ratings with 12 items selected from the previous item analysis of the QUEST (Demers, 2001) were included in the analysis. These target items are listed in table I, together with their definition. Each item was scored with a 5-point satisfaction scale, with a score of 1 denoting "not satisfied at all", 2 "not very satisfied", 3 "more or less satisfied", 4 "quite satisfied", and 5 indicating "very satisfied". In terms of psychometric properties, they were found to be reliable with respect to test retest stability and interrater reproducibility, with weighted kappa values respectively ranging from 0.51 to 0.74 , and from 0.35 to 0.72 (Demers, 1999b). With respect to content validity, all 12 items were considered of primary importance for assessing satisfaction according to $50 \%$ and more assistive technology experts $(n=12)$ recruited in the United States, the Netherlands and Canada (Demers, 1999a). Moreover, these items were rated as highly important (mean scores of 4.00 to 4.85 on a 5 -point importance scale) by 158 Canadian users of assistive technology (Demers, 2001).

\section{Procedures}

Factor analysis is an analytical technique that permits the reduction of a certain number of interrelated variables to a smaller number of latent hidden dimensions (Pedhazur, 1991). In test development and cross-validation, it reveals the pattern of shared variation within a set of items. Principal Axis Factoring (PAF) is the most widely used method of factor extraction for explaining common variance (Pedhazur, 1991) and it was used in this study. Principal Components Analysis (PCA) which is designed to extract total (not common) variance, is automatically produced as a preliminary step to PAF. The statistic pertaining to total variance was examined. 
Because the QUEST provided subjects with the option of scoring items as nonapplicable, there was a large proportion of missing data (24\%). The percentage of missing responses per item is given in table 1 .

Table I: QUEST items, definitions and percentage of missing data

\begin{tabular}{|c|c|c|}
\hline Item & Definition & $\begin{array}{l}\% \text { of missing } \\
\text { data }\end{array}$ \\
\hline 1. Comfort & $\begin{array}{l}\text { Physical and psychological well-being } \\
\text { associated with use of ATD. }\end{array}$ & 5.8 \\
\hline 2. Dimensions & $\begin{array}{l}\text { Convenience of the device's size (height, } \\
\text { width, length) }\end{array}$ & 6.2 \\
\hline $\begin{array}{l}\text { 3. Professional } \\
\text { services }\end{array}$ & $\begin{array}{l}\text { Quality of information on ATD provided, } \\
\text { accessibility and competence of } \\
\text { professionals. }\end{array}$ & 18.1 \\
\hline $\begin{array}{l}\text { 4. Follow-up } \\
\text { services }\end{array}$ & Ongoing support services for ATD. & 42.0 \\
\hline 5. Simplicity of use & Ease in using the ATD. & 2.5 \\
\hline 6. Effectiveness & Goal achievement with the ATD & 7.4 \\
\hline $\begin{array}{l}\text { 7. Repairs and } \\
\text { servicing }\end{array}$ & $\begin{array}{l}\text { Ease in having the ATD repaired and } \\
\text { serviced. }\end{array}$ & 48.6 \\
\hline 8. Durability & Robustness and sturdiness of the ATD. & 9.9 \\
\hline 9. Adjustments & $\begin{array}{l}\text { Simplicity in setting/fixing the components of } \\
\text { ATD. }\end{array}$ & 42.4 \\
\hline 10. Safety & $\begin{array}{l}\text { Degree to which the ATD is safe, secure and } \\
\text { harmless. }\end{array}$ & 6.6 \\
\hline 11. Service delivery & $\begin{array}{l}\text { Ease in acquiring the ATD including length of } \\
\text { time. }\end{array}$ & 14.8 \\
\hline 12. Weight & Ease in lifting and/or moving the ATD. & 62.1 \\
\hline \multicolumn{3}{|c|}{ Legend: ATD Assistive Technology Device } \\
\hline
\end{tabular}

Therefore, in order to avoid a significant reduction of the sample size, a pairwise strategy was used to compute the matrix of inter-item correlation coefficients. Accordingly, all valid responses were analysed. To obtain a simple structure. items loading (correlating) high on one factor and low on the remaining factors were needed. Loading values may vary from 0.000 to 1.000 . Meaningful item loadings for each factor were examined after both orthogonal (varimax) and oblique (oblimin) rotations. In ane case, the factors are independent, whereas in the second case, they are allowed to correlate. The results were similar, but orthogonal rotation was retained because it was easier to interpret.

\subsection{Results}

Factor analysis was performed on a matrix of correlations between item scores obtained from 243 subjects ( $67.5 \%$ of the original sample). This sample size 
exceeded the recommendation of having at least 10 times as many subjects as variables (Nunally, 1978). Both the Bartlett Test of Sphericity $(p<0.000)$ and the Kaiser-Meyer-Olkin Measure of Sampling Adequacy (KMO) (0.76) demonstrated that the data were appropriate for the planned analysis. The results yielded two factors accounting for $40 \%$ of the total common variance among the 12 items. Based on $\mathrm{PCA}_{0}$ the total item variance explained by this solution attained $49 \%$. Consistent with common practice, each factor was interpreted according to the variables (QUEST items) that 'loaded' or were mostly highly correlated.

Table II: Dutch and Canadian results of factor analysis (after orthogonal rotation) of 12 QUEST satisfaction items

\begin{tabular}{|c|c|c|c|}
\hline Item & $\begin{array}{l}\text { Factor } 1 \\
\text { Device }\end{array}$ & $\begin{array}{l}\text { Factor } 2 \\
\text { Services }\end{array}$ & Communalities \\
\hline \multicolumn{4}{|l|}{ Dutch $(n=253)$} \\
\hline \multirow{2}{*}{$\begin{array}{l}\text { 1. Comfort } \\
\text { 2. Dimensions }\end{array}$} & 0.764 & & 0.611 \\
\hline & 0.611 & & 0.399 \\
\hline 5. Simplicity of use & 0.766 & & 0.609 \\
\hline \multirow{3}{*}{$\begin{array}{l}\text { 6. Effectiveness } \\
\text { 8. Durability } \\
\text { 9. Adjustments }\end{array}$} & 0.585 & 0.377 & 0.484 \\
\hline & 0.339 & 0.395 & $0.27 \pi$ \\
\hline & 0.629 & & 0.402 \\
\hline 10. Safety & 0.467 & & 0.305 \\
\hline 12. Weight & 0.474 & 0.316 & 0.325 \\
\hline \multirow{4}{*}{$\begin{array}{l}\text { 3. Professional service } \\
\text { 4. Follow-up services } \\
\text { 7. Repairs/servicing } \\
\text { 11. Service delivery }\end{array}$} & & 0.503 & 0.333 \\
\hline & & 0.651 & 0.434 \\
\hline & & 0.685 & 0.475 \\
\hline & & 0.312 & 0.108 \\
\hline \multicolumn{4}{|l|}{ Canadian $(n=150)$} \\
\hline \multirow{2}{*}{$\begin{array}{l}\text { 1. Comfort } \\
\text { 2. Dimensions }\end{array}$} & 0.420 & & 0.193 \\
\hline & 0.608 & & 0.381 \\
\hline 5. Simplicity of use & 0.661 & & 0.485 \\
\hline 6. Effectiveness & 0.589 & 0.346 & 0.466 \\
\hline 8. Durability & 0.361 & 0.419 & 0.306 \\
\hline 9. Adjustments & 0.658 & & $\overline{0.449}$ \\
\hline \multirow{2}{*}{$\begin{array}{l}\text { 10. Safety } \\
\text { 12. Weight }\end{array}$} & 0.396 & & 0.224 \\
\hline & 0.577 & & 0.338 \\
\hline \multirow{2}{*}{$\begin{array}{l}\text { 3. Professional service } \\
\text { 4. Follow-up services }\end{array}$} & & 0.689 & 0.509 \\
\hline & & 0.823 & 0.696 \\
\hline \multirow{2}{*}{$\begin{array}{l}\text { 7. Repairs/servicing } \\
\text { 11. Service delivery }\end{array}$} & & 0.689 & $0 . \overline{487}$ \\
\hline & & 0.394 & 0.180 \\
\hline
\end{tabular}

The factor structure matrix shown in table II represents the loadings of the 12 items with the factors. The communalities, or the proportion of variance that is accounted for by this solution, are reported in the right-hand column. Small 
portions of durability (\#8), and service delivery (\#11) variances were explained $(0.271$ and 0.108 respectively). For this analysis, a conservative threshold for meaningful loadings at 0.30 was employed (Pedhazur, 1991). Results revealed that most items are high on one factor and low on the other, thus contributing positively to a simple resulting structure. Three items, however, performed slightly differently. Items effectiveness (\#6) and weight (\#12) loaded on both factors but more substantially with Factor 1 . Item durability (\#8) loaded moderately on the two factors, however, somewhat more with Factor 2.

The largest factor was consistent with a Device dimension and accounted for $24.6 \%$ of the explained common item variance. It was characterised by high loadings of all technical and 'user-interface' features of the assistive technology. Indeed, comfort (\#1), dimensions (\#2), simplicity of use (\#5), effectiveness (\#6), adjustments (\#9), safety (\#10), and weight (\#12) all loaded high on this factor. Despite its dual allegiance, it was reasonable to also assign durability (\#8) to Factor 1 because it is usually considered as a technical characteristic of a device.

The second factor, Services, accounted for $15.1 \%$ of the explained common variance. It was defined by high loadings of consumer service aspects of assistive technology. The items involved included professional services (\#3), follow-up services (\#4), repairs/servicing (\#7) and service delivery (\#11). As noted previously, items effectiveness ( $\# 6$ ), durabillity (\#8), and weight (\#12) also moderately correlated with Factor 2, despite their stronger affiliation with Factor 1. Table II also reproduces the Canadian factor analysis in order to make comparison of results.

\subsection{Discussion}

To gain confidence in outcome assessments and increase knowledge of user perception and satisfaction, it is essential to build theoretical backgrounds that support the proposed approaches. Based on a previous study of the QUEST tool, it was hypothesised that satisfaction with assistive technology shouid be considered as a bidimensional construct, encompassing satisfaction with the Device and Services. To test the validity of this proposition, a different sample of subjects from that on which the items were originally selected. By conducting the same analyses as in the original study, we are quite confident that the results of this replication study were not due to some methodological scheme. The existence of the Device and Services components for the assessment of satisfaction with assistive technology was confirmed by the fact that the same factorial structure emerged from this study data. Indeed, the first factor embraced 8 items: comfort, dimensions, simplicity of use, effectiveness, durability, adjustments, safety, and weight. On the basis of content validity, 
it is reasonable to include durability in the device dimension. However, because of its allegiance to both factors, the position of this item is rather weak and should be considered in future studies. It is important to note that, despite some minor differences in loadings and communalities values, the same pooling of items had been obtained in the previous study from Demers et al. (Demers, 2001). From a theoretical perspective, this finding is consistent with those who view technology quality as a top priority in device selection (Vanderheiden, 1987), use (Galvin, 1996), and evaluation (Bain, 1997) (Kohn, 1991) (Elben, 1992). Similarly, the second factor regrouped the four items most closely associated with Services aspects of assistive technology provision:

professional services, follow-up services, repairs/servicing, and service delivery, with loadings and communality values very close to those published originally (Demers, 2001).

Based on the literature reviewed, defining these two key dimensions of satisfaction with assistive technology appears sound. Although it is the first time that such a conceptual structure is empirically supported for satisfaction, theoretical reflections of authors concerned with use, delivery and evaluation of assistive technology distinguish the same dimensions and view the concept in a similar way. This has been highlighted by Bain (Bain, 1997) who, in her systematic evaluative approach, suggested that assistive technology is comprised of devices and service delivery. Similarly, Kohn et al. (Kohn, 1991) explicitly referred to two areas of practice: the provision of services, and the devices themselves. Vanderheiden (Vanderheiden, 1987) also emphasized that the proper choice of advanced technology and effective delivery were the essential conditions for successful assistive technology provision.

The data set used for this study was diametrically different from the original study. Indeed, subjects were assessed in the context of a clinical follow-up, with few standardised procedures. Compared with the strict management of a research protocol, it is not surprising to see more interviewers involved, varying degrees of training and a variety in the types of devices. In addition, although Canada and the Netherlands' health and social services systems may, due to common western values, resemble each other in some ways, delivery of assistive technology in the two countries is clearly distinct. Examples of differences include private/public funding, training, follow-up, and availability of devices, all of which may influence the users' perception. By revealing an identical factorial solution, this study provides a strong support for the adequacy and stability of the measure of satisfaction.

One benefit of this study is to confirm that measurement of satisfaction with assistive technology should be divided in two components, related to the device and the services characteristics of assistive technology. In conclusion, future studies will need to be conducted to support the applicability of the QUEST tool in the European countries. 
J.C. Nunally. Psychometric theory, 2 ed. NewYork: McGraw-Hill, 1978.

C.E. Osborn. Developing instruments for assessment of patient outcomes. J Rehabil Outcomes Measurement: 1998, 2: 18-25.

E.J. Pedhazur, L.P. Schmelkin. Measurement, design, and analysis: An integrated approach. Hillsdale: Lawrence Erlbaum Associates, 1991.

S.C. Robertson, A.P. Colborn. Outcomes research for rehabilitation issues and solutions. J Rehabil Outcomes Measurement: 1997, 1: 15-23.

M.J. Scherer, L.T. Vitaliti. A functional approach to technological factors and their assessment in rehabilitation. In: Dittmar SS, Gresham GE, eds. Functional assessment and outcome measures for the rehabilitation health professional. Gaithersburg: Aspen, 1997: 69-88.

S.E. Simon, A. Patrick. Understanding and assessing consumer satisfaction in rehabilitation. J Rehabil Outcomes Measurement: 1997, 1 (5) 1-14.

S.R. Steiber, W.J. Krowinski. Measuring and managing patient satisfaction. Chigago: American Hospital Publications, 1990.

G.C. Vanderheiden. Service delivery mechanisms in rehabilitation technology. Am J Occup Ther 1987: 41:703-710.

R.D. Wessels, L. de Witte, H.Th.P. Knops. D-QUEST. Hoensbroek: Institute for Rehabilitation Research (iRv), PO 192, 6430 AD Hoensbroek, the Netherlands, 2000 .

R.D. Wessels, L.P. de Witte, R. Weiis-Lambrou, L. Demers, G. Wijthuizen. A Dutch version of QUEST (D-QUEST) applied as a routine follow-up within the service delivery process. In: Placiencia Porrero I, Ballabio E, eds. Improving the quality of life for the European Citizen. Amsterdam: IOS Press: 1998, 420-424.

K.G. Wilson, C.D. Crupi, G. Greene, E. Dehoux, K.T. Korol. Consumer satisfaction with a rehabilitation mobile outreach program. Arch Phys Med Rehabil 1995: 76: 899-904. 


\section{Acknowledgements}

This paper is based on the doctoral thesis of Louise Demers. The authors gratefully acknowledge the financial support provided by the Foundation of Quality and Usability Research of Technical Aids in the Netherlands and the Fonds pour la recherche en santé du Québec in Canada. Special thanks are extended to the assistive technology users and to the personnel of TNO-PG for sharing with us their data. 



\section{6}

\section{Reliability and Validity of the Dutch version of QUEST 2.0 with users of various types of assistive devices}

Roelof D. Wessels, Luc P. de Witte

Institute for Rehabilitation Research, the Netherlands

Published in Disability and Rehabilitation: 2003, 25 (6) 267-272 



\subsection{Introduction}

An important aspect in assessing the quality of provision for assistive devices is the evaluation of client satisfaction (Scherer, 2002) (Shone Stickel, 2002). In 1996 Demers et al. first published the instrument QUEST (Quebec User Evaluation of Satisfaction with assistive Technology) (Demers 1996). Since then, QUEST has been tested and optimised, resulting in the current shortened, self-administered version of the instrument: QUEST 2.0 (Demers, 2002). Like the previous versions (Demers, 1999) (Wessels, 1998), this version was translated into Dutch. This Dutch version (D-QUEST) was used on a large scale for the purposes of the study, which is presented in this paper.

D-QUEST (like QUEST 2.0) consists of a written questionnaire. The respondent is asked to rate his or her satisfaction with respect to twelve different aspects using a five-point scale. The scale ranges from 1 (Not satisfied at all) to 5 (Very satisfied). Theses twelve aspects consist of eight aspects relating to the assistive device (Dimensions, Weight, Adjustments, Safety, Durability, Simplicity of use, Comfort and Effectiveness) and four aspects relating to the process of providing the assistive device (Service delivery, Repairs and servicing, Professional services and Follow-up services) (Demers, 2001). The respondent is asked to rate all twelve aspects. The twelve aspects are derived through data analysis from a much llonger list and are supposed to be generically applicable to all kinds of assistive devices. The two sub-scales are based on a factor analysis developed by Demers (Demers, 2002) (Demers, 2001).

The main purpose of this study was to test the measurement properties of DQUEST when applied to users of various types of assistive devices. Until now, the development and testing of QUEST (and D QUEST) have primarily been based on data relating to mobility aids and seating. Demers studied the measurement properties of QUEST 2.0 for MS patients (Demers, 2002), but that study also related exclusively to mobility aids. And although assistive technology for mobility is the largest single group of AT products, many others exist (Scherer, 2002). In this paper, the reliability and validity of D-QUEST will be analysed when the instrument is used for users of aids for personal care, orthoses and shoe adaptations, hearing aids, optical aids, aids for diabetics, adapted furnishing for homes, elastic compression stockings, prostheses, aids for communication and information and aids for personal mobility.

In this paper the feasibility, relliability and validity of D-QUEST will be tested for each type of assistive device. The additional value of including a nonapplicability option to answers in the instrument will also be studied. 


\subsection{Methods}

In this study, D-QUEST was applied to a population ( $n=2002)$ of users of all kinds of assistive devices provided by medical insurers in the Netherlands. In a study commissioned by the Dutch Ministry of Health. Welfare and Sport (WWS), people who had received an assistive device provided by their medical insurers (i.e. the National Health Service, private insurers or statutory insurers) in the past two years, were asked to complete a questionnaire containing (among other questions) the D-QUEST.

Two modifications were made to the version of D-QUEST used in this study. The first modification involved the addition of two questions: What is your overall level of satisfaction with your assistive device? and What is your overall level of satisfaction with the process of service delivery as a whole? These general questions were included for validation purposes. The other modification consisted of adding a non-applicability option for some answers (i.e. "not applicable'). The latter was done for all aspects except Effectiveness, Service delivery and Professional services as these last three aspects are supposed to be applicable with respect to all kinds of assistive devices; for the other aspects this is not necessarily the case, since the variety of devices in our population is likely to be large. For example, the Adjustments aspect might be considered of no relevance for non-adjustable devices, such as elastic compression stockings. And the Repairs and servicing aspect might be irrelevant for nondurable goods, such as most aids for personal care. The additional value of adding this answering option was studied by comparing results to results of a previous study without the additional answering option.

Samples were taken from a sample of insurers with predetermined numbers of clients who had received an assistive device provision in the past two years. Samples were also taken from the membership records of a number of patients' associations (that is, only those patients' associations whose membership can be expected to use a certain type of assistive device). All of these groups (a total of 13,000 individuals) were approached to participate in the study. A total of 5,112 people (consisting of 3,184 "insured" clients and a further 1,928 members from patients' associations) indicated that they had recently received a new assistive device provision and that they were willing to participate. These respondents were sent a questionnaire. People who were partially sighted received an enlarged version of the questionnaire.

The questionnaire contained questions about the type of assistive device received by a user via his/her insurer, how long ago provision took place and the type of medical insurance cover. The questionnaire also contained questions relating to the following: the use or abandonment of the device provided; the extent to which the provision had redressed the problems it was 


\section{References}

Bain BK. Assistive technology in occupational therapy. In: Neistadt ME, Crepeau EB, eds. Williard and Spackman's occupational therapy. Philadelphia: Lippincott, 1997: 498-513.

L. Demers, B. Ska, F. Giroux, R. Weiss-Lambrou. Stability and reproducibility of the Quebec User Evaluation of Satisfaction with assistive Technology (QUEST). J Rehabil Outcomes Measurement: 1999, 3 (4) 42-52. b

L. Demers, R. Weiss-Lambrou, B. Ska. Development of the Quebec User Evaluation of Satisfaction with assistive Technology (QUEST). Assistive Technology: 1996, 8: 3-13.

L. Demers, R. Weiss-Lambrou, B. Ska. Item analysis of the Quebec User Evaluation of Satisfaction with assistive Technology (QUEST). Assistive Technology: 2001, $12(2)$.

L. Demers, R. Wessels, R. Weiss-Lambrou, R. Ska, L. de Witte. An international content validation of the Quebec User Evaluation of Satisfaction with assistive Technology. Occup Ther I: 1999, 6:159-175. a

F. DeRuyter. Evaluating outcomes in assistive technology: Do we understand the commitment? Assistive Technology: 1995, 7: 3-16.

C. Eblen. Issues involved in the evaluation of assistive devices. Topics Ger Rehabil: 1992, 8 (2) 6-11.

R. Fitzpatrick. Surveys of patient satisfaction: I - Important general considerations. BMJ 1991, 302: 887-889.

J.C. Galvin, M.J. Scherer. Evaluating, selecting, and using appropriate assistive technology. Gaitherburg: Aspen 1996.

Keith RA. Patient satisfaction and rehabilitation services. Arch Phys Med Rehabil: 1998, 79: 1122-1128.

J. Kohn, P. Mortola, M. LeBlanc. Clinical trials and quality control: Checkpoints in the provision of assistive technology. Assist Technol: 1991, 3:67-74.

J. McComas, M. Kosseim, D. Macintosh. Client-centred approach to develop a seating clinic satisfaction questionnaire: a qualitative study. Am J Occup Ther 1995, 49: 980-985. 
intended to solve; the respondents" knowledge of relevant regulations and legislation; satisfaction with respect to the performance of the people and organisations involved in the provision; and the quality of the service delivery. As previously stated, the D-QUEST was also part of the questionnaire.

In the current study, all analyses were performed for the two sub-scales (or "dimensions') separately. Reliability of the two sub-scales was tested by calculating the reliability coefficient (Cronbach's Alpha) for the two scales for each type of assistive device. In this analysis only those respondents who considered all (eight or four) aspects applicable within one scale were included. To test the content validity, the percentage of respondents that considered questions 'not applicable' was analysed for each type of assistive device. The results were compared to rates of missing data in a previous study (Demers, 2001). To test construct validity, the relationship was analysed between satisfaction (D-QUEST scores) and the problem-solving abilities of the provided device, as measured by the question about the extent to which the provision had redressed the problems it was intended to solve. The expectation is that someone whose problem has been solved more satisfactorily will be more satisfied about the solution. The relationship between the mean scores on the two sub-scales and the scores on the added general satisfaction questions was analysed. A positive correlation was expected. Finally, the mean satisfaction of users of each type of assistive device was analysed. This was done by calculating the mean of all scores considered 'applicable' by a respondent.

\subsection{Results}

\section{Subjects}

A total of 3,148 persons returned the questionnaire. Respondents younger than 18 years of age were excluded (as they should not have been included in the first place) and likewise, respondents who had received the assistive device more than 24 months ago and respondents who had received a device other than ones provided by insurers. Questionnaires in which there were more than 4 missing answers to the 22 questions (relating to general characteristics of the respondent, the type of device, satisfaction and degree of problem solving) were also excluded. Because the purpose of this study was to examine the performance of D-QUEST for various types of assistive devices, substantial numbers for each type of assistive device were required. Types of assistive devices that were represented by less than 60 respondents (dentures, aids for respiratory therapy, aids for administering food and aids for therapy) were therefore excluded. Questionnaires that were included in the study were those that were received from users of aids for personal care, orthoses and shoe adaptations, hearing aids, optical aids, aids for diabetics, adlapted furnishing for homes, elastic compression stockings, prostheses, aids for communication and 
information and aids for personal mobility. Additionally, respondents who failed to indicate the most recently received assistive device and respondents who had given multiple answers to that particular question were excluded. All this resulted in a data set with data on 2,002 respondents. Some basic characteristics of this population are presented in table 1.

\section{Table 1: Characteristics of the study population $(n=2002)$}

\begin{tabular}{|cc|}
\hline fernale $(\%)$ & 60.7 \\
age $(\%)$ & \\
$<50$ & 29.0 \\
$50-59$ & 24.3 \\
$60-69$ & 20.2 \\
$70-79$ & 18.0 \\
$>80$ & 8.5 \\
Mean age (S.D.) & $58.0(15.7)$ \\
insured with private insurer (\%) & 34.0 \\
insured with National Health Service $(\%)$ & 62.0 \\
insured with statutory insurer $(\%)$ & 4.0 \\
\hline
\end{tabular}

As can be seen in almost any population of assistive device users, about 60 percent is female and the mean age is rather high (table 1). The diversity in types of assistive devices represents the set of types of assistive devices provided by medical health insurance in the Netherlands (with the exception of dentures, aids for respiratory therapy, aids for administering food and aids for therapy). However, the breakdown in the numbers of different types does not represent the breakdown in the actual numbers provided because the total study population is not a random sample (table 2).

Table 2: Breakdown of the study population by types of assistive devices

\begin{tabular}{|l|cc|}
\hline \multicolumn{1}{|c|}{ Type of assistive device } & N & $\%$ \\
\hline Aids for personal care & 386 & 19.3 \\
Orthoses / shoe adaptations & 217 & 10.8 \\
Hearing aids & 227 & 11.3 \\
Optical aids & 105 & 5.2 \\
Aids for diabetics & 229 & 11.4 \\
Home furnishings & 97 & 4.8 \\
Elastic compression stockings & 166 & 8.3 \\
Prostheses & 299 & 14.9 \\
Aids for communication and information & 105 & 5.2 \\
Aids for personal mobility & 171 & 8.5 \\
& & 100 \\
\hline
\end{tabular}

\section{Reliability}

Reliability coefficients (Cronbach's Alpha) of the device scale are rather high $(>0.8)$ for all types of assistive devices except for elastic compression stockings. The relatively lower alpha $(0.68)$ for elastic compression stockings can be 
(partially) explained by the low number of respondents in this group (table 3 ). On average, reliablity coefficients of the service scale are lower, but range consistently between 0.73 and 0.85 for all types of assistive devices. The numbers of respondents $(\mathrm{N})$ in this analysis are smaller than the total numbers of respondents in this study, because this calculation of Cronbach's Alpha requires a complete data set for every subject. Only those respondents who considered all (eight or four) aspects applicable within one scale could be included.

Table 3: Reliability coefficients of the two sub-scales for each type of assistive device

\begin{tabular}{|l|cc|cc|}
\hline \multicolumn{1}{|c|}{ Type of assistive device } & \multicolumn{2}{c|}{$\begin{array}{c}\text { Device related } \\
\text { aspects (8) }\end{array}$} & \multicolumn{2}{c|}{$\begin{array}{c}\text { Service related } \\
\text { aspects (4) }\end{array}$} \\
\cline { 2 - 5 } & $\mathbf{N}$ & \multicolumn{1}{|c|}{ Alpha } & $\mathbf{N}$ & Alpha \\
\hline Aids for personal care & 90 & 0.89 & 51 & 0.82 \\
Orthoses / shoe adaptations & 87 & 0.90 & 148 & 0.84 \\
Hearing aids & 110 & 0.85 & 178 & 0.82 \\
Optical aids & 26 & 0.85 & 34 & 0.78 \\
Aids for diabetics & 68 & 0.82 & 94 & 0.81 \\
Home furnishings & 41 & 0.88 & 44 & 0.85 \\
Elastic compression stockings & 34 & 0.68 & 41 & 0.73 \\
Prostheses & 74 & 0.89 & 126 & 0.83 \\
Aids for communication and information & 18 & 0.92 & 46 & 0.82 \\
Aids for personal mobility & 112 & 0.84 & 49 & 0.77 \\
Total & 660 & 0.88 & 811 & 0.84 \\
\hline
\end{tabular}

\section{Validity}

In the version of D-QUEST used in this study, the non-applicability option for answers was included for all questions except those relating to Effectiveness, Service delivery and Professional services. Table 4 shows the percentages of respondents that considered the non-applicability of a question for each type of assistive device. The percentage of questions which were considered 'not applicable' for a certain type of assistive device ranges from 0.4 (Simplicity of use of hearing aids) to 85.1 (Repairs and servicing of aids for personal care). Adjustments and Repairs and servicing, in particular, are often considered "not applicable' for the majority of types of assistive devices. Simplicity of use is the aspect, which is most often deemed to be 'applicable' for almost every type of assistive device (table 4). The large variation in non-applicability rates for an aspect between types of assistive devices is striking. The non-applicability rates for the Adjustments aspect reaches $73.0 \%$ for users of elastic compression stockings, whilst this is only $11.2 \%$ for the users of aids for personal mobility. The non-applicability rates for the Repairs and servicing aspect reaches $85.1 \%$ for users of aids for personal care, whilst this is only $18.8 \%$ for users of hearing aids. 
Table 4: Percentage of respondents that considered a question 'not applicable' for each type of assistive device

\begin{tabular}{|c|c|c|c|c|c|c|c|c|c|c|}
\hline & $\begin{array}{l}\frac{8}{2} \\
\frac{2}{8} \\
\frac{8}{8} \\
\frac{8}{6} \\
\frac{8}{6}\end{array}$ & 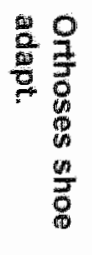 & $\begin{array}{l}\frac{7}{8} \\
\frac{0}{2} \\
\frac{0}{3} \\
\frac{2}{0}\end{array}$ & 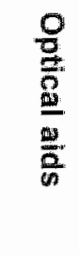 & 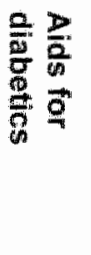 & 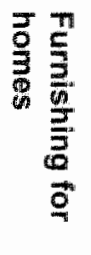 & 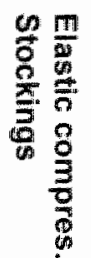 & $\begin{array}{l}\frac{0}{8} \\
8 \\
\frac{9}{5} \\
8 \\
0 \\
0 \\
0 \\
0\end{array}$ & 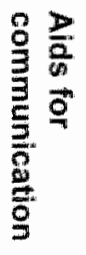 & 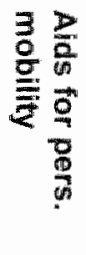 \\
\hline Dimensions $(\%)$ & 16.9 & 11.1 & 9.7 & 15.2 & 20.6 & 8.2 & 3.0 & 9.4 & 11.4 & 3.5 \\
\hline Weight $(\%)$ & 31.8 & 11.2 & 15.0 & 30.1 & 27.4 & 37.5 & 38.7 & 5.1 & 41.3 & 9.9 \\
\hline Adjustments (\%) & 72.7 & 41.0 & 16.3 & 45.0 & 60.5 & 20.6 & 73.0 & 70.7 & 59.6 & 11.2 \\
\hline Safety $(\%)$ & 29.8 & 37.2 & 36.9 & 43.7 & 36,3 & 15.5 & 67.7 & 42.8 & 42.2 & 8.8 \\
\hline Durability (\%) & 35.8 & 7.4 & 14.1 & 20.4 & 22,5 & 16.8 & 4.2 & 5.4 & 26.2 & 10.7 \\
\hline $\begin{array}{l}\text { Simplicity of use } \\
(\%)\end{array}$ & 6.0 & 4.6 & 0.4 & 4.8 & 3.9 & 2.1 & 6.6 & 4.7 & 2.9 & 1.2 \\
\hline Comfort $(\%)$ & 6.3 & 2.3 & 7.1 & 18.1 & 25.7 & 1.0 & 10.3 & 6.4 & 17.3 & 8.4 \\
\hline Effectiveness $(\%)$ & - & - & - & - & - & - & - & - & - & 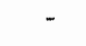 \\
\hline $\begin{array}{l}\text { Mean number of } \\
\text { aspects } \\
\text { considered not } \\
\text { applicable } \\
\text { (out of } 7 \text { ) }\end{array}$ & 2.1 & 1.2 & 1.2 & 1.8 & 2.0 & 1.1 & 2.1 & 1.5 & 2.1 & 0.6 \\
\hline $\begin{array}{l}\text { Service delivery } \\
(\%)\end{array}$ & - & - & - & - & - & - & - & - & $=$ & 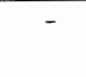 \\
\hline $\begin{array}{l}\text { Repairs/servicing } \\
(\%)\end{array}$ & 85.1 & 24.2 & 18.8 & 63.1 & 52.9 & 45.8 & 71.3 & 53.2 & 53.8 & 64.0 \\
\hline Prof.services $(\%)$ & - & - & - & - & - & - & - & - & - & - \\
\hline $\begin{array}{l}\text { Follow-up services } \\
(\%)\end{array}$ & 24.7 & 13.3 & 4.5 & 28.2 & 22.9 & 39.6 & 28.8 & 29.1 & 18.3 & 35.4 \\
\hline $\begin{array}{l}\text { Mean number of } \\
\text { aspects } \\
\text { considered not } \\
\text { applicable } \\
\text { (out of } 2 \text { ) }\end{array}$ & 1.1 & 0.5 & 0.3 & 1.0 & 0.8 & 0.9 & 1.0 & 0.8 & 0.7 & 1.1 \\
\hline
\end{tabular}

In a test with the previous version of D-QUEST, 243 subjects completed the questionnaire (Demers, 2001). Of the twelve aspects represented in the current version of D-QUEST, the highest rates of missing data were found for the aspects of Weight $(62.1 \%)$, Repairs and servicing (48.6\%), Adjustments $(42.4 \%)$ and Follow-up services ( $42.0 \%)$. The version used then did not contain the non-applicability option. In the original data set used for this study (before excluding cases with too many missing data) $(n=3,148)$, the highest rates of missing data were found on the aspects of Adjustments (10.9\%), Repairs and servicing $(9.4 \%)$, Safety $(8.1 \%)$, Weight $(7.4 \%)$ and Follow-up services $(7.3 \%)$. It seems reasonable to assume, that respondents answering 'not applicable' in our version, would not have answered at all in the original version. In that respect, the findings by Demers correspond reasonably well with the findings in 
this study. Only in this study the Safety aspect is considered applicable much less frequently (and relatively more often missing).

One would expect clients whose problem is solved more satisfactorily will be more satisfied with the solution. Table 5 shows that this assumption is true. The mean satisfaction level for the device provided increases from 3.59 for people whose problem has not been solved at all, to 4.31 for people whose problem has been fully solved. The mean satisfaction level for the service provided increases from 3.71 for people whose problem has not been solved at all, to 4.24 for people whose problem has been fully solved. Apparently the degree to which the problem is solved has a slightly larger influence on the satisfaction level for the device, than it has on the satisfaction level for the service. This is shown by the Spearman's rho correlations. As might be expected, the device itself shows a stronger relationship with the problem-solving ability of the device than the process of obtaining it. However, both relationships are significant (table 5). These correlations support the validity of D-QUEST. They are not extremely high of course, because satisfaction and problem-solving ability are different constructs.

Table 5: Relation between satisfaction and the problem being solved

\begin{tabular}{|c|c|c|c|c|c|c|}
\hline \multirow[b]{2}{*}{$\begin{array}{l}\text { Problem } \\
\text { solved }\end{array}$} & \multicolumn{3}{|c|}{ Satisfaction with device } & \multicolumn{3}{|c|}{ Satisfaction with service } \\
\hline & $\begin{array}{c}\text { Mean } \\
\text { satisfaction }\end{array}$ & Std. Dev. & $\mathbb{N}$ & $\begin{array}{c}\text { Mean } \\
\text { satisfaction }\end{array}$ & Std Dev. & $N$ \\
\hline Not at all & 3.59 & 1.00 & 151 & 3.71 & 1.03 & 151 \\
\hline A little & 3.64 & 0.72 & 189 & 3.77 & 0.86 & 189 \\
\hline More or less & 3.68 & 0.65 & 338 & 3.72 & 0.84 & 338 \\
\hline Largely & 4.05 & 0.48 & 739 & 4.00 & 0.76 & 739 \\
\hline Totally & 4.31 & 0.47 & 458 & 4.24 & 0.72 & 459 \\
\hline $\begin{array}{l}\text { Spearman's } \\
\text { rho }\end{array}$ & $0.38^{* *}$ & & & $0.23^{* *}$ & & \\
\hline
\end{tabular}

Two general questions were added to the version of D-QUEST used in this study: 'What is your overall level of satisfaction with your assistive device?' and "What is your overall level of satisfaction with the process of service delivery as a whole?' Although the twelve questions about the specific aspects are expected to present a much more accurate image of the satisfaction levels of users of assistive devices, one might expect a certain correlation between mean satisfaction levels with respect to specific aspects and the two questions relating to general satisfaction. Table 6 confirms this expectation (table 6). 
Table 6: Correlations between mean satisfaction score on aspects and general satisfaction score for each type of assistive device

\begin{tabular}{|c|c|c|}
\hline & $\begin{array}{l}\text { Assistive dewice: } \\
\text { Correlation mean } \\
\text { satisfaction } 8 \text { aspects } \\
\text { and general } \\
\text { satisfaction } \\
\text { (Spearnan's tho) }\end{array}$ & $\begin{array}{c}\text { Service } \\
\text { Correlation mean } \\
\text { satisfaction } 4 \text { aspects } \\
\text { and general } \\
\text { satisfaction } \\
\text { (Spearman's rho) }\end{array}$ \\
\hline Aids for personal care & $0.77^{\# *}$ & $0.74^{* * *}$ \\
\hline Orthoses / shoe adaptations & $0.82^{* *}$ & $0.79^{* x^{2}}$ \\
\hline Hearing aids & $0.79^{* *}$ & $0.81^{* * *}$ \\
\hline Optical aids & $0.68^{* * *}$ & $0.74^{* * *}$ \\
\hline Aids for diabetics & $0.68^{\text {tht }}$ & $0.71^{\text {*** }}$ \\
\hline Home furnishings & $0.72^{* *}$ & $0.87^{* * *}$ \\
\hline Elastic compression stackings & $0.75^{* *}$ & $0.78^{* * *}$ \\
\hline Prostheses & $0.82^{* * *}$ & $0.84^{\star *}$ \\
\hline $\begin{array}{l}\text { Aids for communication and } \\
\text { information }\end{array}$ & $0.79^{\text {*** }}$ & $0.88^{\text {*kx }}$ \\
\hline Aids for personal mobility & $0.75^{\text {m*x }}$ & $0.83^{* *}$ \\
\hline Total & $0.78^{* * *}$ & $0.81 * *$ \\
\hline
\end{tabular}

\section{Satisfaction}

When examining the total population, people are equally as satisfied with the device provided as they are with the service provided. However, differences can be identified between types of assistive devices. Users of aids for diabetics and users of aids for personal care are the most satisfied with their devices; users of aids for communication and information and users of furnishing for homes are the least satisfied about the service provided (although they are satisfied with their devices (table 7).

\section{Table 7: Mean satisfaction per type of assistive device}

\begin{tabular}{|l|cc|}
\hline \multicolumn{1}{|c|}{ Type of assistive device } & $\begin{array}{c}\text { Mean } \\
\text { satisfaction with } \\
\text { device } \\
\text { (Std.Dew.) }\end{array}$ & $\begin{array}{c}\text { Mean } \\
\text { satisfaction with } \\
\text { service } \\
(\text { Std.Dev.) }\end{array}$ \\
\hline Aids for personal care $(n=386)$ & $4.1(0.5)$ & $4.3(0.6)$ \\
Orthoses / shoe adaptations $(n=217)$ & $3.9(0.7)$ & $3.8(0.9)$ \\
Hearing aids $(n=227)$ & $3.9(0.6)$ & $4.0(0.7)$ \\
Optical aids $(n=105)$ & $4.0(0.6)$ & $4.0(0.7)$ \\
Aids for diabetics $n=229)$ & $4.3(0.5)$ & $4.2(0.6)$ \\
Home furnishings $(n=97)$ & $4.0(0.7)$ & $3.4(1.0)$ \\
Elastic compression stockings $(n=166)$ & $3.8(0.6)$ & $3.9(0.7)$ \\
Prostheses ( $n=299)$ & $3.8(0.8)$ & $4.0(0.8)$ \\
Aids for communication and information $(n=105)$ & $4.0(0.6)$ & $3.4(1.0)$ \\
Aids for personal mobility ( $n=171)$ & $4.0(0.6)$ & $3.8(0.9)$ \\
& $4.0(0.6)$ & $4.0(0.8)$ \\
\hline Total $(n=2002)$ & &
\end{tabular}




\subsection{Conclusions}

All in all, D-QUEST (and therefore also QUEST) proves to be well applicable to users of all kinds of assistive devices. It has now been tested for aids for personal care, orthoses and shoe adaptations, hearing aids, optical aids, aid's for diabetics, adapted furnishing for homes, elastic compression stockings, prostheses, aids for communication and information and aids for personal mobility. The users of all these devices were well able to complete the questionnaire with only the limited standard written instructions.

The relatively high Cronbach's Alphas on both sub-scales for all types of assistive devices show a high internal consistency in both sub-scales, indicating an acceptable level of reliability. The significant correlations between satisfaction, as measured with D-QUEST, on the one hand, and the degree of problem solving and questions on general satisfaction on the other, support the construct validity of the instrument.

The inclusion of the non-applicability option would appear to present an improvement when the instrument is applied to users of various types of assistive devices. Respondents are provided with an option to "customise" the questionnaire to suit their own specific device. This substantially lowers the numbers of missing values, but does not interfere with the possibility to calculate a mean satisfaction score. The high internal consistency of both scales makes it relatively harmless to leave out an aspect. It is consistent with the 'client-centred approach' in which the instrument was developed to let the respondent choose which aspects he or she considers to be applicable to his or her situation.

The high rates of non-applicability (up to $85 \%$ for repairs and servicing of aids for personal care) prove the need for the respondent to be given an option to 'customise' the questionnaire to specific types of devices. The diversity in nonapplicability rates for aspects between various types of assistive devices proves that it is not recommended to omit any aspects from the questionnaire. The fact that no aspect scores a high rate of 'non-applicability' for every type of assistive device supports the content validity of the questionnaire in relation to assistive devices in general. One recommendation might be to establish an upper limit for the number of aspects considered 'not applicable' by one respondent, for instance three aspects (out of eight) 'not applicable' for the device scale and one aspect (out of four) 'not applicable' for the service scale. 


\section{References}

L. Demers, M. Monette, Y. Lapierre, D. Arnold, C. Wolfson. Reliability, validity and applicability of the Quebec User Evaluation of Satisfaction with assistive Technology (QUEST 2.0) for adults with multiple sclerosis. Disability and Rehabilitation: 2002, 24 (1/2/3) 21-30.

L. Demers, R. Weiss-Lambrou, B. Ska. Development of the Quebec User Evaluation of Satisfaction with assistive Technology (QUEST). Assistive Technology: 1996, 8: 3-13.

L. Demers, R.D. Wessels, R. Weiss-Lambrou, B. Ska, L. de Witte. An international content validation of the QUEST. Occupational Therapy International: 1999, 6 (3) 159-175.

L. Demers, R.D. Wessels, R. Weiss-Lambrou, B. Ska, L. de Witte. Key dimensions of client satisfaction with assistive technology: a cross-validation of a Canadian measure in the Netherlands. Journal of Rehabilitation Medicine: 2001, 33: 187-191.

M. Scherer. The change in emphasis from people to person: introduction to the special issue on Assistive Technology. Disability and Rehabilitation: 2002, 24 $(1 / 2 / 3) 1-4$.

M. Shone Stickel, S. Ryan, P. Rigby, W. Jutai. Toward a comprehensive evaluation of the impact of electronic aids to daily living: evaluation of consumer satisfaction. Disability and Rehabilitation: 2002, 24 (1/2/3) 115-125.

R.D. Wessels, L. de Witte, R. Weiss-Lambrou, L. Demers, G. Wijhuizen. A Dutch version of QUEST (D-QUEST) applied as a routine follow-up within he service delivery process. In: Placencia E, Ballabio E (Eds.). Improving the Quality of Life for the European Citizen. Washington, DC: IOS Press: 1998, 420-424. 


\section{Conclusions and discussion}

Roelof D. Wessels, Luc P. de Witte, Wim J.A. van den Heuvel Institute for Rehabilitation Research, the Netherlands 



\subsection{Conclusions and Discussion}

Assessing the provision of assistive technology from a user perspective is important, whatever point of view you adopt. First of all, if we look at it from a user point of view, we should recognise the fact that users of assistive devices are becoming more and more emancipated. They feel they have the right themselves to decide what is best for them. This not only means taking part in the decision-making process, but also taking part in the process of evaluating the decision and its execution. After all, it is they who have asked for help and it is they who have to use the device, so they are the ones who can best judge whether the device is able to provide a satisfactory solution to their problem. In the whole field of medicine, we see a shift from doctor-based decision-rnaking to a joint doctor-patient approach towards developing a plan for treatment. The patient - or in the case of assistive technology provision, the client - is demanding to be taken more seriously. Instead of just being a number, which needs to be treated, patients are now insisting on being treated as a full partner in the decision-making process.

From the service provider's point of view, we see a shift towards a clientcentred practice. This is a shift that is in line with the clients' changing attitude. Nowadays, the service provider is expected to take client opinion much more seriously. This client-centred practice involves a collaborative approach, which is aimed at enabling increased participation on the part of clients. In this approach, not only do occupational therapists demonstrate a respect for their clients, they also involve them in decision making, stand up for their needs and rights and fully take into account the experiences and knowledge of the client. This not only applies to decision making, but also to its evaluation and execution.

From a policymaker's point of view, tools to assess outcomes from a user perspective are required so that the effects of their policy making can be properly evaluated. Policymakers are generally aware of the amount of money that is spent on the provision of assistive devices, but they do not know the degree to which this helps them achieve their goals, that is, helping people. The only real way to find out the extent to which people have been helped, is to ask them. And that is exactly what outcome measures from a user perspective do: they do not approach clients from a professional perspective, but ask the client directly. The effectiveness measure we developed asks: "what is your problem?" and later, after the intervention: "to what degree has this problem been solved?" The measure of satisfaction simply asks the client directly about his or her level of satisfaction. In this way, policymakers are able to assess the extent to which a new policy really makes a difference for the people concerned or what the difference is between a number of policies.

From a society-based point of view, we can identify a trend in which individual citizens are being taken more and more seriously. This applies in equal measure to those citizens who use assistive devices. What's more, as a group, people with disabilities are becoming increasingly emancipated, demanding to 
be treated on an equal footing with others, which means that their opinion must be taken into account. Outcome measures from a user perspective help to support this.

This thesis describes the IPPA and D-QUEST instruments and their development as well as testing the measurement properties and the viability of both instruments. If it can be proven that both these instruments are sound and applicable to the Dutch situation, an important step will have been made towards a package of instruments that can be used to measure the outcomes of all kinds of assistive technology provisions from a user perspective.

\section{$7.2 \quad$ IPPA}

IPPA is presented and its viability and validity studied. 248 clients in Italy, Norway, Sweden and the Netherlands, applying for the provision of a new assistive device, took part in the study. All these people faced problems in mobility, hearing, speech related communication or self-care in the bathroom. As such, they were provided with an assistive device to help solve their problem. Before the provision process started, an IPPA baseline interview was conducted with them. Once they had received the assistive technology and had used it for three months, the IPPA follow-up interview was conducted. 188 clients participated in this follow-up interview. Based on the data from these 188 clients, IPPA was tested.

The viability of IPPA turned out to be good. The use of the instrument fits very well in the process of assistive technology service delivery. Clients understood the questions well and could answer them. The IPPA interview also enabled them to express their problems more easily. In this way, the instrument is not only client-centred - in the sense that the client decides what the questions are about - it also empowers the client to set his or her own goals. The maximum number of seven problems was sufficient. After the results had been analysed the scoring procedure was improved by replacing the numbered scales with verbal answers.

Unfortunately, testing the IPPA"s reliability was limited. We have tried to assess test-retest stability, but a failure in the design made it impossible to draw any conclusions.

Hard evidence on the reliability of IPPA will therefore only be available after further, specific study.

With respect to the validity, the results show that in most sub-groups analysed, changes in IPPA scores are consistent with changes in SIP68 scores, which supports the content validity. The changes in IPPA scores appear to be larger than for other scores, which is consistent with the principles of the instrument that IPPA measures the essence of the changes caused by assistive technology provision, that is, the degree to which problems that the individual client wants to solve are actually solved. So in conclusion, the validity of IPPA is promising (on the assumption that the reliability is good). 
The use of IPPA in two more studies is described to further validate the instrument. One of these studies duplicates the study described in chapter 2. The results were roughly similar, so confirming the results in chapter 2 . The other study aimed to study the applicability of IPPA to a different kind of assistive technology and a different kind of user. This did not cause any inconsistencies. IPPA proved to be equally applicable to hi-tech, multipurpose assistive devices as well as to severely disabled respondents.

When looking at the results of a study population, the average score of the total population should not be considered on its own. It is necessary to look at individual scores and identify extreme deviations. If not respondents with very low scores will become lost in the overall average, thus creating too positive an image. The results show that a significant number of individuals with a poor or negative score can be concealed within a generally positive, overall score. This should be noted as it provides an important signal.

\subsection{QUEST}

A theoretical framework for measuring satisfaction with assistive technology has been examined. In 1996 Demers studied this by carrying out a literature search. She concluded that no specific theoretical framework on satisfaction with assistive technology existed. A search of the MEDLINE, CIRRIE and CINAHL databases was performed in order to find out whether any new theory had been added since 1996, but this, as it subsequently appeared, was not the case. Most literature published since, relates to QUEST, which is based on the limited amount of theory available. The instrument was designed using the following criteria:

1. Satisfaction is a multidimensional phenomenon that embodies a broad range of variables most likely to influence the degree of user satisfaction with assistive technology;

2. The variables should represent all the relevant sources of satisfaction and dissatisfaction: the environment, the user and the assistive technology device. In the latest version of QUEST these three dimensions have been replaced by two dimensions: the assistive technology device and the service delivery process (Demers, 2002):

3. The relative importance of the satisfaction items should be determined by the user of the assistive technology (i.e. the individual respondent) because satisfaction is a highly subjective concept. This criterion was later abandoned, after it appeared that respondents generally considered all variables equally important. In the latest version of the instrument (Demers, 2002) this question was omitted.

Since 1996, QUEST, as an instrument, has constantly been tested and improved. Not much theory has been added, so it could be said that state-ofthe-art theory on satisfaction with assistive technology, however small it may be, lies with QUEST 
In the presentation of QUEST, the purpose of the study was to conduct a crossvalidation of its two dimensional structure. Data were drawn from a follow-up study of 243 subjects in the Netherlands who had been given the Dutch version of QUEST. Ratings relating to 12 satisfaction items were analysed. Factor analysis results showed that the underlying structure of satisfaction with assistive technology consists of two dimensions relating to assistive technology, Device (eight items) and Services (four items), accounting for $40 \%$ of the common variance. This finding was consistent with a previous Canadian study and was interpreted as supporting the adequacy and stability of the QUEST measure of satisfaction

D-QUEST was tested for reliability and validity in a study into the satisfaction of assistive technology users with a large variety of assistive devices. The purpose was to study the applicability of (D-)QUEST to all kinds of assistive devices. 2002 users of all kinds of assistive devices provided by Dutch medical insurers, participated in the study. These included users of aids for personal care, orthoses and shoe adaptations, hearing aids, optical aids, aids for diabefics, adapted furnishings for homes, elastic compression stockings, prostheses, aids for communication and information and aids for personal mobility. They were recruited by taking samples from various insurance companies and the membership records of a number of patient associations. Participants received the questionnaire by mail.

Two modifications were made to the version of D-QUEST used in this study. The first modification involved the addition of two questions: "What is your overall level of satisfaction with your assistive device?" and "What is your overall level of salisfaction with the process of service delivery as a whole?" These general questions were included for validation purposes. The other modification consisted of adding a non-applicability option for some answers (i.e. 'not applicable'). The latter was done for all aspects except Effectiveness, Service delivery and Professional services as these last three aspects are expected to be applicable with respect to all kinds of assistive devices; for the other aspects this is not necessarily the case. The additional value of adding this answering option was studied by comparing the results to those of a previous study without the additional answering option.

Questionnaire viability turned out to be good for every kind of assistive device. All respondents were able to complete the questionnaire and response rates were thigh. In fact, respondents appeared eager to provide an opinion on the device provided as well as on the service provision.

Reliability of the two sub-scales of D-QUEST (device and service) was tested for each type of assistive device by calculating the reliability coefficient (Cronbach's Alpha) for the two scales for each type of assistive device. Reliability coefficients (Cronbach"s Alpha) of the device scale were rather high $(>0.80)$ for all types of assistive devices, except for elastic compression stockings. The relatively lower alpha (0.68) for elastic compression stockings can be (partially) explained by the low number of respondents in this group ( $n=$ 
34). On average, reliability coefficients of the service scales are lower, but range consistently between 0.73 and 0.85 for all types of assistive devices. Both scales show a high internal consistency, indicating an acceptable level of reliability. All in all, reliability of the instrument is good for all types of assistive devices.

The validity was tested in three different ways. The percentage of questions which were considered "not applicable" for a certain type of assistive device was analysed. The large variation in non-applicability rates for an aspect between types of assistive devices is striking. The high rates of non-applicability (up to $85 \%$ for repairs and servicing of aids for personal care) prove the need for the respondent to be given an option to 'customise' the questionnaire to specific types of devices. The diversity in non-applicability rates for aspects between various types of assistive devices proves that it is not recommended to omit any aspects from the questionnaire. The fact that no aspect scores a high rate of 'non-applicability' for every type of assistive device supports the content validity of the questionnaire in relation to assistive devices in general. Adding a nonapplicability option to the answering options improves the applicability of the instrument with all kinds of assistive devices. It also improves the client centred perspective, because it enables the client to customize the instrument to his or her personal circumstances.

Analysis of the relation between mean satisfaction levels and the degree to which problems are solved shows a significant correlation between the two, supporting the validity of D-QUEST. Also, the positive correlations between mean satisfaction levels with respect to specific aspects and the two added questions related to general satisfaction support the validity of D-QUEST.

To summarize, it can be said that D-QUEST (and likewise QUEST) is a usable, reliable and valid instrument for measuring user satisfaction with a large variety of types of assistive technology. Because assistive devices included in this study were so diverse, it seems fair to conclude that the instrument can be applied to all kinds of assistive technology.

\subsection{Discussion}

This thesis has brought about several new insights into the measurement of user satisfaction. IPPA turns out to be an instrument with good viability and promising validity. These results were confirmed in a duplicate study. The instrument D-QUEST (and therefore also QUEST) is now available in a shortened, paper version. This version is now well validated with all kinds of assistive devices. All this means, that we now have two effective tools with which to assess assistive technology outcomes from a user perspective. This is an important step in the process of creating a proper package of tools for assessing assistive technology interventions from a user perspective. One tool is to assess the effectiveness in terms of solving user problems, i.e. meeting user goals. The other one is to assess user satisfaction with this solution. 
Of course, there are still a few shortcomings to the studies performed in this thesis. IPPA has now been tested with a limited number of assistive devices. The viability and validity of the instrument when applied to other types of assistive devices and with other kinds of respondents than those in these studies are still uncertain and need to be studied. Another shortcoming is that the IPPA and D-QUEST have so far not been tested together in one study. Knowledge about the relationship between the two is still lacking. Although the correlation between the two is not expected to be very high (they are two completely different constructs), it is expected that there will be some positive correlation. It would be interesting to know the exact nature of this relationship.

Evaluating assistive devices is not the same as evaluating medical interventions. One big difference is that assistive devices are used for individual, very specific goals. This makes it hard to perform an ordinary costoutcome analysis. Such an analysis requires aggregating the results of a group of respondents. In a group of assistive device users, each user will have his or her own goals and therefore his or her own way of assessing outcomes. In fact, the outcome of assistive devices can only really be assessed on an individual level. Outcomes gathered with IPPA and D-QUEST can be summed up for a whole group of users, but they are most meaningful in relation to a single user.

Having these two new instruments enables us to assess outcomes of assistive technology more easily, first of all, outcomes for individuall users, and secondly, and to a somewhat lesser extent, outcomes for groups of users. The fact that these instruments enable us to assess outcomes from a user perspective is especially important for assistive devices, because of the individual goals pursued by the use of assistive devices. This makes it necessary to use individualized, preference-based instruments. If we are able to assess outcomes more easily, we will of course be in a better position to perform costoutcome analyses, although the assessment of costs has not been improved and remains problematic.

\subsection{Future developments}

\section{Research}

In view of the aforementioned shortcomings and in the light of other uncertainties, several aspects still need further study.

- The reliability of IPPA needs to be studied. Reliability with respect to the items (i.e. the problems that people identify) is uncertain but more importantly, reliability with respect to the scores is. In the end, the outcome of an IPPA measurement consists of a score. This score has to be reliable; a specific study to check the test-retest stability is needed to ensure reliability. 
- The method of calculating a total IPPA score can be debated and needs to be studied. For this purpose available data can be analysed.

- Following on the same lines, the use of importance scores needs to be studied. It is uncertain whether the use of importance scores actually adds anything to the total score. Seerningly, people consider all problems with almost equal importance. What's more, respondents are often confused when ascribing importance to a problem. Apparently importance of a problem and the difficulty it causes are difficult to distinguish. Analysing this can be done using available data.

- It is unclear whether it is possible to create alternative formats for IPPA (other than two face-to-face interviews). For instance, a telephone interview or even a typed questionnaire would be much cheaper and easier to perform. To analyse this a specific study comparing between alternative formats is required.

- The validity of IPPA, when applied to other kinds of assistive devices than those in the studies performed, is still uncertain and requires further study. And even more importantly, the validity of IPPA when applied to totally different kinds of interventions not related to assistive technology, needs to be studied. There is no reason why the use of IPPA should be restricted to assistive technology. It should be possible to apply the instrument to any kind of intervention that aims to solve problems of individuals. This most certainly deserves further study. The instrument IPPA could be of value at least for the total field of rehabilitation medicine.

- One aspect that requires further study is the influence of client expectations prior to embarking on the service delivery process on their evaluation afterwards. Especially with the problem identification in IPPA, this might bias the outcomes and needs to be studied further.

- Another completely different requirement is for the creation of a theoretical framework of satisfaction with assistive technology. This is most certainly required for studying the phenomenon of user satisfaction. If we want to improve user satisfaction, we need to know how it works. What aspects influence user satisfaction and in what way do they influence it?

- One final aspect, which deserves further study, is the question: "Does the application of the two instruments in a standardized manner in the service delivery process actually improve service delivery?" It seems a reasonable assumption to make, but it can only be confirmed by actually trying it and studying it.

\section{Policy}

Based on the results of this thesis, several policy measures can be taken. Both IPPA and D-QUEST can be used in two different ways for two different purposes. First of all, they can be applied in a routine manner in assistive technology service delivery in order to improve the service. Using IPPA will structure the selection process, making sure that all relevant problems of the client are given attention when choosing the most appropriate device. The use of IPPA will likewise enable service providers to evaluate the process and its results afterwards. They will be able to assess the effectiveness achieved in individual cases. Applying IPPA hardly requires any extra work, because the 
questions need to be asked anyway, except this time in a structured manner. The use of D-QUEST will enable service providers to establish a follow-up service. In the past, D-QUEST has proved to be an excellent starting point for establishing a follow-up service. The instrument serves as a checklist; all relevant aspects are paid attention to, any problem or shortcoming will surface and can be dealt with. In this way individual provisions can be optimised. Doing this regularly enables the service provider to monitor the quality of the service delivery. Shartcomings in the process or in the procedures can be detected if more problems occur in relation to the same aspect.

The second manner in which IPPA and D-QUEST can be used is incidental for a (cost-) outcome analysis. Of course, in a cost-outcome analysis, both instruments are only of use for the outcome side of the equation. Cost-outcome analyses are used for instance, for making a comparison between different systems of provision, for comparing different solutions for similar problems (which often occurs), and for evaluating new policy, the execution of policy by different parties or the cost-effectiveness of new types of provisions. In fact, this type of study can be used on any occasion when the outcome of an intervention needs to be defined. 
Summary 



\section{Chapter 1. Introduction}

During the last decade three major developments in health policy can be identified. First of all, there has been a political desire for controlling the volume and costs of health care, resulting in a widespread collection of data on the outcomes and costs of medical interventions. Secondly, there is the emphasis on evidence-based interventions. This development calls for validated instruments to measure health care outcomes. Thirdly, patients/consumers in health care try to protect their rights and interests. User perspective has become an aspect to be taken into account in relation to quality of care.

Strangely enough, these developments have not affected the field of assistive technology very much until now, although the importance of costs and evidence of assistive technology interventions is evident. A growing demand exists for instruments, which allow us to carry out standardized assessment of the outcome of the provision of assistive devices. Besides the efficiency aspect, it is also the potential for participation through the availability of assistive devices for people with functional limitations that requires proper outcome measures.

Because of a number of specific characteristics of assistive devices, instruments available to assess the outcomes of rehabilitation in general are less appropriate for use in the field of assistive devices. Specific instruments are required to assess the effectiveness of assistive device interventions. These instruments:

- $\quad$ must be responsive to small subtle changes in specific fields identified by the individual respondent;

- $\quad$ must not be related to disease or to disfunctioning but to activity and participation;

- $\quad$ must use scales that fit in the frame of reference of people with longterm disabilities.

Not only is the intention of a provision to solve the problem effectively, but the user also has to be content with it. User satisfaction is a strong indicator of the service quality. Assessment of both effectiveness and satisfaction provides us with a useful tool to assess user-centred outcomes of a provision.

Outcomes of rehabilitation, and therefore outcomes of assistive device interventions, can be quantified both objectively and subjectively. The objective point of view is overwhelmingly dominant in the prevailing models and measures of disablement. However, the subjective perceptions of a client with respect to his or her own situation should be considered as an outcome that is relevant in addition to conventional objective outcome measures. It can be 
argued, that in evaluating assistive technology provision, the user's opinion is the most important one and that the user has the best knowledge about his or her own specific individual situation. Therefore, in this thesis we will focus on the user perspective. This thesis aims to present and test instruments that are useful to measure the outcome of assistive devices from a user perspective. The research questions studied in this thesis are:

1. Is Individually Prioritized Problem Assessment (IPPA) useful, reliable and valid for determining the outcome of assistive devices from a user perspective?

2. Is an instrument to assess user satisfaction with assistive devices, such as the Quebec User Evaluation of Satisfaction with assistive Technology (QUEST) useful, reliable and valid to determine the outcome of assistive devices from the user perspective?

\section{Chapter 2.}

\section{Instruments for the assessment of outcomes of assistive devices from a user perspective: an exploration of the literature}

If we look at outcomes from a user perspective, two aspects are important: user preference has to be included and user satisfaction has to be considered.

Several methods and instruments have been developed for measuring outcomes on the basis of user preference (dimensions defined by the individual respondent). The most widely used is Goal Attainment Scaling (GAS). GAS is used in many fields. It measures the difference between the expected level of outcome and the actual level of outcome realized. Another preference-based instrument is the Patient Generated Index (PGI), initially developed to assess quality of life in patients with low back pain. The patient is asked to identify the five most important activities that have been affected by the disorder and to score how badly they have been affected. The MACTAR patient preference disability questionnaire is a patient preference-based questionnaire to assess disability in arthritic patients. The patient is asked to identify and rank (both at baseline and at follow-up) activities, which have been restricted as a result of the arthritis. This method evolved into the Patient Elicitation Technique (PET). One preference-based questionnaire designed for use in the field of assistive technology service delivery is the Canadian Occupational Performance Measure (COPM). It is a tool for implementing the philosophy of a user-centred perspective within the service delivery process. For a number of reasons, these measures are not suitable to be applied for research purposes in the field of assistive technology service delivery. An instrument is needed that assesses the degree to which problems identified by the individual respondent are solved by the provision of an assistive device. 
The subject of satisfaction with assistive technology is studied by looking at some theory about consumer satisfaction and patient satisfaction. Various models are found.

None of them seems to suffice in every situation, most of them will be suitable in some cases. In 1996 Demers studied the theory behind user satisfaction with assistive technology. She concluded that no useful theoretical framework existed. She started the development of an instrument to assess user satisfaction with assistive technology, QUEST (Québec User Evaluation of Satisfaction with assistive Technology). It was originally based on a limited amount of theory, some of which was later abandoned.

A literature search was performed to study new developments in theory about user satisfaction with assistive technology originating after 1996. Not counting the publications by Demers about QUEST, we came up with eight publications. It turned out that not much new theory has been added since 1996. The existing theoretical framework about satisfaction with assistive technology is still very limited. The amount of literature about it is also very limited. Most of it relates to the development of QUEST.

\section{Chapter 3.}

\section{IPPA, a user-centred approach to assess effectiveness of assistive technology provision}

For a number of reasons, there is a growing need to prove the effectiveness of the resources spent on assistive technology service delivery. In very general terms, people start using assistive technology to reduce problems whilst performing activities. The effectiveness of an assistive technology provision can, in its most basic form, be therefore defined as the degree to which problems are actually solved in relation to its intended aim. The most direct way to assess this, is to find out the degree to which problems are actually solved. For a number of reasons existing instruments in the field of health technology assessment are inadequate for use in the field of assistive technology provision. The specific individual goals represent the key aspect when assessing the effectiveness of assistive technology provisions. A new instrument was developed for this purpose, IPPA (Individually Prioritized Problem Assessment). It extended the line of reasoning with respect to existing instruments using an individualized scale (e.g. Goal Attainment Scaling (GAS), the MACTAR patient preference disability questionnaire and the Problem Elicitation Technique (PET). 
IPPA is intended to measure the effectiveness of the provision of assistive technology. It assesses the extent to which the problems in daily activities identified by the respondent have diminished as a result of this provision. The respondent is asked to identify the problems that he or she experiences in daily life and that he or she hopes are eliminated or diminished as a result of the provision. The client is allowed to identify up to seven problems. For each problem identified, the client has to assign scores both with respect to the importance of the problem and the level of difficulty associated with performing the said activity. Scores are rated on a seven-point rating scale. The 'difficulty' scores are added up, using the 'importance' scores as weighting factors, the result of which is then divided by the number of problems, resulting in the total IPPA score (ranging between 1 and 49). This score represents the total average perceived inconvenience experienced by the client with respect to the problems identified. During the follow-up interview, a few months after the client has started using the newly provided assistive technology, the client has to assign a difficulty score for each of the same activities. The importance scores from the first interview are used again as weighting factors. The difference between the total IPPA score from the first and the second interview is considered to represent the effectiveness, thus indicating the degree to which the perceived inconvenience with respect to the problems identified has diminished.

The instrument was applied in the context of assistive technology service delivery in Italy, the Netherlands, Norway and Sweden. Respondents were clients who experienced problems relating to mobility, hearing, speech related communication or self-care. To assess the feasibility of IPPA, the interviewers were asked to rate some aspects of each interview using an evaluation form. Also, a meeting with all interviewers was arranged to exchange experiences and discuss aspects of feasibility. The construct validity of IPPA was assessed by comparing the scores with the results of EuroQol and SIP68. Changes in IPPA scores were expected to co-vary with changes in SIP68 scores, but at the same time EuroQol scores were supposed to remain fairly stable. The responsiveness of IPPA was studied by looking at the effect size.

In total, around 300 clients were approached, 248 of whom participated in a baseline interview. Of these 248 clients, 118 also participated in a follow-up interview. Sixty percent of the study population was female, the mean age was about 60 to 70 years old. In general, the interviews could be performed without difficulty. The questions fit well into the frame of reference of both clients and services delivery professionals. Some clients had trouble rating their problems in terms of numbers. The maximum number of seven problems turned out to be sufficient. The direction of changes measured with the IPPA was consistent with what was to be expected. Changes in IPPA were larger than in the other instruments. The correlation between IPPA and the other instruments at the same point in time was as expected. 
The feasibility of IPPA is satisfactory. Some adjustments were made to the instrument and the instructions for its use. The five-point scoring scales were replaced with multiple-choice answers with five verbal answering options. Construct validity is promising; IPPA measures the essence of the changes caused by AT provision.

\section{Chapter 4.}

\section{Effectiveness of provision of outdoor mobility service and devices in the Netherlands}

Despite all the modern communication techniques currently available, mobility is still an important factor in enabling social participation. In the Netherlands devices and services for people with disabilities in outdoor mobility are provided under a law called the Service for the Disabled Act (SDA). In this study the following questions will be answered:

1. What problems do people with outdoor mobility disabilities encounter?

2. What solutions are offered to them by local authorities in the

Netherlands under the SDA?

3. How effective are these solutions in the view of the users?

The instrument used to collect data in this study is the client-centred instrument IPPA. In this study the responsiveness of the IPPA will be further tested when used for the specific purpose of outdoor mobility problems.

This study is based on the data collected in two studies, the EBV study and the EATS study. The results of both studies are combined and treated as a single set of data. Firstly, the importance that respondents attached to the problems they had identified was analysed. The problems (disabilities) that people identified were classified according to the domains, contained within the Activities and Participation domains of the ICF and analysed. Next, the effectiveness of the solutions provided in order to solve the problems was analysed, firstly on the basis of the effectiveness per individual problem and then on the basis of the effectiveness per client/solution. In order to analyse the effectiveness of the provisions per problem, the effect sizes were calculated per ICF domain. The responsiveness of IPPA was assessed by calculating effect sizes and applying the responsiveness index by Cohen.

The study sample included 59 persons who applied for a new assistive device or service related to outdoor mobility. The mean age of the respondents was 73 , about 70 percent of whom were female. The 59 respondents together identified a total of 274 problems (mean 4.6 ). It turned out that all problems identified were considered more or less equally important. It can be concluded that the 
order in which problems were identified bears no relation to the importance of the problems. The problems identified were often very individual and very specific. When classified according to the ICF classification it turned out that most problems were related to Community, Social and Civic Life (98 problems), Interpersonal Interactions and Relationships (78 problems), Domestic Life (53 problems) or Self-Care (27 problems). Problems in the Domestic Life, Interpersonal Interactions and Relationships and Community, Social and Civic Life domains were mentioned by more than half of the respondents.

In order to solve the problems, the 59 respondents were provided with a mobility device, the use of a shared taxi service or a combination of both. The most common solution turned out to be an electric scooter (12 persons) or the use of a shared taxi service ( 35 persons). All types of problems were solved reasonably well. All individual problems were solved moderately or well. However, 7 clients experienced no (positive) effect at all. This calls for the service delivery process to adopt a structured, individual-oriented approach (similar to the IPPA approach) and for a structured activity/disability oriented evaluation to be carried out for every individual client afterwards.

\section{Chapter 5.}

\section{Key dimensions of client satisfaction with assistive technology: A cross-validation of a Canadian measure in the Netherlands}

Although the use of user satisfaction in the field of assistive technology is strongly advocated, satisfaction assessment tools are scarce, due in part to a vacuum in the theoretical knowledge concerning the phenomenon under study. Empirical work supports the multidimensional model of satisfaction. To date however, there has been little agreement about the conceptual structure of satisfaction measures with assistive technology.

QUEST was designed to measure satisfaction with assistive technology devices in a structured and standardized way. Originally, it consisted of 24 variables. An item analysis reduced this number to 12 . These items were found to be reliable with respect to test-retest stability and interrater reproducibility. With respect to content validity, all 12 items were considered of primary importance for assessing satisfaction according to Dutch, American and Canadian experts. Also, these items were rated as highly important by Canadian users of assistive technology. The 12 items were submitted to factor analysis. Results suggested that the underlying structure of satisfaction consists of 2 key dimensions: Device and Service. The Device dimension contains 8 items; the Service dimension contains 4 items. Several studies have been published which support the bi- 
dimensional approach to assistive technology, thus strengthening its validity. This study was performed in order to conduct a cross-validation of the bidimensional structure of satisfaction with assistive technology, using a sample of subjects in the Netherlands that was different from the sample in the original research with respect to cultural setting and types of devices.

Subjects were obtained from a follow-up study involving 374 subjects. They were provided with all kinds of home adaptations and mobility devices three months before the interview. All subjects were administered the Dutch version of the 24 item QUEST, the D-QUEST. The D-QUEST was administered in full, but in this study, only the satisfaction ratings with the 12 items selected from the previous item analysis of the QUEST were included in the analysis. Each item was scored on a five-point satisfaction scale, rating from 1 (not satisfied at all) to 5 (very satisfied).

Factor analysis was performed on a matrix of correlations between items scores obtained from 243 subjects. The data were appropriate for the planned analysis. The results yielded two factors accounting for 40 percent of the total common variance among the 12 items. The total item variance explained by this solution attained 49 percent. Consistent with common practice, each factor was interpreted according to the variables (QUEST items) that loaded or were mostly highly correlated. Results revealed that most items are high on one factor and low on the other, thus contributing positively to a simple resultant structure. Three items however, performed slightly differently. The items effectiveness and weight loaded on both factors but limited more substantially with the factor Device. The item durability loaded moderately on the two factors, however, somewhat more with the factor Service. The items comfort, dimensions, simplicity of use, effectiveness, adjustments, safety and weight all loaded high on the factor Device. It was reasonable to also assign durability to this factor because it is usually considered as a technical characteristic of a device. The factor Services was defined by high loadings of consumer service aspects of assistive technology. The items involved were professional services, follow-up services, repairs/servicing, and service delivery. As noted previously, the items effectiveness, durability and weight also correlated moderately with the factor Services "despite their stronger affiliation with the factor Device. The results of this replication study confirm the validity of the bi-dimensional structure of QUEST. Theoretical reflections distinguish the same dimensions. 


\section{Chapter 6.}

\section{Reliability and validity of the Dutch version of QUEST 2.0 with users of various types of assistive devices}

The latest version of QUEST (Québec User Evaluation of Satisfaction with assistive Technology) consists of a self-administered, written questionnaire. Like the previous versions it was translated into Dutch (D-QUEST). The respondent is asked to rate his/her satisfaction with respect to twelve different aspects using a five-point scale (rating from 1 (not satisfied at all) to 5 (very satisfied)). 8 of the 12 items relate to the assistive device, 4 items relate to the process of providing the device. The main purpose of this study is to test the measurement properties of D-QUEST when applied to users of various types of assistive devices. The feasibility, reliability and validity of D-QUEST will be analysed when the instrument is used for users of aids for personal care, orthoses and shoe adaptations, hearing aids, optical aids, aids for diabetics, adapted furnishing for homes, elastic compression stockings, prostheses, aids for communication and information and aids for personal mobility.

In this study, D-QUEST was applied to a population $(n=2002)$ of users of all kinds of assistive devices provided by medical insurers in the Netheriands. Two modifications were made to the original D-QUEST. Two questions were added for validation purposes about the overall satisfaction with the device and the service. Also, a non-applicability option was added to some of the answers (i.e. not applicable) because of the large variety of devices. The additional value of this answering option was studied. Samples of clients who had received an assistive device provision in the last two years were taken from a sample of insurers. Also, samples were taken from the membership records of a number of patient associations. A total of 5112 clients were sent a questionnaire. The questionnaire contained D-QUEST and other questions among which a question about the degree to which the problem had been solved by the device. All analyses were performed separately for the two sub-scales (devices and service). Reliability was tested by calculating the reliability coefficients (Cronbach's Alpha) for each type of assistive device. To test content validity, the percentage of respondents that considered questions not applicable was analysed for each type of assistive device. Results were compared to results of a previous study. To test construct validity the relationship was analysed between D-QUEST scores and the problem-solving abilities of the provided device.

A total of 3148 persons returned the questionnaire. After excluding all respondents who did not fit the requirements, 2002 respondents remained. Their mean age was 58 , about 60 percent were female. Reliability coefficients of the device scale are rather high $(>0.8)$ for all types of assistive devices 
except for elastic compression stockings (0.68). On average, reliability coefficients of the service scale are slightly lower (between 0.73 and 0.85 ) for all types of assistive devices. The percentage of questions which were considered not applicable for a certain type of assistive device ranges from 0.4 (simplicity of use of hearing aids) to 85.1 (repairs and servicing of aids for personal care). There is a large variation in non-applicability rates for an aspect between types of assistive devices. Clients whose problem is solved more satisfactorily are clearly more satisfied with the solution. As might be expected, the device itself shows a stronger relationship with the problem solving ability of the device than the process of obtaining it. However, both relationships are significant. This supports the validity of D-QUEST. Correlations between mean satisfaction scores and the added general satisfaction scores also confirm the validity of DQUEST.

All in all, D-QUEST (and therefore also QUEST) proves to be well applicable to users of all kinds of assistive devices. Adding a non-applicability option to the answers proves to be an improvement of the instrument.

\section{Chapter 7. Conclusions and Discussion}

Assessing the provision of assistive technology from a user perspective is important. This thesis describes IPPA and D-QUEST, their development and their testing. If these instruments prove to be valid, a package of instruments exists to measure the outcomes of all kinds of assistive technology provisions from a user perspective. IPPA turns out to be an instrument with good viability and promising validity. These results were confirmed by a duplicate study. The instrument D-QUEST (and therefore also QUEST) is now available in a shortened, paper version. This version is now well validated with all kinds of assistive devices. All this means that we now have two effective tools with which to assess assistive technology outcomes from a user perspective.

Two shortcomings of the studies in this thesis are that IPPA has only been tested with a limited number of assistive devices and that IPPA and D-QUEST have so far not been tested together in one study.

Performing a cost-outcome analysis requires aggregating the results of a group of respondents. In a group of assistive device users, each user will have his or her own goal and therefore his or her own way of assessing outcomes. In fact, the outcome of assistive devices can only really be assessed on an individual level. Outcomes gathered with IPPA and D-QUEST can be summed up for a whole group of users, but they are most meaningful in relation to a single user. 
Several aspects still need further study:

- The reliability of IPPA needs to be studied. A specific study is required.

- The method of calculating a total IPPA score needs to be studied.

Available data can be analysed for this purpose.

- The use of importance scores needs to be studied. This can be done by analysing available data.

- A specific study to compare alternative formats for IPPA is required.

- The validity of IPPA when applied to different kinds of assistive devices requires further study. Also, the validity of IPPA when applied to totally different kinds of interventions, unrelated to assistive technology, needs to be studied.

- The influence of client expectations prior to embarking on the service delivery process on their evaluation afterwards needs to be studied.

- The creation of a theoretical framework of satisfaction with assistive technology is required.

- A study needs to be performed to find out whether the application of the two instruments in a standard manner in the service delivery process actually improves service delivery.

IPPA and D-QUEST can be used in a routine manner in assistive technology service delivery in order to improve the service. Using the IPPA will structure the selection process and enable service providers to evaluate the process and its results afterwards. The use of D-QUEST will enable service providers to establish a follow-up service. The instrument serves as a checklist; all problems or shortcomings will emerge. Doing this on a regular basis enables the service provider to monitor the quality of the service delivery. Both instruments can also be used occasionally for a (cost) outcome analysis. Of course, both instruments are only of use for the outcome side of the equation. This type of study can be used on any occasion when the outcome of an intervention needs to be defined. 


\section{Samenvatting}





\section{Hoofdstuk 1. Inleiding}

De laatste tien jaar kunnen er drie grote ontwikkelingen in het beleid rond de gezondheidszorg worden onderscheiden. Ten eerste is er de politieke wens om volume en kasten van de gezondheidszorg te beheersen; dit resulteert in een uitgebreide verzameling van data over de kosten en gevolgen van medische interventies. Ten tweede is er de aandacht voor evidence-based interventies. Hiervoor zijn gevalideerde instrumenten nodig. Ten derde, proberen patiënten/consumenten in de gezondheidszorg steeds meer hun belangen te verdedigen. Het perspectief van de cliënt wordt steeds belangrijker.

Vreemd genoeg hebben deze ontwikkelingen tot nu toe weinig invloed gehad op het gebied van hulpmiddelen, hoewel het belang van de kosten en de bewezen effectiviteit van hulpmiddelen duidelijk is. Er bestaat een groeiende vraag naar instrumenten die ons in staat stellen een gestandaardiseerde beoordeling van de resultaten van een hulpmiddelverstrekking uit te voeren. Behalve het efficiëntie-aspect, is het ook de mogelijkheid voor mensen met beperkingen om te participeren door de beschikbaarheid van hulpmiddelen die roept om goede uitkomstmaten.

Vanwege een aantal specifieke eigenschappen van hulpmiddelen, zijn bestaande instrumenten voor het beoordelen van de resultaten van de revalidatie-in-het-algemeen minder geschikt om te gebruiken op het gebied van hulpmiddelen. Er zijn specifieke instrumenten vereist om de effectiviteit van hulpmiddelinterventies te beoordelen. Deze instrumenten:

- dienen responsief te zijn voor kleine, subtiele veranderingen op specifieke gebieden, geselecteerd door de individuele respondent;

- dienen niet gerelateerd te zijn aan ziekte of beperkingen maar aan activiteiten en participatie;

- dienen meetschalen te gebruiken die passen in het referentiekader van mensen met beperkingen.

Het doel van een verstrekking is niet alleen om een probleem effectief op to lossen, maar de gebruiker moet er ook tevreden mee zijn.

Gebruikerstevredenheid is een sterke indicator van de kwaliteit van de service. Het beoordelen van zowel de effectiviteit als de tevredenheid biedt ons een bruikbaar middel om de uitkomsten van een verstrekking te beoordelen waarbij de gebruiker centraal staat.

De resultaten van revalidatie, en daarmee de resultaten van hulpmiddelenverstrekking, kunnen zowel objectief als subjectief beoordeeld worden. De objectieve wijze van beoordelen is sterk overheersend in de bestaande modellen en maten van beperkingen. Echter, de subjectieve beoordeling van een cliënt met betrekking tot zijn of haar eigen situatie moet meegenomen worden als een uitkomst die relevant is als toevoeging op conventionele, objectieve uitkomstmaten. Je zou kunnen stellen, dat bij het evalueren van een hulpmiddelverstrekking, de mening van de gebruiker de 
belangrijkste is en dat de gebruiker de meeste kennis heeft over zijn eigen specifieke, individuele situatie. Daarom concentreren we ons in dit proefschrift op de mening van de gebruiker. Het doel van dit proefschrift is om instrumenten te presenteren en te testen die bruikbaar zijn voor het meten van de resultaten van hulpmiddelen vanuit het perspectief van de gebruiker. De onderzoeksvraag in dit proefschrift is: Zijn IPPA (Individually Prioritized Problem Assessment) en QUEST (Québec User Evaluation of Satisfaction with assistive Technology) bruikbaar, betrouwbaar en valide voor het beoordelen van de resultaten van hulpmiddelverstrekking vanuit het perspectief van de gebruiker?

\section{Hoofdstuk 2.}

\section{Instrumenten voor het beoordelen van de effecten van hulpmiddelen vanuit het perspectief van de gebruiker: een literatuurverkenning}

Als we kijken naar de effecten van hulpmiddelen vanuit het perspectief van de gebruiker, zijn twee zaken van belang: de voorkeur van de gebruiker moet een rol spelen en er moet rekening worden gehouden met gebruikerstevredenheid. Er zijn verschillende methoden en instrumenten ontwikkeld om effecten te meten op basis van de voorkeuren van de gebruiker (dimensies gekozen door de individuele respondent). De meest gebruikte methode is Goal Attainment Scaling (GAS). GAS wordt op vele terreinen gebruikt. Het meet het verschil tussen het verwachte uitkomstniveau en het werkelijk gerealiseerde uitkomstniveau. Een ander instrument dat is gebaseerd op de voorkeuren van de respondent is de Patient Generated Index (PGI), oorspronkelijk ontwikkeld om de kwaliteit van leven bij patiënten met lage rugpijn te meten. De MACTAR patient preference disability questionnaire is een vragenlijst, gebaseerd op de voorkeur van de respondent, om beperkingen bij patiënten met reuma te meten. Deze methode ontwikkelde zich tot de Problem Elicitation Technique (PET). Een vragenlijst gebaseerd op de voorkeuren van de respondent, ontwikkeld voor gebruilk op het gebied van hulpmiddelen is de Canadian Ocupational Performance Measure (COPM). Dit is een hulpmiddel om de fillosofie van het "user-centred perspective" te implementeren binnen het verstrekkingsproces. Om een aantal redenen zijn deze instrumenten niet geschikt om te worden loegepast voor onderzoeksdoeleinden op het gebied van hulpmiddelverstrekking. Er is behoefte aan een instrument waarmee gemeten kan worden in welke mate de verstrekking van een hulpmiddel de door de respondent genoemde problemen heeft opgelost.

Het onderwerp 'tevredenheid met hulpmiddelen' is bestudeerd door te kijken naai enkele theorieën over consumententevredenheid en patiëntentevredenheid. Er zijn verschillende modellen gevonden, waarvan er echter geen in iedere situatie voldoet. In 1996 is de theorie over tevredenheid met hulpmiddelen door Demers bestudeerd. Ze concludeerde dat er geen bruikbaar theoretisch kader bestaat. Zij ontwikkelde een instrument om de tevredenheid met hulpmiddelen zijn meten: QUEST (Québec User Evaluation of 
Satisfaction with assistive Technology). Het was oorspronkelijk gebaseerd op een beperkte hoeveelheid theorie, waarvan een deel later weer is losgelaten.

Er is een literatuurstudie uitgevoerd, om de ontwikkelingen in theorie over gebruikerstevredenheid met hulpmiddelen van na 1996 te bestuderen. De publicaties van Demers over QUEST buiten beschouwing gelaten, vonden we acht publicaties. Er bleek niet veel nieuwe theorie te zijn toegevoegd sinds 1996. Het bestaande theoretisch kader over tevredenheid met hulpmiddelen is nog steeds zeer beperkt. De hoeveelheid literatuur erover is ook nog steeds zeer beperkt. Het grootste deel ervan heeft betrekking op de ontwikkeling van QUEST.

\section{Hoofdstuk 3. \\ IPPA, een methode om de effectiviteit van hulpmiddelverstrekking te beoordelen, waarbij de gebruiker centraal staat}

Om een aantal redenen, bestaat er een groeiende behoefte om de effectiviteit te bewijzen van middelen die gespendeerd worden aan hulpmiddelverstrekking. Mensen gaan hulpmiddelen gebruiken, om problemen met het uitvoeren van activiteiten te verminderen. De effectiviteit van een verstrekking kan daarom het gemakkelijkst worden gedefinieerd als de mate waarin problemen daadwerkelijk zijn opgelost met betrekking tot het beoogde doel. De meest directe manier om dit te meten, is door te vragen, in welke mate de problemen daadwerkelijk zijn opgelost. Om een aantal redenen voldoen bestaande instrumenten op het gebied van gezondheidstechnologie niet, voor gebruik op het gebied van hulpmididelverstrekking. Het belangrijkste aspect bij het meten van de effectiviteit van hulpmiddelverstrekking is dat het betrekking heeft op de specifieke, individuele doelen van de gebruiker. Een nieuw instrument dat voor dit doel is ontwikkeld is IPPA (Individually Prioritized Problem Assessment). Het borduurt voort op de gedachtegang van bestaande instrumenten die gebruikmaken van geindividualliseerde meetschalen "Goal Attainment Scalling. the MACTAR patient preference disability questionnaire en the Problem Elicitation Technique).

IPPA is bedoeld om de effectiviteit van hulpmiddeiverstrekkingen te meten. Het stelt vast in welke mate de problemen met dagelijkse activiteiten genoemd door de respondent zijn verminderd dankzij de verstrekking. De respondent wordt gevraagd die problemen te noemen die hij of zij in het dagelijks leven ervaart en waarvan hij of zij hoopt dat ze door de verstrekking worden opgelost. De respondent mag maximaal zeven problemen noemen. Aan elk probleem moet de respondent een score toekennen met betrekking tot het belang van het probleem en met betrekking tot de moeite die de betreffende activiteit kost. Scores worden toegekend op een zeven-punts schaal. De moeite scores worden opgeteld, waarbij de belang scores werden gebruikt als weegfactor. Het resultaat daarvan wordt gedeeld door het aantal problemen. Dit resulteert in 
een totale IPPA score (tussen 1 en 49). De score staat voor het gemiddelde totale ongemak ervaren door de cliënt met betrekking tot de genoemde problemen. Tijdens het follow-up interview, enkele maanden nadat de cliënt is begorinen het verstrekte hulpmiddel te gebruiken, dient de cliënt opnieuw een moeite score toe te kennen aan elk van de genoemde activiteitem. De belang scores van het eerste interview worden opnieuw gebruikt als weegfactoren. Het verschil tussen de totale IPPA score van het eerste en het tweede interview staat voor de effectiviteit, daarmee de mate aangevend waarin het ervaren ongemak met betrekking tot de genoemde problemen/activiteiten is verminderd.

Het instrument is toegepast in Italië, Nederland, Noorwegen en Zweden. De respondenten waren cliënten met problemen op het gebied van mobiliteit, horen, communicatie of zelf-verzorging. Om de bruikbaarheid van IPPA vast te stellen, werd de interviewers gevraagd over elk interview een vragenlijst in te vullen. Ook werd een bijeenkomst met alle interviewers georganiseerd om ervaringen uit te wisselen en aspecten van de bruikbaarheid te bespreken. De construct validiteit van IPPA werd beoordeeld door de scores te vergelijken met de resultaten van EuroQol en SIP68. De responsiviteit van IPPA is bestudeerd door te kijken naar de effect size.

In totaal werden ongeveer 300 cliënten benaderd. 248 van hen deden mee aan een baseline interview. Daarvan deden er 118 ook mee aan een follow-up interview. Zestig procent van de populatie was vrouwelijk, de gemiddelde leeftijd was tussen de 60 en de 70 . In het algemeen konden de interviews zonder problemen worden afgenomen. De vragen pasten goed in het

referentiekader van cliënten en adviseurs. Sommige cliënten hadden moeite de ernst van hun problemen in cijfers uit te drukken. Het maximum aantal van 7 problemen bleek toereikend. De richting van de veranderingen gemeten met IPPA kwam overeen met wat was verwacht. De veranderingen in IPPA waren groter dan in de andere instrumenten. De correlatie tussen IPPA en de andere instrumenten op één moment was als verwacht.

De bruikbaarheid van IPPA is goed. Aan het instrument werden enkele aanpassingen gedaan. De vijf-punts antwoordschalen werden vervangen door multiple choice antwoorden met vijf tekstuele antwoordmogelijkheden. De construct validiteit is veelbelovend. IPPA meet de essentie van dat wat verandert ten gevolgen van een hulpmiddelverstrekking.

\section{Hoofdstuk 4. \\ De effectiviteit van de verstrekking van dienstverlening en hulpmiddelen voor buitenvervoer in Nederland}

Ondanks alle moderne communicatietechniek die tegenwoordig bestaat is mobiliteit nog steeds een belangrijke voorwaarde voor sociale participatie. In Nederland worden hulpmiddelen en diensten voor mensen met beperkingen op het gebied van buitenvervoer verstrekt volgens de WVG. 
In deze studie worden de volgende vragen beantwoord:

1. Welke problemen komen mensen met beperkingen op het gebied van buitenvervoer tegen?

2. Welke oplossingen worden aan hen aangeboden door de gemeenten in Nederland in het kader van de WVG?

3. Hoe effectief zijn deze oplossingen volgens de gebruikers?

Het instrument dat in deze studie is gebruikt om data te verzamelen is IPPA, dat geheel uitgaat van de cliënt. In deze studie wordt de responsiviteit van IPPA bestudeerd wanneer het instrument gebruikt wordt voor de specifieke toepassing van buitenvervoersproblemen.

In deze studie wordt gebruikgemaakt van data die is verzameld in twee studies: de EBV-studie en d EATS-studie. De resultaten van beide studies zijn samengevoegd en worden behandeld als één set data. Allereerst zijn de belangscores van de verschillende problemen geanalyseerd. De problemen (beperkingen) die mensen noemden zijn geclassificeerd volgens de indeling in Activiteiten en Participatie domeinen van de ICF en geanalyseerd. Eerst op het niveau van effectiviteit per probleem, daarna op het niveau van effectiviteit per cliënt/oplossing. Om de effectiviteit van de verstrekkingen per probleem te analyseren is de effect size per ICF domein berekend. De responsiviteit van IPPA is berekend door de effect sizes te berekenen en de responsiviteitsindex van Cohen toe te passen.

59 personem die een nieuw hulpmiddel of een service aanvroegen voor buitenvervoer namen deel aan de studie. Hun gemiddelde leeftijd was 73 , ongeveer 70 procent was vrouw. De 59 respondenten noemden samen een totaal van 274 problemen (gemiddeld 4.6). Alle genoemde problemen bleken ongeveer even belangrijk gevonden te worden. Blijkbaar was er geen relatie tussen de volgorde waarin de problemen werden genoemd en het belang van de problemen. De genoemde problemen waren vaak zeer individueel en zeer specifiek. Het bleek dat de meeste problemen betrekking hadden op de ICF domeinen: Community, social and civic life (98 problemen), Interpersonal interactions and relationships ( 78 problemen), Domestic live ( 53 problemen) en Self-care (27 problemen). Problemen in de domeinen Domestic live, Interpersonal interactions and relationships and Community, social and civic live werden genoemd door meer dan de helft van de respondenten.

Om hun problemen op te lossen kregen de 59 respondenten een mobiliteitshulpmiddel, het gebruik van een collectief vervoer service of een combinatie van beide. De meest voorkomende oplossing bleek een scootmobiel te zijn (12 personen) of het gebruik van een collectief vervoer service (35 personen). Alle soorten problemen werden redelijk opgelost. Elk individuele probleem werd matig tot goed opgelost. Echter, zeven cliënten ondervonden geen enkel (positief) effect. Dit roept om een meer gestructureerde. individugeoriënteerde aanpak van de dienstverlening (zoals de IPPA aanpak) en een gestructureerde activiteiten/beperkingen georiënteerde evaluatie van iedere individuele cliënt na afloop van thet dienstverleningsproces. 


\section{Hoofdstuk 5.}

\section{De belangrijkste dimensies van cliënt tevredenheid met hulpmiddelen: een validering van een Canadees instrument aan Nederlandse data}

Hoewel het meten van tevredenheid op het gebied van hulpmiddelen sterk wordt gepromoot, zijn er nauwelijks tevredenheidsmaten. Dit komt gedeeltelijk door een gebrek aan theoretische kennis. Empirische studies ondersteunen het multidimensionele model van tevredenheid. Er bestaat echter nog weinig overeenstemming over de conceptuele structuur van maten voor tevredenheid met hulpmiddelen.

QUEST was ontworpen om tevredenheid met hulpmiddelen te meten op een gestructureerde en gestandaardiseerde wijze. Oorspronkelijk bestond het uit 24 items. Met behulp van een item analyse werd dit gereduceerd tot 12. Deze 12 items bleken betrouwbaar wat betreft de test-hertest stabiliteit en de interbeoordelaar reproduceerbaarheid. Wat betreft de content validiteit, werden alle 12 items van primair belangl gevonden om tevredenheid te beoordelen volgens Nederlandse, Amerikaanse en Canadese experts. Bovendien werden deze items als zeer belangrijk beoordeeld door Canadese gebruikers van hulpmiddelen. Een factoranalyse is toegepast op de 12 items. De resultaten suggereren dat de onderliggende structuur van tevredenheid bestaat uit twee dimensies: Hulpmiddel en Dienstverlening. De dimensie Hulpmiddel bestaat uit acht items, de dimensie Dienstverlening uit vier items. Verschillende studies zijn gepubliceerd waarin deze tweedimensionale aanpak van hulpmiddelen wordt ondersteund, wat de validiteit weer versterkt. Deze studie is uitgevoerd om een kruis-validering uit te voeren van de tweedimensionale structuur van tevredenheid met hulpmiddelen. Daarbij werd een groep respondenten gebruikt die verschilde van de groep in de originele studie wat betreft culturele achtergrond en soorten hulpmiddelen.

Respondenten waren afkomstig uit een follow-up studie mel 374 proefpersonen. Aan hen werden allerlei woningaanpassingen en mobiliteitshulpmiddelen verstrekt, drie maanden voorafgaand aan het interview. De Nederlandstalige versie van de 24 item QUEST (D-QUEST) werd volledig bij hen afgenomen, maar alleen de scores van de 12 items die uit de item analyse naar voren waren gekomen werden meegenomen in de analyse. Elk item werd gescoord op een viff-punts levredenheidsschaal, lopend van 1 (totaal niet tevreden) tot 5 (zeer tevreden).

Een factoranalyse is uitgevoerd op de matrix van correlaties tussen de item scores verkregen van de 374 respondenten. De data was geschikt voor de geplande analyse. Uit de resultaten kwamen twee factoren naar voren die goed waren voor 40 procent van de totale variantie tussen de 12 items. Uit de resultaten blijkt dat de meeste items hoog scoorden op de ene factor en laag op de andere, daarmee bijdragend aan de eenvoudige structuur. Drie items gedroegen zich echter anders. De items Effectiviteit en Gewicht droegen bij aan 
beide factoren, maar iets meer aan de factor Hulpmiddel. Hel item

Duuzaamheid droeg matig bij aan alle twee de factoren, maar iets meer aan de factor Dienstverlening. De items, Comfort, Afmetingen, Gebruiksgemak, Effectiviteit, Aanpassen, Veiligheid en Gewicht droegen allemaal bil aan de factor Hulpmiddel. Het was redelijk om ook Duurzaamheid aan deze factor toe te voegen, omdat dit gewoonlijk beschouwd wordt als een technische eigenschap van het hulpmiddel. De factor Dienstverlening bestaat uit Professionele dienstverlening, Follow-up services, Reparatie/onderhoud en Verstrekking. De resultaten van deze de duplicatie studie bevestigen de validiteit van de tweedimensionale structuur van QUEST. Theoretische beschouwingen onderscheidden dezelfde dimensies.

\section{Hoofdstuk 6.}

\section{Betrouwbaarheid en validiteit van de Nederlandstalige versie van QUEST 2. 0 bij gebruikers van verschillende soorten hulpmiddelen}

\section{De laatste versie van QUEST (Québec User Evaluation of Satisfaction with} assistive Technology) bestaat uit een door de respondent zelf in te vullen, schriftelijke vragenlijst. Deze is, net als eerdere versies, vertaald in het Nederlands (D-QUEST). De respondent wordt gevraagd zijn/haar tevredenheid aan te geven met 12 verschillende aspecten op een vijf-punts schaal lopend van 1 (totaal niet tevreden) tot 5 (zeer tevreden). 8 van de 12 aspectem hebben betrekking op het hulpmiddel, 4 aspecten hebben betrekking op de dienstverlening. Het belangrijkste doel van deze studie is om de meeteigenschappen van D-QUEST te testen wanneer het instrument wordt toegepast bij verschillende soorten hulpmiddelen. De bruikbaarheid, betrouwbaarheid en validiteit van D-QUEST worden geanalyseerd wanneer het instrument wordt gebruikt bij gebruikers van hulpmiddelen voor persoonilike verzorging , orthesen en schoenaanpassingen, hoorapparaten, optische hulpmiddelen, hulpmiddelen voor diabetici, aangepaste meubilair, elastische kousen, prothesen, hulpmiddelen voor communicatie en informatie en mobiliteitshulpmiddelen.

In deze studie is D-QUEST toegepast bij en populatie $(n=2002)$ van gebruikers van alle soorten hulpmiddelen, verstrekt door zorgverzekeraars in Nederland. De originele D-QUEST is op twee punten aangepast. Er zijn, voor validatie doeleinden, twee vragen toegevoegd over de algemene tevredenheid met hulpmiddel en dienstverlening. Bovendien is er een niet-van-toepassing optie toegevoegd aan enkele van de antwoorden, vanwege de grote verscheidenheild aan hulpmiddelen. De toegevoegde waarde van deze antwoordoptie is bestudeerd. Uit een steekproef van verzekeraars is een steekproef van cliênten getrokken die de afgelopen twee jaar een hulpmiddelverstrekking hebben ontvangem. Ook zijn er steekproeven getrokken uit de ledenlijsten van een aantal patiëntenverenigingen. In totaal werd aan 5112 cliënten een vragenlijst gestuurd. Deze vragenlijst bevatte de D-QUEST en andere vragen waaronder een vraag over de mate waarin het hulpmiddel het probleem had opgelost. Alle analyses zijn uitgevoerd voor de twee sub-schalen (Hulpmiddel en 
Dienstverlening) apart. De betrouwbaarheid van D-QUEST is getest door het berekenen van de betrouwbaarheidscoëfficiënt (Cronbach's Alpha) voor elke soort hulpmiddel. Om de content validiteit te testen is het percentage respondenten dat een vraag van toepassing vond geanalyseerd voor elke soort hulpmiddel. De resultaten daarvan zijn vergeleken met de resultaten van een eerdere studie. Om de construct validiteit te testen, is de relatie tussen DQUEST scores en de mate van probleemoplossing van het verstrekt hulpmiddel geanalyseerd.

In totaal 3148 persoon retourneerden de vragenlijst. Na het opschonen van de data, bleven er 2002 respondenten over. Hun gemiddelde leeftijd was 58 , ongeveer 60 procent was vrouw. Betrouwbaarheidscoëfficiënten van de Hulpmiddel schaal waren vrij hoog $(>0.8)$ voor elk type hulpmiddel, behalve voor elastische kousen (0.68). Gemiddeld waren de betrouwbaarheidscoëfficiënten voor de Dienstverlening schaal iets lager (tussen 0.73 en 0.85 ) voor alle soorten hulpmiddelen. Het percentage vragen dat niet van toepassing werd geacht voor een bepaald type hulpmiddel varieert van 0.4 (gebruiksgemak van hoorapparaten) tot 85.1 (reparaties en onderhoud van hulpmiddelen voor persoonlijke verzorging). De mate waarin een vraag van toepassing is varieert sterk tussen verschillende soorten hulpmiddelen. Cliënten van wie het probleem meer naar tevredenheid is opgelost zijn duidelijk meer tevreden met de oplossing. Zoals verwacht mocht worden, heeft het hulpmiddel zelf een sterkere relatie met het probleemoplossend vermogen dan de dienstverlening. Beide relaties zijn echter significant. Dit ondersteunt de validiteit van D-QUEST. Ook de correlaties tussen gemiddelde tevredenheid scores en de toegevoegde algemene tevredenheid scores bevestigen de validiteit van D-QUEST. Al met al blijkt D-QUEST (en dus ook QUEST) een goed toepasbaar instrument voor gebruikers van alle soorten hulpmiddelen. Het toevoegen van de niet-van-toepassing optie aan de antwoorden blijkt een verbetering van het instrument te zijn.

\section{Hoofdstuk 7. Conclusies en Discussie}

Het is belangrijk om verstrekking van hulpmiddelen te beoordelen vanuit het perspectief van de gebruiker. Dit proefschrift beschrijft IPPÄ en D-QUEST, de ontwikkeling van deze instrumenten en het testen er van. Als deze instrumenten valide blijken te zijn, beschikten we over een pakket instrumenten om de resultaten van alle soorten hulpmiddelverstrekkingen te beoordelen vanuit het perspectief van de gebruiker. IPPA blijkt een goed bruikbaar en valide instrument te zijn. Deze resultaten werden bevestigd in een duplicatie studie. Het instrument D-QUEST (en dus ook QUEST) is nu beschikbaar in een verkorte, schriftelijke versie. Deze versie is nu goed gevalideerd met alle soorten hulpmiddelen. 
Twee tekortkomingen in de studies in dit proefschrift zijn dat IPPA alleen getest is met een beperkt aantal verschillende hulpmiddelen en dat IPPA en D-QUEST tot nu toe nog nooit samen in één studie zijn getest.

Voor een cost-outcome analyse is het nodig dat de resultaten van een groep respondenten bij elkaar worden opgeteld. In een groep hulpmiddelgebruikers zal elke gebruiker zijn of haar eigen doelen hebben en daarmee zijn of haar eigen manier om de effecten te beoordelen. In feite kunnen de effecten van hulpmiddelen alleen echt beoordeeld worden op individueel niveau. Resultaten verkregen met IPPA en D-QUEST kunnen bij elkaar worden opgeteld voor een hele groep gebruikers, maar ze zeggen het meest in relatie tot één individuele gebruiker.

Verschillende aspecten moeten nog nader worden onderzocht:

- De betrouwbaarheid van IPPA moet bestudeerd worden. Hiervoor is een specifieke studie nodig.

- De methode om de totale IPPA score te berekenen moet bestudeerd worden. Dit kan gebeuren door beschikbare data te analyseren.

- Het gebruik van de belangscores moet bestudeerd worden. Dit kan gebeuren met behulp van beschikbare data.

- Een specifieke studie is nodig om alternatieve methoden voor het afnemen van IPPA met elkaar te vergelijken.

- De validiteit van IPPA wanneer deze wordt gebruikt voor andere soorten hulpmiddelen moet bestudeerd worden. Ook moet de validiteit van IPPA worden bestudeerd wanneer deze wordt toegepast op geheel andere interventies, die geen relatie hebben met hulpmiddelen.

- De invloed van verwachtingen die de cliënten had voorafgaand aan het verstrekkingsproces op zijn of haar evaluatie achteraf moet bestudeerd worden.

- Het is nodig een theoretisch kader over tevredenheid met hulpmiddelen te creëren.

- Er is de behoefte aan een studie om uit te vinden of standaard toepassing van de twee instrumenten in het verstrekkingsproces de dienstverlening daadwerkelijk verbetert.

IPPA en D-QUEST kunnen standaard gebruikt worden in een hulpmiddelverstrekking om de service te verbeteren. Gebruik van IPPA zal het selectieproces structureren en de dienstverleners in staat stellen het proces en de resultaten achteraf te evalueren. Het gebruik van D-QUEST zal de dienstverleners instaat stellen een follow-up service aan te bieden. Het instrument dient daarbij als een checklist; alle problemen en tekorkomingen zullen naar voren komen. Wanneer dit standaard gebeurt, stelt het de dienstverleners in staat de kwaliteit van de dienstverlening te monitoren. Beide instrumenten kunnen ook incidenteel worden gebruikt voor een (cost-)outcome analyse. Natuurlijk hebben beide instrumenten alleen nut voor de outcome kant van de vergelijking. Dit type onderzoek kan gebruikt worden bij elke gelegenheid waarbij de resultaten van een interventie moeten worden vastgesteld. 

Dankwoord 

Luc, mijn co-promotor, om te beginnen moet ik natuurlijk jou bedanken. Jij was de initiator van dit project (ik heb het schrijven van dit proefschrift eigenlijk altijd gewoon als één van mijn projecten beschouwd) en jij bent daarna altijd de grote motivator gebleven. Jij was een groot deel van de tijd het perfecte één-mans begeleidingsteam. Ik denk met veel plezier terug aan onze reisjes naar Helsinki, Gryt en Oslo. En aan de avondjes, samen met Jos, bij mij thuis. Het klikte van het begin af aan prima tussen ons. Je had een Delftenaar kunnen zijn (en dat is een compliment). Jos, jij hebt, vooral in het begin, met Luc mee-begeleid. Je commentaar was soms wat onverwacht, maar altijd nuttig. En er viel altijd wat te lachen. Helaas vertrok je bij het iRv. Ik had nog graag langer met je samengewerkt.

Hett laatste anderhalf jaar kwam Wim erbij als promotor. Toen kwam er meteen tempo in het project. Je eerste vraag was: Wat is de planning? Ik herinner me nog dat ik op de receptie na je inaugurale rede tegen je zei: Ik word je eerste promovendus in Maastricht. Die belofte heb ik altijd willen houden. Dat was een goede motivatie.

Aan de projecten die aan dit proefschrift ten grondislag liggen, hebben vele mensen meegewerkt. $\mathrm{k}$ ben hen allen dank verschuldigd. Allereerst was er het EATS-project, mijn eerste Europese project. Samen met de partners Jan Persson (nu lid van de beoordelingscommissie), Hakan Brodin, Oivind Lorensen, Massimo Ferrario, Renzo Andrich, Taeke Van Beekum, Wija Oortwijn en Luc hebben we vele aangename bijeenkomsten gehad en legden we onder andere de basis voor IPPA. Mijn dank aan hen is groot. EATS team, thank you for a wonderful time in which I have learned a lot about assessing outcome and have seen a lot of Europe. Karin, bedankt voor het doen van de interviews. Hoewel we destijds zo onze bedenkingen hadden bij het project, wordt de opbrengst daarvan zoals je ziet nu nog steeds gebruikt.

Aan het MANUS-project en het WWS-project hebben veel iRv-collega's meegewerkt: Gert Jan, Beatrice, Dick, Marielle, Karin, Leontine, Helma, Harry en Luc. Allemaal heel erg bedankt dat ik de vruchten van jullie harde werk mocht gebruiken voor dit proefschrift.

En dan is er natuurlijk Louise Demers in Canada. Samen met Louise hebben we jarenlang gewerkt aan QUEST en D-QUEST. Dit gebeurde volledig per e-mail. Pas na een jaar of drie ontmoetten we elkaar in het echt, in Oslo. Ondanks deze wat afstandelijke manier van samenwerken heb ik het altijd heel prettig gevonden. Louise, thank you for this wonderful Trans-Atlantic co-operation.

En wat ik zeker niet mag vergeten, zijn de vele iRV-collega's die niet direct bij de projecten betrokken waren, maar die het werken bij het iRv zeer aangenaam maakten. Allereerst natuurlijk mijn kamergenotes. Anja, jij was de perfecte kamergenote. Ik ben blij dat je nu, na je vertrek, bij de buren werkt zodat ik je 
nog regelmatig zie. Je opvolgster, Leantine, was eerst mijn stagiaire, toen milin collega en nu zelfs mijn paranimf. Leontine, dank je wel, voor je gezelligheid en voor de ontelbare kleine dingetjes die ikzelf met mijn onhandige handen niet meer kar en die jij voor mij doet. I $k$ vind het jammer dat je maar zo weinig dagen per week op het iRv bent. En dank je wel dat jij mij, samen met Susan, als paranimf terzijde wil staan om deze dag tot een succes te maken. Susan, dank je wel dat ik de data van jouw EBV-project mocht gebruiken. Met jou heb ik (buiten het begeleidingsteam) nog wel het meest overlegd over de inhoud van mijn (en jouw) proefschrift. Vooral toen je nog in Utrecht werkte, werkten we veel samen. Dank je wel dat je mijn paranimf willde zijn, we zullen er een mooie dag wan maken.

In het begin van het promotie-project was er Jolanda, bij wie ik dagelijks met veel plezier terecht kon voor een kopje koffie en een gezellig praatje. Toen jij vertrok Jolanda, viel er een gat in mijn dagelijks ritme en heb ik mijn koffiepauzes moeten verplaatsen naar één verdieping lager. Suzanne, Judith en Enid, dank jullie wel voor de vele, gezellige koffiepauzes, soms met een koekje, altijd met gezelligheid.

Natuurlijk mag ik alle andere collega's nilet vergeten. De dames van het secretariaat, de heren van de computers, de dames en heren onderzoekers, alle mensen van het IAC, allemaal bedankt voor de fijne collegialiteit. Jullie maken allemaal met elkaar dat ik met heel veel plezier bij het iRv werk.

Andrew Davies, bedankt voor het corrigeren van mijn Engels. Ik dacht dat het eigenlijk niet nodig was, maar jij wist er toch altijd weer het nodige aan te verbeteren.

Bianca, toen het proefschrift bijna af was, heb jij de opmaak verzargd. De voorkant is prachtig geworden en de tekst ziet er keurig uit. Hartstikke goed werk, dank je wel.

Mijn familie wil ik bedanken voor het feit dat ze mij lekker lieten aanmodderen met mijn proefschrift en mij niet lastig vielen met vragen over of dat nou wel verstandig was en of ik dat wel aankon met mijn gezondheid. Op die manier, hebben jullie mij altijd gestimuleerd om te doen wat ik wilde, zonder mijzelff beperkingen op te leggen vanwege mijn gezondheid.

En Helma, lieve Helma, jou ben ik het meeste dank verschuldigd van allen. Toen ik er geen zin meer in had wist jij mij met je enthousiasme te motiveren om door te gaan. Door jou kreeg ik er weer zin in. Daarom is dit ook jouw proefschrift. 
Over de auteur 

Roelof Wessels is geboren op 8 oktober 1968 in Eindhoven. Zijn jeugd bracht hij door in Waalre. Hij volgde het Gymnasium b op het Lorenz Lyceum in Eindhoven en deed daar in 1987 eindexamen op het Atheneum B. Roelof ging Industrieel Ontwerpen studeren aan de TU in Delft. In 1993 studeerde hij af op het ontwerp van een baliewerkplek voor de poliklinieken van het Leyenburg Ziekenhuis in Den Haag. Tijdens zijn afstuderen werd Roelof ziek en bleek hij MS te hebben. Na zijn afstuderen ging hil werken bij het iRv. Hij deed verschillende projecten op het gebied van bruikbaarheidsonderzoek, onderzoek onder hulpmiddelgebruikers, gebruikerstevredenheid van hulpmiddelgebruikers, autonomie van mensen met een functiebeperking en het niet-gebruik van verstrekte hulpmiddelen. Van 1998 tot en met 2000 zat Roelof in de ondernemingsraad van het iRv, waarvan de laatste twee jaar als voorzitter. In 1997 begon hij met het Europese project EATS. Daarmee begon hij aan een serie projecten over de effecten van hulpmiddelverstrekking. Hij hield zich met name bezig met de wijze waarop dit gemeten kan worden. Hieruit volgden verschillende publicaties, waarvan er nu enkele deel uitmaken van dit proefschrift. Na zijn promotie is Roelof van plan om op dezelfde voet verder te gaan met het uitvoeren van projecten. 